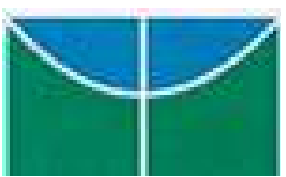

Universidade de Brasília

Instituto de Psicologia

Programa de Pós-Graduação em Psicologia Social, do Trabalho e das Organizações

Motivação e Suporte Psicossocial à Transferência como preditores de Impacto de Treinamentos no Trabalho

\author{
Mestrado \\ Rafaela Marcolino El-Corab Moreira
}

Brasília, DF 


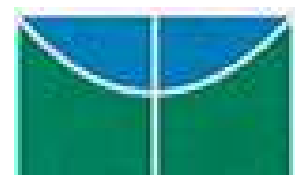

Universidade de Brasília

Instituto de Psicologia

Programa de Pós-Graduação em Psicologia Social, do Trabalho e das Organizações

Motivação e Suporte Psicossocial à Transferência como preditores de Impacto de Treinamentos no Trabalho

\author{
Mestrado \\ Rafaela Marcolino El-Corab Moreira \\ Dissertação de Mestrado apresentada ao Programa de \\ Pós-Graduação em Psicologia Social, do \\ Trabalho e das Organizações \\ como parte dos requisitos para obtenção do \\ título de Mestre em Psicologia.
} Essa dissertação contou com recursos do CNPq.

Orientador: Profa. Dra. Gardênia da Silva Abbad

Brasília, DF

Março de 2017 
Ficha catalográfica elaborada automaticamente, com os dados fornecidos pelo(a) autor(a)

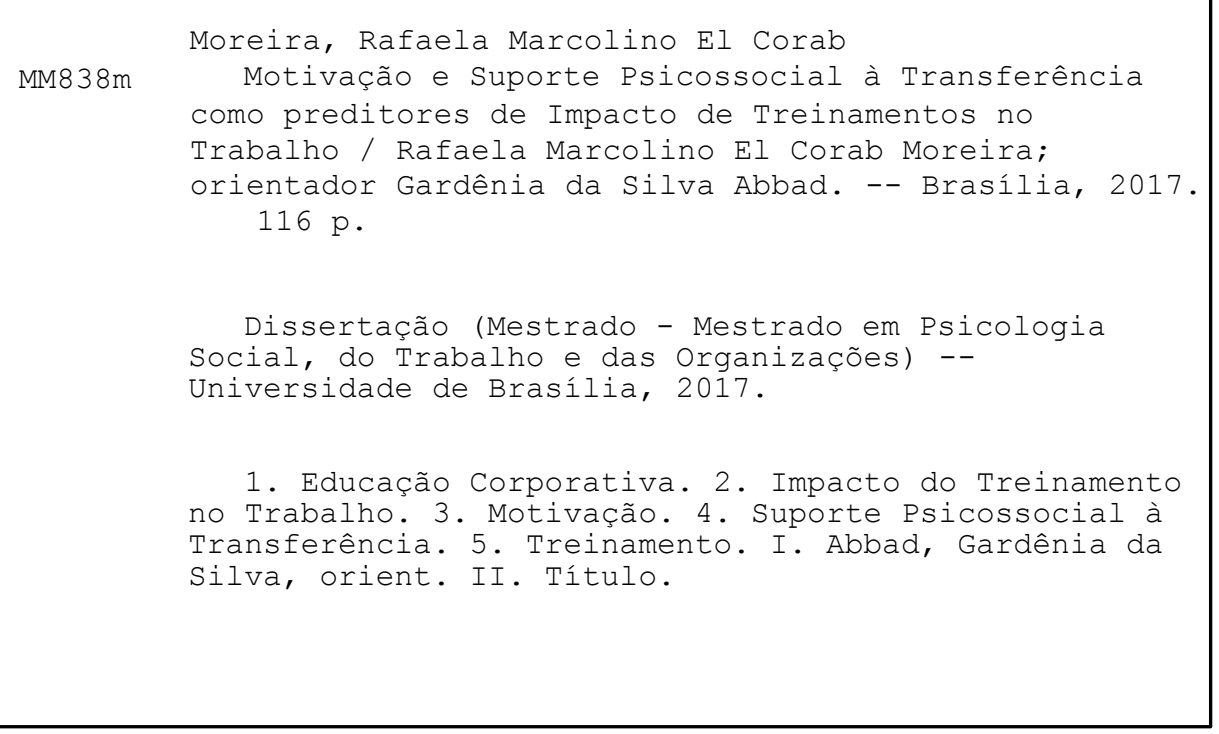




\section{MOTIVAÇÃO E SUPORTE PSICOSSOCIAL À TRANSFERÊNCIA COMO PREDITORES DE IMPACTO DE TREINAMENTOS NO TRABALHO}

Dissertação de Mestrado submetida ao Programa de Pós-Graduação em Psicologia Social, do Trabalho e das Organizações como requisito para obtenção do grau e mestre em Psicologia pela Universidade de Brasília.

Aprovada pela seguinte Comissão Examinadora:

Profa. Dra. Gardênia da Silva Abbad (Orientadora)

Instituto de Psicologia/Universidade de Brasília

Profa. Pós-Dra. Elaine Rabelo Neiva (Membro Efetivo)

Instituto de Psicologia/ Universidade de Brasília

Profa. Dra. Isa Aparecida Freitas (Membro Efetivo)

Banco do Brasil

Prof. Dr. Josemberg Moura Andrade (Membro Suplente)

Instituto de Psicologia/ Universidade de Brasília 
Dedico esta dissertação a toda a minha linda familia, em especial aos meus pais, Marco Antônio e Marcia, por terem me dado a base para tudo que sou hoje, tanto pessoal como profissionalmente. Vocês são meus exemplos! 


\section{AGRADECIMENTOS}

À minha querida orientadora Gardênia da Silva Abbad, pelo apoio, incentivo, dedicação, críticas e elogios. É um exemplo a ser seguido, mostrando sua paixão pelo que faz. Obrigada por ter me aceitado e incentivado a entrar no mestrado e por ter entrado em minha vida desde a graduação.

Ao grupo de pesquisa IMPACTO, que me deu o suporte necessário durante todo o mestrado, não só contribuindo nas fantásticas "cricrizagens", nas revisões e auxílio com literatura e conhecimento. Todos esses anos de grupo, desde a graduação, me tornaram uma pessoa e profissional bem melhor. Vocês são como uma família, que em momentos difíceis me acolheram e em momentos felizes vibraram comigo.

Agradeço também ao CNPq por financiar essa pesquisa.

Aos professores do PSTO que me deram grande suporte durante toda essa jornada, cresci bastante com suas críticas e contribuições. Cada um com sua forma de ser e aplicar o conhecimento, fez com que eu criasse a minha própria "assinatura". E à secretaria do PSTO por ter prestado todo o suporte durante todo o mestrado.

Aos meus amigos da UnB, desde o tempo da graduação e aos da pós, da época de colégio e aos que a vida me deu, obrigada por serem meu apoio, me escutarem e me distrair! Nossos encontros, raros, porém super agradáveis me aliviavam das obrigações.

À toda minha família, tios, primos, "agregados”. Obrigada por sempre estarem ao meu lado e por entenderem o aperto no tempo que se deu ao final do mestrado e não poder encontrá-los direito.

Ao meu avô Albino (in memorian) por ter sido (e até hoje é) um grande exemplo em minha vida, me ensinando a ter gosto pelos estudos e querer mais e mais conhecimentos! Assim como a todos meus avós, cada um com seu jeitinho especial. Obrigada por sempre estarem por perto, mesmo que longe fisicamente. E por aceitarem 
a minha visita com espaço de tempo tão prolongado, dói não ter sido tão presente, mas nada é em vão e agora recuperaremos o tempo!

Aos meus pais, Marco Antônio e Marcia, e meus irmãos, Silvio e Thiago por estarem sempre comigo, por me aturarem nos momentos de cansaço e fazerem de tudo para me animar, bem como meu amado namorado, Michel, que teve a "sorte" de me conhecer justamente quando iniciei o mestrado e me deu a maior força com tudo que precisei. Obrigada, meu amor, por ser essa pessoa maravilhosa! AMO VOCÊS!

Obrigada, Deus, por ter me iluminado durante esses anos e pelas pessoas que colocaste em minha vida! Sou muito abençoada e só tenho o que agradecer! 


\section{SUMÁRIO}

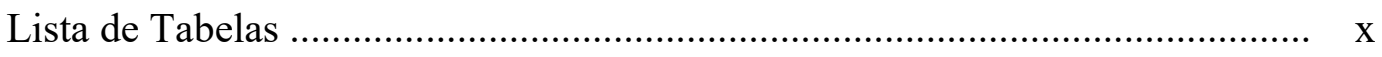

Lista de Figuras ............................................................................... xi

Lista de Siglas ..........................................................................................

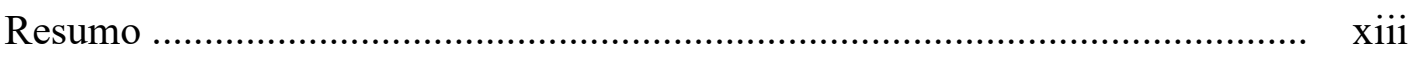

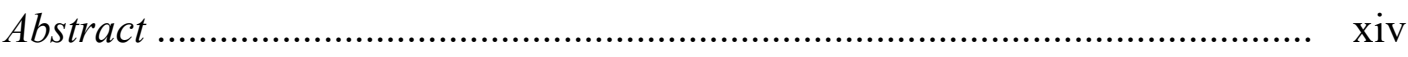

INTRODUÇÃO ............................................................................... 15

1. REFERENCIAL TEÓRICO _.................................................................... 19

1.1 Motivação para o Treinamento .............................................................. 19

1.2 Suporte à Transferência de Treinamento no Trabalho .......................... 25

1.3 Transferência de Treinamento e Impacto do Treinamento no Trabalho . 28

2. REVISÃO DE LITERATURA ............................................................... 34

2.1 Resultados da Análise da Produção de Conhecimentos ......................... 35

3. MÉTODO ….............................................................................. 41

3.1 Contexto de Pesquisa .......................................................................... 41

3.2 Caracterização dos treinamentos avaliados .......................................... 42

3.3 Caracterização geral dos participantes ................................................. 45

3.4 Instrumentos de Coleta de dados ......................................................... 46

3.5 Procedimento de Coleta de dados ....................................................... 48

3.6 Procedimentos de Análise de dados ................................................... 48

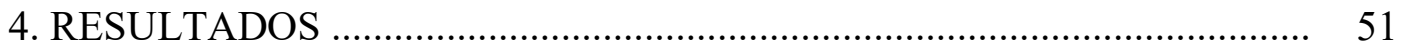

4.1 Evidência de validade das escalas ......................................................... 51

4.1.1 Escala de Instrumentalidade (Utilidade do Treinamento) ............ 52

4.1.2 Escala de Valência (Importância do Treinamento) ....................... 54

4.1.3 Medida de Expectância (Expectativa) ........................................ 56

4.1.4 Escala de Suporte Psicossocial à Transferência de Treinamento .. 57

4.1.5 Escala de Impacto do Treinamento no Trabalho .......................... 59

4.2 Comparação entre os treinamentos ........................................................ 61

4.2.1 Escala de Instrumentalidade (Utilidade do Treinamento) ............. 61

4.2.2 Escala de Valência (Importância do Treinamento) ....................... 62

4.2.3 Medida de Expectância (Expectativa) ......................................... 62

4.2.4 Medida de Força Motivacional .................................................. 62

4.2.5 Escala de Suporte Psicossocial à Transferência de Treinamento .. 63 
4.2.6 Escala de Impacto do Treinamento no Trabalho

4.3 Teste do Modelo Geral de Investigação .................................................. 63

4.3.1 Resultados das Regressões Múltiplas para os três treinamentos ... 64

treinamento

4.3.2 Resultados das Regressões Múltiplas separadas por tipo de

4.4 Teste do Modelo de Mediação 66

4.4.1 Resultados da Regressão para Mediação dos três treinamentos ... 69

4.4.2 Resultados da análise de mediação para Agente de Melhorias e Gestão do Absenteísmo

4.4.3 Resultados da análise de mediação para o Treinamento SEI . 70

5. DISCUSSÃO 70

5.1 Considerações finais 72 REFERÊNCIAS 75

Anexo A: Referência dos artigos selecionados para Revisão de Literatura 80

Anexo $B$ : Relação entre a quantidade de artigos por expressões-chave 88

Anexo $C$ : Relação de periódicos por países 95

Anexo D: Relação de periódicos por área 97

Anexo E: Instrumento de coleta de dados 100 


\section{Lista de Tabelas}

Tabela 1. Definições de motivação para o treinamento ......................................... 20

Tabela 2. Definições e medidas de motivação baseadas na teoria VIE .................. 23

Tabela 3. Definições e medidas de Suporte e conceitos correlatos ........................ 26

Tabela 4. Definições e medidas de Impacto do Treinamento no Trabalho e construtos correlatos ...................................................................... 31

Tabela 5. Objetivos específicos do treinamento de Agente de Melhorias ............. 42

Tabela 6. Objetivos instrucionais do curso de Gestão do Absenteísmo .................. 43

Tabela 7. Estatísticas descritivas dos respondentes ......................................... 46

Tabela 8. Estrutura Empírica da Escala de Instrumentalidade (Utilidade) do Treinamento ..................................................................................... 52

Tabela 9. Estrutura Empírica da Escala de Valência (Importância) do Treinamento .............................................................................. 54

Tabela 10. Estrutura Empírica da Escala de Suporte Psicossocial à Transferência de Treinamento ............................................................................. 58

Tabela 11. Estrutura Empírica da Escala de Impacto do Treinamento no Trabalho . 59

Tabela 12. RM para Impacto dos três treinamentos sobre o trabalho dos egressos .. 64

Tabela 13. RM para impacto dos três treinamentos sobre o trabalho dos egressos -

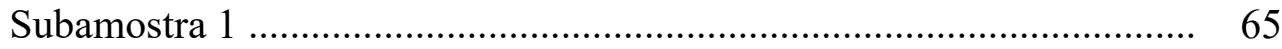

Tabela 14. RM para impacto dos três treinamentos sobre o trabalho dos egressos Subamostra 2 ........................................................................ 65

Tabela 15. RM para impacto dos três treinamentos sobre o trabalho dos egressos -

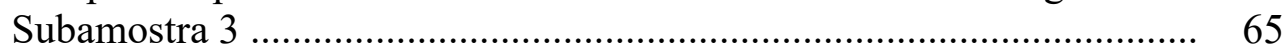

Tabela 16. RM para impacto do treinamento SEI sobre o trabalho dos egressos ..... 66

Tabela 17. RM para impacto do treinamento SEI sobre o trabalho dos egressos Subamostra 1 ............................................................................... 67

Tabela 18. RM para impacto do treinamento SEI sobre o trabalho dos egressos Subamostra 2 .............................................................................. 67

Tabela 19. RM para impacto do treinamento SEI sobre o trabalho dos egressos -

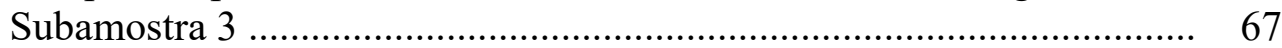

Tabela 20. RM para impacto dos treinamentos Agente de Melhoria e Gestão do Absenteísmo sobre o trabalho dos egressos 


\section{Lista de Figuras}

Figura 1. Modelo conceitual de Impacto do Treinamento no Trabalho e construtos

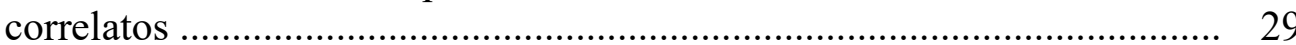

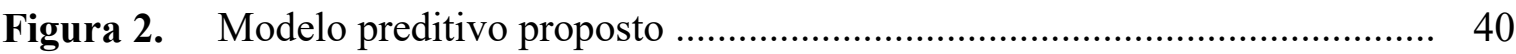

Figura 3. Modelo de mediação proposto ……...................................................... 40

Figura 4. Modelo final Preditivo de Impacto no Treinamento ................................. 69 


\section{Lista de Siglas}

FM

Força Motivacional

IMTT

Impacto do Treinamento no Trabalho

MelhoraAbsent. Agente de Melhorias e Gestão do Absenteísmo

$\mathbf{R M}$

Regrssão Múltipla

SEI

Sistema Eletrônico de Informação

SUPSI

Suporte Psicossocial à Transferência de Treinamento

T\&D

Treinamento e Desenvolvimento

TD\&E

Treinamento, Desenvolvimento e Educação 


\section{RESUMO}

Programas de treinamento proporcionam uma série de benefícios para as organizações. Há uma preocupação crescente em avaliar efeitos de treinamento no desempenho dos egressos, bem como nos resultados organizacionais, visando buscar evidências de transferências de novas aprendizagens no trabalho e melhores resultados organizacionais. Apesar dos altos investimentos, nem sempre o que é aprendido converte-se em comportamento no trabalho, tampouco em mudança e melhores resultados organizacionais. Estudos têm mostrado que motivação para aprender e para transferir e suporte gerencial e social à aplicação de novas aprendizagens no trabalho são preditores de transferência de treinamento para o trabalho. Por isso, transferência de treinamento e motivação para transferir se tornaram temas relevantes para pesquisa e para a gestão de recursos humanos. Dessa forma, este estudo tem como objetivo avaliar a influência de percepções de Suporte Psicossocial à Transferência e Força Motivacional sobre Impacto do Treinamento no Trabalho, a partir da avaliação de três treinamentos corporativos. Para isso, participaram desta pesquisa 2.975 funcionários de uma empresa pública federal que responderam a um questionário contendo quatro blocos: (1) Motivação - Itens de Valor Instrumental e Expectância; (2) Autoavaliação de Impacto do Treinamento no Trabalho; (3) Suporte Psicossocial à Transferência de Treinamento; e (4) Questões sócio-demográficas. Os resultados das análises fatoriais exploratórias indicaram evidências de validade para todas as escalas utilizadas, os testes $\mathrm{t}$ para amostras independentes apontaram para uma diferença entre as médias dos treinamentos avaliados, indicando que egressos dos treinamentos de gestão expressaram opiniões mais favoráveis sobre o suporte psicossocial recebido, atribuíram maior valor ao treinamento, apresentaram expectativas mais otimistas de que a suas participações no treinamento os fariam atingir os resultados pessoais e profissionais almejados, bem como relataram maior impacto desse treinamento no trabalho do que os egressos do treinamento em habilidades de manuseio de um sistema de comunicação e tramitação de documentos administrativos. Os resultados das regressões múltiplas para os treinamentos avaliados indicaram que Força Motivacional e Suporte Psicossocial à Transferência são preditores de Impacto do Treinamento no Trabalho. Foram encontradas evidências de que Suporte Psicossocial à Transferência é mediador parcial das relações entre Força Motivacional e Impacto do Treinamento no Trabalho.

Palavras-chave: Educação Corporativa; Impacto do Treinamento no Trabalho; Motivação; Suporte Psicossocial à Transferência; Treinamento 


\section{ABSTRACT}

Training programs offer a variety of benefits for organizations. Yet, there is growing concern regarding evaluating the effects of training on the performance of participants, including organizational results, aiming to find evidence for the transfer of new learning to work and better results for the organization. Despite high investments, what is learned does not always convert to behavior at work, nor to changes or better results for the organization. Studies have shown that motivation to learn and to transfer as well as managerial and social support for the application of new learning at work are predictors of transfer of training to work. As such, transfer of training and motivation to transfer have become relevant topics for research and for human resources management. Consequently, this study aims to evaluate the influence of the perceptions of psychosocial support for transfer and strength of motivation on the impact of training on work through the evaluation of three corporate training events. In this study, 2,975 employees of a federal public office responded to a questionnaire that contained four blocks: (1) Motivation - Instrumental Value and Expectations Items; (2) Self-evaluation of the Impact of the Training on Work; (3) Psychosocial Support for the Transfer of Training; and (4) Sociodemographic questions. The results of the exploratory factor analysis indicate evidence for validity for all of the scales utilized; the t-tests for independent samples indicated a difference between the training measures evaluated, indicating that participants in managerial training sessions expressed more favorable opinions about the psychosocial support received, attributed more value to the training, presented more optimistic expectations that their participation in the training would help them to attain the personal and professional goals desired, and also indicated more impact of this training on work than those participants who were trained on the skills for the use of communications systems and transmission of administrative documents. The results of multiple regression for the training sessions that were evaluated indicated that the Strength of Motivation and Psychosocial Support for Transfer are predictors of the Impact of Training on Work. Evidence to indicate that that Psychosocial Support for Transfer is a partial mediator variable between Strength of Motivation and Impact of Training on Work was also identified.

Key words: Corporate Education; Impact of Training on Work; Motivation; Psychosocial Support for Transfer; Training 
O interesse de pesquisadores em estudar motivação não é recente e vem se expandindo a cada dia. Um deles é a motivação para aprender e para transferir novas aprendizagens para o trabalho, (Alves-Filho \& Borges, 2014; Lacerda \& Abbad, 2003; Massenberg, Spurk \& Kauffeld, 2015; Mourão \& Marins, 2010), assuntos que serão tratados na presente pesquisa. Por mais que haja estudos que tenham pesquisado a motivação na área de Treinamento \& Desenvolvimento (T\&D), inclusive relacionando variáveis motivacionais com suporte ao treinamento e impacto do treinamento no trabalho, poucos o fizeram comparando respostas de egressos de treinamentos diferentes. Assim como avaliações de treinamentos são importantes para verificar a eficiência, eficácia e efetividade desses, mensurar a motivação dos treinandos para transferir o aprendido para o trabalho também se faz importante, uma vez, que dependendo do quão motivado o indivíduo estiver, maiores serão as chances dele se dedicar ao treinamento e posteriormente à transferência das novas aprendizagens para o ambiente de trabalho.

A motivação para o treinamento depende de inúmeros fatores, alguns dos quais ligados às características cognitivas, atitudinais e de personalidade dos treinandos (instabilidade emocional, extroversão, amabilidade, escrupulosidade e abertura para a experiência, autoeficácia, estilos motivacionais, locus de controle, comprometimento); outras, ligadas às próprias características do treinamento (instrumentalidade do treinamento para o alcance de objetivos profissionais e pessoais; tipo de engajamento: voluntário ou compulsório; valor para o treinando das consequências ou resultados associados à participação no treinamento) e ao contexto organizacional (expectativas e percepções de suporte - organizacional, social, psicossocial, gerencial - e clima favoráveis à aprendizagem e transferência de aprendizagem no ambiente de trabalho, entre outras).

Curado, Henriques e Ribeiro (2015) sugerem que a participação voluntária no curso pode afetar positivamente a motivação para o treinamento. E a participação compulsória, por outro lado, pode influenciar negativamente a motivação. Em função disso, este estudo avaliou três treinamentos corporativos: (1) Sistema Eletrônico de Informação (SEI), ofertado a todos os integrantes da organização, tendo em vista a implantação de um sistema de informações e comunicação organizacional que deverá ser utilizado obrigatoriamente por todos os integrantes da organização a fim de tramitar processos administrativos; (2) Agente de Melhorias e (3) Gestão do Absenteísmo e o Incentivo à Presença Produtiva (Gestão do Absenteísmo), ofertados principalmente para gestores, visando melhorar a gestão dos processos de trabalho e reduzir os níveis de absenteísmo na organização. Dessa forma, 
esperava-se comparar a motivação para transferência em egressos dos dois tipos de cursos, os de caráter obrigatório (altamente recomendado pela organização) e os de caráter voluntário, focado na função do treinando.

Estudar motivação e suporte como preditores do impacto do treinamento no trabalho é importante, uma vez que ainda há lacunas na área (Al-Eisa, Furayyan \& Alhemoud, 2009; Lacerda \& Abbad, 2003; Massenberg et al., 2015), entre as quais a análise da influência conjunta das variáveis motivação e suporte sobre transferência de treinamento. Além disso, pesquisas sobre motivação possuem grande relevância prática, uma vez que poderão fornecer informações que subsidiem a implementação de ações de melhoria dos sistemas instrucionais, de modo a tornar os treinamentos mais estimulantes e motivadores para os participantes e mais eficazes e efetivos para a organização.

Em função das lacunas anteriormente mencionadas e da relevância dos temas, o objetivo geral desta pesquisa foi avaliar a influência de percepções de Suporte Psicossocial à Transferência (SUPSI) e Força Motivacional (FM) sobre Impacto do Treinamento no Trabalho (IMTT), a partir da avaliação de três treinamentos corporativos (Agente de Melhorias, Gestão do Absenteísmo e o Incentivo à Presença Produtiva, e Sistema Eletrônico de Informação).

Os objetivos específicos foram: (1) Investigar evidências de validade dos instrumentos de avaliação de Impacto do Treinamento no Trabalho (medida em amplitude), Suporte Psicossocial à Transferência no Trabalho e Força Motivacional; (2) Comparar os treinamentos no que se refere às percepções de Suporte à Transferência de Treinamento, Força Motivacional e Impacto do Treinamento no Trabalho; (3) Investigar as relações entre as variáveis preditoras Suporte Psicossocial e Força Motivacional e a variável critério Impacto do Treinamento no Trabalho em amplitude, testando modelos multivariados de avaliação, baseados no modelo IMPACT (Abbad, 1999; Lacerda \& Abbad, 2003; Silva, 2007); e (4) Investigar se Suporte Psicossocial à Transferência é mediador do relacionamento entre Força Motivacional (variável antecedente) e Impacto do Treinamento no Trabalho (variável critério).

Esta pesquisa possui três variáveis principais: (1) Força Motivacional (variável preditora), que é definida como um processo de tomada de decisão sobre a quantidade de esforço que o indivíduo está disposto a investir em uma determinada escolha de ação, a partir da análise da importância de determinados resultados almejados e da expectativa de sucesso no alcance desses resultados; (2) Suporte Psicossocial à Transferência de Treinamento 
(variável preditora), que é definido como o apoio que o egresso recebe, tanto de seus pares, líderes como da organização, para aplicar o aprendizado do treinamento no trabalho; e (3) Impacto do Treinamento no Trabalho (variável predita), que é definido como o efeito direto da transferência de treinamento sobre o desempenho do egresso. Importante destacar que o conceito de Impacto é utilizado principalmente em estudos nacionais, enquanto que pesquisas internacionais adotam o conceito de transferência de treinamento, que consiste na generalização de novas aprendizagens para o trabalho.

Esta pesquisa se insere no tema avaliação de treinamento, que se baseia em modelos avaliativos, baseados em resultados, como: os de Kirkpatrick (1976), que aborda reação, aprendizagem, comportamento no cargo e resultados; e Hamblin (1978), que avalia os mesmos três primeiros níveis de avaliação propostos por Kirkpatrick e subdividiu o último em mudança organizacional e valor final, e o Modelo de Kaufman e Keller (1994), que avalia reação, aquisição, aplicação, resultados organizacionais e societais; e outros modelos, baseados em abordagens sistêmicas, que integram variáveis do contexto, insumos, processos, produtos, resultados e feedback, como: (1) CIPP - Contexto, Insumos, Processos e Produto (Stufflebeam, 2003); (2) HRD - Human Resources Development Evaluation and Research Model (Holton, 1996), que aborda aprendizagem, mudança no desempenho individual após o treinamento e resultados do treinamento no nível da organização; e (3) CIRO - Conteúdos /Contextos, Insumos, Reações e Resultados (Warr, Bird \& Rackham, 1970). No Brasil, existem modelos, similares aos últimos, denominados MAIS - Modelo Avaliação Integrado e Somativo (Borges-Andrade, 1982) e o Modelo IMPACT (Abbad, 1999), sendo que ambos têm sido utilizados parcialmente em diversas pesquisas nacionais.

A avaliação de treinamento pode ser compreendida como um subsistema da área de treinamento que visa obter informações sistemáticas que possibilitem julgar a eficácia e a efetividade de programas e eventos instrucionais, bem como propiciar feedbacks para melhoria contínua dos sistemas instrucionais em organizações. Como linha de pesquisa, a avaliação de treinamento visa, entre outros objetivos, analisar a influência de variáveis do indivíduo, ou insumos, (cognitivo-comportamentais, motivacionais, psicossociais, sóciodemográficas e repertório de entrada); contexto interno (suporte gerencial e social, suporte organizacional, suporte à aprendizagem, clima para transferência e variáveis correlatas), ambiente externo à organização; processos e procedimentos (desenho instrucional, natureza do treinamento, processo de aprendizagem, estratégias e recursos instrucionais de ensino, qualidade dos materiais, entre outros) sobre os resultados imediatos (reações e aprendizagem) 
e mediatos (transferência de treinamento/impacto no trabalho, aplicação no trabalho e comportamento no cargo).

A presente pesquisa adotará uma versão simplificada do Modelo IMPACT, anteriormente mencionado. O Modelo Integrado de Avaliação de Impacto do Treinamento no Trabalho (IMPACT) é constituído por sete componentes: (1) Percepção de Suporte Organizacional; (2) Características do Treinamento; (3) Características clientela/participantes; (4) Reação; (5) Aprendizagem; (6) Suporte à Transferência; e (7) Impacto do Treinamento no Trabalho - autoavaliação do participante sobre os efeitos produzidos pelo treinamento em seus níveis de desempenho, motivação, autoconfiança e abertura a mudanças nos processos de trabalho.

Nesta pesquisa foram utilizadas variáveis ligadas a quatro componentes do modelo IMPACT: Características da Clientela (variável Força Motivacional), Treinamento (tipo: treinamento em gestão versus em habilidades técnicas-administrativas), Suporte à Transferência (variável Suporte Psicossocial à Transferência de Treinamento) e Impacto do Treinamento no Trabalho. Foram utilizados esses componentes, uma vez que agrupam as variáveis aqui estudadas.

Por fim, esta dissertação está estruturada em cinco capítulos: (1) Referencial Teórico, que irá abarcar os principais referenciais teóricos adotados pela literatura científica da área para definir e analisar os conceitos de Motivação, Suporte para o treinamento e Impacto do treinamento no trabalho; (2) Revisão de Literatura, que descreve características da produção de conhecimentos sobre motivação para o treinamento, motivação para aprender, motivação para transferir, baseada em uma pesquisa bibliográfica que abrangeu artigos científicos publicados em revistas revisadas por pares no período de 2000 a 2016; (3) Método, que descreve o delineamento, as etapas e as estratégias metodológicas adotadas na pesquisa; (4) Resultados, que apresenta os principais achados, oriundos da pesquisa empírica; e (5) Discussão, que apresenta as contribuições do estudo para o avanço do conhecimento na área de avaliação de treinamento, as limitações do estudo e uma agenda de pesquisas futuras. 


\section{CAPÍTULO 1: REFERENCIAL TEÓRICO}

Esta seção apresenta os referenciais teóricos que embasaram este estudo. São analisados os conceitos de motivação para o treinamento, motivação para aprender e para transferir, suporte à transferência de treinamento e impacto do treinamento no trabalho.

\subsection{Motivação para o Treinamento}

Motivação, segundo o dicionário Aurélio, pode ser definida como o ato ou efeito de motivar, é o conjunto de fatores psicológicos (conscientes ou inconscientes), de ordem fisiológica, intelectual ou afetiva, os quais agem entre si e determinam a conduta de um indivíduo. Em outras palavras, pode-se dizer que a motivação é o que irá fazer com que o indivíduo se predisponha a realizar algo.

Na linguagem técnica, motivação pode ser definida como variável antecedente ou como causa de comportamentos (impulsos, estímulos, necessidades), bem como razões associadas às ações do indivíduo, as quais podem estar ligadas a metas, objetivos e resultados esperados. Algumas abordagens definem motivação como um processo de tomada de decisão e outras a analisam mais em termo de conteúdos da motivação (necessidades, desejos, intenções comportamentais) do que de processos motivacionais. Há, ainda, teorias que abordam a motivação como um construto multidimensional que inclui processos cognitivos e afetivos, metas e objetivos, resultados e consequências das ações do indivíduo e suas expectativas de sucesso no alcance de objetivos e resultados almejados e alcançáveis por meio dessas ações.

Nas pesquisas da área de Treinamento, Desenvolvimento e Educação (TD\&E) têm sido usados diversos construtos teóricos correlatos para definir as variáveis motivacionais de interesse, entre os quais: motivação para o treinamento, motivação para aprender e motivação para transferir a aprendizagem para o trabalho. Motivação para o treinamento é um construto geral que inclui o de motivação para aprender e para transferir aprendizagens para o trabalho. Motivação para aprender é definida como o desejo manifestado pelo treinando de aprender o conteúdo de um programa de treinamento (Noe, 1986); motivação para transferir, refere-se à disposição do participante para aplicar, no trabalho, os conteúdos aprendidos no treinamento (Lacerda \& Abbad, 2003). Em suma, o conceito de motivação tem sido definido em TD\&E como desejo, interesse, envolvimento ou esforço despendido pelo indivíduo no processo de 
aprendizagem e/ou na transferência da aprendizagem para o trabalho. A Tabela 1 mostra algumas definições apresentadas em estudos sobre motivação em contextos de treinamento.

\section{Tabela 1}

Definições de motivação para o treinamento

\section{Definições}

Desejo específico de aprender o conteúdo do treinamento manifestado pelo participante.

Esforço despendido pelo indivíduo para aprender os conteúdos de um curso.

Percepções dos treinandos sobre o quanto o treinamento poderia levá-lo a ter um melhor desempenho no trabalho e, em consequência disto, a alcançar resultados valorizados.

Direção, intensidade e persistência da aprendizagem em contextos de treinamento.

Intenção de esforçar-se para acompanhar um programa específico de treinamento.

Intensidade e persistência dos esforços aplicados pelos treinados em atividades de melhoria, orientadas para a aprendizagem, antes, durante e após o treinamento.

Motivação para transferir é o desejo de usar no trabalho os conhecimentos e habilidades adquiridas no programa de treinamento.

\section{Autores}

Gegenfurtner, 2011; Noe e Schmitt, 1986; Zaniboni, Fraccaroli, Truxillo, Bertolino e Bauer, 2007

Hicks e Klimoski, 1987; Meneses e Abbad, 2003; Santos e Mognon, 2016

Jodlbauer, Selenko, Batinic e Stiglbauer, 2011; Mathieu, Tannenbaum, e Salas, 1992; van der Locht, van Dam e Chiaburu, 2013

Abdullah, Baroto, Ismail e Tat, 2011; Colquitt, LePine, e Noe, 2000; Santos e Souza, 2014

Bauer, Orvis, Ely e Surface, 2015; Campbell e Kuncel, 2001

Burke e Hutchins, 2007; Van den Bossche, Segers e Jansen, 2010

Curado, Henriques e Ribeiro, 2015; Noe (1986)

A motivação para o treinamento é também definida com base em potenciais implicações comportamentais, como a quantidade e a persistência do esforço para aprender (Burke \& Hutchins, 2007; Campbell \& Kuncel, 2001; Colquitt et al., 2000; Mathieu et al., 1992), intenções de alcançar metas (Mathieu et al., 1992) e como um processo de tomada de decisão sobre a quantidade de esforço que o indivíduo está disposto a investir em uma determinada escolha de ação (Força motivacional), a partir da análise da importância de determinados resultados almejados e da expectativa de sucesso no alcance desses resultados. Força motivacional, nesse tipo de abordagem, é definida de acordo com a teoria da expectância de Vroom (1964), que trata motivação como sendo função de três outros 
construtos, Valência, Instrumentalidade e Expectância (VIE) do indivíduo em relação a comportamentos e a resultados de ações.

A Teoria da Expectância de Vroom (1964) define Valência como orientações afetivas (positivas, negativas ou nulas) em direção a resultados específicos, que reflete preferências dos indivíduos. Instrumentalidade é definida como a percepção do quanto um determinado desempenho produzirá resultados esperados. Por fim, Expectância é definida como uma crença momentânea sobre a probabilidade de que um determinado ato será seguido por um determinado resultado específico. Essa probabilidade é subjetiva e pode ser descrita segundo sua intensidade.

Em pesquisas realizadas na área de TD\&E, força motivacional é definida como o resultado da interação entre Valência, Instrumentalidade e Expectância, que influenciam o indivíduo a tomar decisões e a fazer escolhas. A medida de Força Motivacional é calculada pela multiplicação dessas três dimensões:

$$
\mathrm{FM}=\mathrm{E}\left(\sum \mathrm{V}_{\mathrm{i}} * \mathrm{I}_{\mathrm{i}}\right)
$$

Na qual "FM" é a Força Motivacional, "E" a Expectância, "V" a Valência e "I" a Instrumentalidade (Alves-Filho \& Borges, 2014; Pilati, 2004; Vroom, 1964).

Pilati (2004) descreve esses três componentes como: (1) Valência - conjunto de preferências acerca de possíveis resultados associados ao envolvimento do indivíduo com um determinado treinamento e ao tipo de vínculo que o indivíduo possui com o seu trabalho, ou seja, é tida como o quanto uma pessoa deseja alcançar uma consequência favorável; (2) Instrumentalidade - avaliação subjetiva que o indivíduo faz de que o envolvimento com o treinamento o levará a atingir os resultados esperados, que foram identificados na valência, isto é, a estimativa de que aquele desempenho será um meio adequado para chegar à recompensa ou a consequências positivas esperadas; e (3) Expectância - atribuição subjetiva de probabilidade de alcançar os resultados esperados (valência) por meio da participação no evento instrucional (instrumentalidade), ou seja, a estimativa pessoal da probabilidade de que um determinado esforço resultará em um desempenho bem-sucedido.

A Teoria de Expectância (VIE) tem sido adotada total ou parcialmente em pesquisas da área de TD\&E. No estudo de Lacerda e Abbad (2003), valor instrumental do treinamento é um constructo inspirado na teoria de Vroom que aborda apenas dois componentes, a valência e a instrumentalidade e é definido como as crenças do indivíduo de que as novas habilidades por ele adquiridas em um determinado treinamento lhes serão úteis para que possa atingir 
resultados positivos ou recompensas de várias naturezas (instrumentalidade do treinamento) e como as percepções do indivíduo sobre a importância ou o valor de cada uma dessas recompensas (valência) (Lacerda \& Abbad, 2003). Em outro estudo, Pilati (2004) adotou o conceito de força motivacional, que inclui os três construtos da teoria de Vroom (1964), a expectância, a valência e a instrumentalidade. Alves-Filho e Borges (2014) realizaram um estudo que analisou a motivação para o trabalho dos profissionais da área de saúde e utilizou a Teoria da Expectância considerando-a como um fenômeno processual que envolve os componentes referidos como resultados do trabalho, expectativas, valência, instrumentalidade e força motivacional. Silva (2007) propõe em seu modelo de investigação que Valor Instrumental (Valência e Instrumentalidade) prediz a percepção do egresso sobre o Impacto da Oficina de Gestão de carreira, estudada na pesquisa, na vida pessoal e profissional, para isso, utilizou como o estudo de Lacerda (2002) como base para a investigação da relação entre as variáveis.

Estudos internacionais também utilizam a Teoria de Vroom, tal como Zaniboni et al. (2007), que tiveram como objetivo de estudo validar, em uma amostra italiana, uma medida multidimensional de motivação para o treinamento baseada na VIE, bem como examinar a rede nomológica que envolve o construto. Shweiki et al. (2015) exploraram a correlação entre a teoria motivacional de Vroom e a educação para estudantes de residência e concluíram que a Teoria da Expectância fornece uma perspectiva inovadora na área de saúde.

Várias são as teorias que abarcam o tema de motivação, entre as mais citadas nos artigos revisados neste estudo, estão: a teoria da autodeterminação e a de estabelecimento de metas. A Teoria da Autodeterminação propõe que as motivações dos indivíduos são determinadas e orientadas por contextos e necessidades psicológicas. Com base nessa abordagem, a motivação pode manifestar-se de três formas: (1) desmotivação - ausência da motivação ou da intenção de se comportar; (2) motivação extrínseca - originada do ambiente externo ao indivíduo, que investe em uma atividade na expectativa de obter resultados favoráveis ou por outras contingências (inerentes ou não a essa atividade); e (3) motivação intrínseca - oriunda do envolvimento do indivíduo com determinada atividade, e da sua opinião sobre o quanto ela é interessante, envolvente ou, de alguma forma, geradora de satisfação (Gagné \& Deci, 2005).

No estudo de Gegenfurtner, Festner, Gallenger, Lehtinen e Gruber (2009) o construto motivação para transferir, definido a partir da Teoria da Expectância e da Teoria de Autodeterminação, inclui motivação autônoma (desejo de transferir a aprendizagem que, 
neste caso, é iniciada, governada pelo indivíduo) e motivação controlada (desejo de transferir a aprendizagem em função de recompensas extrínsecas ou punições). O instrumento de motivação para transferir adotado nesse estudo contém itens de motivação controlada sobre o quanto a aplicação bem sucedida do treinamento (instrumentalidade) será provavelmente apreciada (elogios) pelo supervisor e o quanto resultará em recompensas (bônus financeiro) e, ainda, o quanto o indivíduo considera importantes (valência) esses dois tipos de consequências extrínsecas. Os itens de motivação autônoma tratam da importância da transferência de treinamento como experiência de aprendizagem e de quanto essa experiência é desafiante e excitante para o individuo (instrumentalidade) e o quanto a aprendizagem e desafios são importantes para o indivíduo (valência). Os dois construtos foram medidos por dois pares de itens, de modo que dois deles referem-se a valência e dois a instrumentalidade. A Tabela 2 mostra definições e descrições de medidas de motivação em pesquisas que adotaram a Teoria da Expectância como um dos referenciais teóricos.

\section{Tabela 2}

Definições e medidas de motivação baseadas na teoria VIE

\begin{tabular}{|c|c|c|}
\hline Autores & $\begin{array}{c}\text { Definições de Valência, Instrumentalidade e } \\
\text { Expectância }\end{array}$ & $\begin{array}{c}\text { Instrumento para } \\
\text { mensuração da Motivação }\end{array}$ \\
\hline $\begin{array}{l}\text { Lacerda e } \\
\text { Abbad } \\
(2003)\end{array}$ & $\begin{array}{l}\text { Valência: Importância que o participante do } \\
\text { curso atribui a determinadas recompensas. } \\
\text { Instrumentalidade: Benefícios do programa de } \\
\text { treinamento para o participante, relacionados a } \\
\text { resultados futuros. } \\
\text { Expectância: Estimativa de que o esforço de um } \\
\text { indivíduo resultará em um desempenho bem- } \\
\text { sucedido ou a chance de que esse desempenho } \\
\text { produza o resultado esperado. }\end{array}$ & $\begin{array}{l}\text { Questionário de } \begin{array}{r}\text { Valor } \\
\text { Instrumental }\end{array} \\
\text { Treinamento com duas } \\
\text { escalas: (1) Escala de } \\
\text { Importância - valência; (2) } \\
\text { Escala de Utilidade - } \\
\text { instrumentalidade. Cada } \\
\text { escala continha 14 itens } \\
\text { avaliados em uma escala de } \\
\text { cinco pontos. }\end{array}$ \\
\hline
\end{tabular}

Carvalho e Valência: Expressa o montante do desejo de Souza (2007) atingir um objetivo pessoal.

Entrevista semi-estruturada com oito questões sobre Instrumentalidade: Grau de relação percebido VIE. entre o desempenho e a obtenção dos resultados. Expectância: Estimativa do indivíduo ao julgar até que ponto o desempenho será determinado pelo esforço despendido.

Zaniboni et Valência: Grau em que o desempenho do al. (2007) trabalho bem sucedido foi avaliado. Instrumentalidade: Crença de que o desempenho no treinamento levaria ao sucesso do desempenho no trabalho.

Expectância: Crença de que o esforço no treinamento levaria a um desempenho bem sucedido neste.
Escala de nove itens adaptada de Truxillo e Weathers (2005). Possui três subescalas: Valência, Instrumentalidade e Expectância, com três itens cada, avaliada em escala Likert de cinco pontos. 
Tabela 2

Continuação

\begin{tabular}{|c|c|c|}
\hline Autores & $\begin{array}{c}\text { Definições de Valência, Instrumentalidade } \\
\text { e Expectância }\end{array}$ & $\begin{array}{c}\text { Instrumento para } \\
\text { mensuração da Motivação }\end{array}$ \\
\hline $\begin{array}{l}\text { Alves-Filho e } \\
\text { Borges (2014) }\end{array}$ & $\begin{array}{l}\text { Valência: Orientação acerca dos resultados } \\
\text { que se definem em termos de atração ou } \\
\text { satisfação antecipada. } \\
\text { Instrumentalidade: Grau percebido de } \\
\text { relação entre a execução das tarefas e a } \\
\text { obtenção dos resultados. } \\
\text { Expectância: Avaliação subjetiva da } \\
\text { probabilidade de ocorrência do resultado } \\
\text { esperado. }\end{array}$ & $\begin{array}{lr}\text { Questões referentes } & \text { às } \\
\text { expectativas } & \text { e } \\
\text { instrumentalidades } & \text { do } \\
\text { IMST. } & \end{array}$ \\
\hline $\begin{array}{l}\text { Carvalho e } \\
\text { Mourão (2014) }\end{array}$ & $\begin{array}{l}\text { Valência: Valor que a pessoa atribui ao } \\
\text { incentivo ou recompensa. } \\
\text { Instrumentalidade: Crença de que a obtenção } \\
\text { do resultado está ligada a uma recompensa. } \\
\text { Expectância: Percepção de que os esforços } \\
\text { levarão ao resultado desejado. }\end{array}$ & $\begin{array}{l}\text { Escala de motivação para } \\
\text { aprender, de Warr, Allan e } \\
\text { Bird (1999), e adaptada por } \\
\text { Lacerda e Abbad (2003) e } \\
\text { Pilati (2004). Com } 5 \text { itens } \\
\text { associados em escala de } \\
\text { concordância. }\end{array}$ \\
\hline $\begin{array}{l}\text { Wingo, } \\
\text { Thomas, } \\
\text { Thompson e } \\
\text { Cook (2015) }\end{array}$ & $\begin{array}{l}\text { Valência: Importância de aprender para o } \\
\text { indivíduo. } \\
\text { Instrumentalidade: (Não foi conceituada). } \\
\text { Expectância: Medida em que o treinando } \\
\text { espera ter sucesso. }\end{array}$ & $\begin{array}{l}\text { MSLQ antes de iniciar o } \\
\text { primeiro módulo ( } 31 \\
\text { questões em escala de sete } \\
\text { pontos). Inventário de } \\
\text { motivação aplicado } \\
\text { imediatamente após cada } \\
\text { módulo (13 questões). }\end{array}$ \\
\hline
\end{tabular}

A partir da análise da Tabela 2, desprende-se que diferentes pesquisas utilizam os construtos propostos por Vroom (1964), porém a forma de mensuração varia desde questionários com quantidades diferentes de itens para cada fator e escalas diferentes até entrevistas semi-estruturadas. Além disso, por mais que os autores definam valência, instrumentalidade e expectância em suas pesquisas, nem todos avaliam os três fatores.

A Teoria do Estabelecimento de Metas (Locke e Latham,1990) afirma que as metas afetam o desempenho na tarefa de três formas: (1) as metas energizam o desempenho por motivar os indivíduos a se esforçar para enfrentar as dificuldades ou demanda da meta/tarefa; (2) as metas motivam as pessoas a persistirem nas suas atividades durante um determinado tempo, sendo que metas difíceis forçam o indivíduo a manter-se trabalhando ou executando uma atividade por mais tempo do que quando as metas são fáceis; e (3) metas claras e específicas direcionam a atenção do indivíduo para comportamentos ou resultados relevantes. Pesquisas utilizaram a Teoria do Estabelecimento de Metas como principal referencial teórico, entre as quais, estão os estudos de: Bosset e Bourgeois (2015), que utilizou esta teoria 
com o objetivo de analisar as condições sob as quais um funcionário que participa de um programa de treinamento fora da organização está disposto a transferir seus resultados de aprendizagem para o local de trabalho; e Bueno, Zenorini, Santos, Matumoto e Buchatsky (2007), que tinha como objetivo analisar a motivação para aprender por meio da investigação da estrutura fatorial, da precisão e das correlações entre os fatores de uma escala de metas de realização.

Para a presente pesquisa, a teoria motivacional escolhida foi a Teoria da Expectância de Vroom (1964). As medidas utilizadas neste estudo basearam-se nas pesquisas de Lacerda e Abbad (2003) e Silva (2007) sobre Valor Instrumental de Treinamento (Valência e Instrumentalidade) e Pilati (2004), que, ao incluir expectância, calculou a Força Motivacional de acordo com a Teoria de Vroom. Esses instrumentos de medida foram escolhidos porque incluíram uma amostra qualitativamente representativa de possíveis resultados associados a treinamento que podiam ser, ao mesmo tempo, avaliados pelo indivíduo quanto à valência e à instrumentalidade, produzindo uma avaliação, provavelmente, com maior validade de conteúdo do que os instrumentos de Truxillo e Weathers (2005), que utilizavam menor quantidade de itens e escalas distintas para valência e instrumentalidade. Quanto à expectância, terceira dimensão de FM, adotou-se item único como na pesquisa de Pilati (2004), apesar de experiências com instrumentos de três itens de Truxillo e Weathers (2005) e quatro fatores de Alves-Filho e Borges (2014).

\subsection{Suporte à Transferência de Treinamento no Trabalho}

Nesta seção são analisados conceitos ligados ao contexto de trabalho, que exercem influência sobre Transferência de Treinamento, Impacto do Treinamento no Trabalho e conceitos correlatos. Na literatura da área de TD\&E são propostos diversos conceitos para se referir às variáveis do ambiente de trabalho como: suporte organizacional, suporte gerencial, suporte psicossocial à transferência, clima para transferência, cultura de aprendizagem, entre outros. Na Tabela 3 são apresentadas as definições constitutivas, exemplos de itens e escala de pontuação, adotados pelos pesquisadores nos estudos sobre motivação para transferência. 
Tabela 3

Definições e medidas de Suporte e conceitos correlatos

Autores

Definições de Suporte

Instrumento para mensuração de Suporte

\begin{tabular}{ll}
\hline Lacerda e & Suporte à Transferência de Treinamento \\
Abbad (2003) & ou Apoio gerencial ao treinamento: \\
& Opinião do participante do treinamento a \\
& respeito do empenho demonstrado pelas \\
& chefias para viabilizar a sua participação \\
& em eventos instrucionais.
\end{tabular}

Meneses e

Abbad (2003)

Zaniboni et al. (2007)

Chiaburu, Van Dam e Hutchins (2010)
Suporte à Transferência de Treinamento: Opinião dos participantes, chefias e colegas de trabalho a respeito do nível de apoio psicossocial e material fornecido pelo ambiente ao uso eficaz de novas habilidades no trabalho.

Suporte à aprendizagem no trabalho: grau em que o trabalho é projetado para promover a aprendizagem constante e dar flexibilidade para o desenvolvimento de novos conhecimentos e habilidades.

Suporte Social que abrange:

Percepção do Suporte Organizacional (POS): Crença sobre o quanto a organização se preocupa com os treinandos e valoriza suas contribuições. Suporte do supervisor: Visão geral do desenvolvimento do funcionário como um aspecto importante do trabalho dos supervisores, juntamente com aspectos mais imediatos e práticos.
16 itens auto-avaliados em escala Likert de cinco pontos, onde 1 corresponde a "Nunca" e 5 a "Sempre".

Exemplo de item: "Tenho sido encorajado pela minha chefia imediata a aplicar, no meu trabalho, o que aprendi no treinamento" (Abbad, 1999).

16 itens hetero-avaliados em uma escala Likert de cinco pontos, onde 1 corresponde a "Nunca" e 5 a "Sempre".

Exemplo de item: "O empregado tem tido oportunidades de usar no trabalho as habilidades que aprendeu no treinamento (Meneses, 2002).

Cinco itens avaliados em escala Likert de cinco pontos, onde 1 corresponde a "Absolutamente não" e 5 a "Extremamente desenhado para promover a aprendizagem".

Exemplo de item: "Obter novas informações sobre formas de realizar o trabalho de forma eficaz é importante nesta organização" (p.139).

Percepção do Suporte Organizacional - Escala POS de sete itens (Exemplo de item: "A ajuda está disponível na organização quando tenho um problema.").

Suporte do supervisor é medido por uma escala de cinco itens (Chiaburu \& Tekleab, 2005; Yarnall, 1998) (Exemplo de item: "Meu supervisor me fornece o tempo que preciso para praticar as habilidades aprendidas no treinamento.") 
Tabela 3

Continuação

Autores

Definições de Suporte

Instrumento para mensuração de Suporte

Massenberg, et Suporte do supervisor: Até que ponto o al. (2015)

gerentes apóiam e reforçam o uso do treinamento no trabalho.

Suporte dos pares: Até que ponto os colegas reforçam e apóiam o uso de aprendizagem no trabalho.
Nove itens avaliados em uma escala de cinco pontos, onde 1 corresponde a "Discordo totalmente" e 5 a "Concordo totalmente". Dos nove itens, cinco compreendem suporte do supervisor (Ex.: "Meu supervisor define metas para mim que me encorajam a aplicar meu treinamento no trabalho"); e quatro compreendem o suporte dos pares (Ex.: "Meus colegas me encorajam a usar as habilidades que aprendi no treinamento") (p. 168)

Observa-se que, suporte pode ser definido de várias maneiras a depender do tipo e do foco em que a pesquisa se encontra, além disso, nota-se que apesar das definições constitutivas desses construtos serem similares, as medidas são distintas, dificultando a generalização dos achados. Nos estudos apresentados na Tabela 3 e em outros das últimas décadas, pode-se notar que suporte à transferência é entendido como um dos principais preditores de impacto do treinamento no trabalho.

O Suporte à Transferência refere-se ao apoio que o treinando recebe para transferir os conhecimentos e habilidades adquiridos no treinamento para seu ambiente de trabalho (Abbad et al., 2012). Trata-se de um construto bidimensional medido pelos fatores: (1) Suporte Psicossocial à Transferência - que irá avaliar o apoio que o egresso recebe, tanto de seus pares, líderes como da organização, para aplicar o aprendizado do treinamento no trabalho. Esse fator possui ainda dois subfatores, os fatores situacionais de apoio e consequências associadas à aplicação de novas habilidades no trabalho; e (2) Suporte Material à Transferência - que irá avaliar os recursos materiais e financeiros de forma qualitativa, quantitativa e pela sua disponibilidade, além da qualidade e adequação do ambiente físico do local de trabalho à transferência de treinamento.

Dentre os instrumentos para mensurar Suporte, destaca-se a Escala de Suporte à Transferência de Treinamento (EST) (Abbad, 1999; Abbad \& Sallorenzo, 2001) ao qual possui 22 itens, sendo 16 relacionados ao suporte psicossocial (nove itens de ligados a fatores 
situacionais de apoio e sete de consequências associadas ao uso de novas habilidades no trabalho) e seis itens de suporte material. Dos estudos que utilizaram a EST destacam-se os que encontraram relação positiva de predição entre Suporte à Transferência e Transferência de Treinamento (Pereira, 2009; Martins, 2014; Santos Jr., 2012; Silva, 2007), além da pesquisa de Tamayo e Abbad (2006), que encontrou relação de predição entre Suporte à Transferência e Impacto do Treinamento no Trabalho.

A presente pesquisa utilizou somente o fator suporte psicossocial à transferência de treinamento no trabalho da escala brasileira, uma vez que esta abarca de forma mais abrangente os itens para suporte. A subescala de suporte material não foi utilizada, pois poucos estudos trabalham com ela e devido ao fato de suporte psicossocial ser um maior preditor de impacto do treinamento no trabalho (Abbad, 1999; Lacerda \& Abbad, 2003; Salas \& Cannon-Bowers, 2001).

\subsection{Transferência de Treinamento e Impacto do Treinamento no Trabalho}

Transferência de Treinamento e Impacto do Treinamento no Trabalho são expressões utilizadas como sinônimos, porém há algumas diferenças em suas definições. Impacto do Treinamento no Trabalho, Transferência de Treinamento e comportamento no cargo são definidos como a aplicação, no ambiente de trabalho, dos CHAs adquiridos nos eventos instrucionais (Freitas, Borges-Andrade, Abbad \& Pilati 2006). Essa definição constitutiva tem inspirado a construção de diferentes medidas de efeitos pós-treinamento sobre o desempenho, motivação e atitudes de egressos.

Um modelo de análise conceitual de impacto do treinamento no trabalho foi proposto por Pilati e Abbad (2005), em que são apresentadas definições de conceitos relacionados à processos efeitos da aprendizagem em contextos de treinamento. Esse modelo sugere

processos interdependentes e que exigem medidas distintas. A Figura 1 apresenta esquematicamente essa análise. 


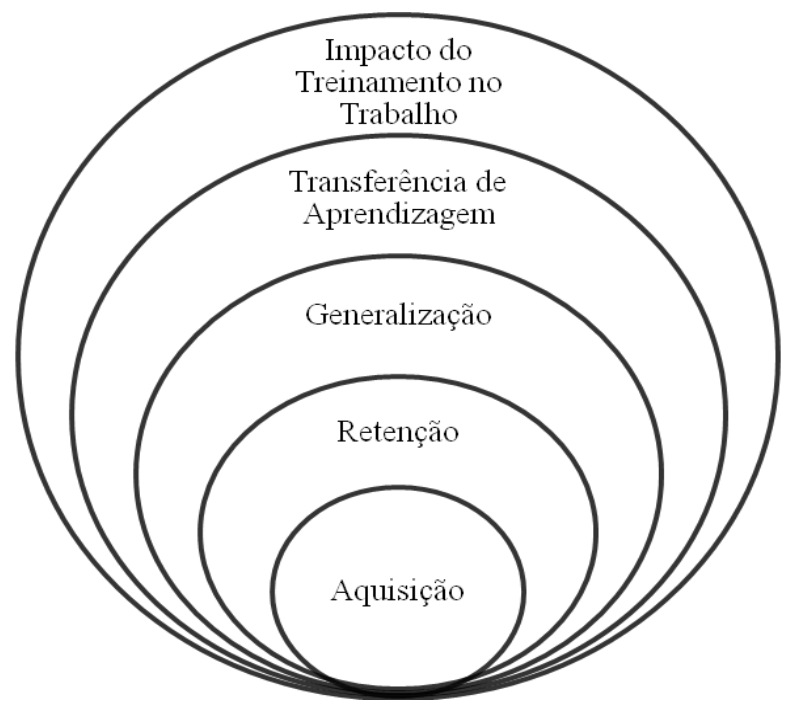

Figura 1. Modelo conceitual de Impacto do Treinamento no Trabalho e construtos correlatos Fonte: Pilati e Abbad (2005, pp.44)

Os efeitos do treinamento no ambiente organizacional dependem da aquisição, processo básico de apreensão de novos CHAs, que é condição necessária para que as demais etapas ocorram. A retenção, que se refere à memorização das novas aprendizagens, primeiramente na memória de curto prazo e posteriormente na de longo prazo, é condição necessária aos demais resultados. A generalização é a emissão de comportamentos aprendidos a partir de diversos estímulos (estratégias, recursos, meios e situações de ensino e aprendizagem) semelhantes entre si, porém não exatamente iguais àqueles presentes no ambiente de trabalho do egresso do treinamento. Esses três processos e resultados, segundo a teoria instrucional (Gagné \& Medsker, 1996) requerem diferentes condições internas e externas de aprendizagem. Um desenho instrucional eficaz deveria, nesse contexto, variar as situações de prática, aproximando-as da realidade do trabalho, bem como oportunizar a repetição para a fixação dos conteúdos. Desse modo, a generalização terá maiores chances de ocorrer. O quarto conceito, transferência de treinamento, é a aplicação eficaz no trabalho dos CHAs adquiridos no treinamento, que depende, para ocorrer, da aquisição, retenção e generalização, as quais geralmente são promovidas pelo treinamento. A transferência de treinamento ou de aprendizagem sofre influência do contexto de trabalho, uma vez que depende de suporte propício à expressão das novas aprendizagens no trabalho, das características do treinamento (qualidade da instrução) e das características do indivíduo. A transferência pode ser positiva, negativa ou neutra. No primeiro caso, se houver transferência, provavelmente haverá efeito positivo sobre o comportamento do egresso no trabalho. Se a 
transferência for negativa, é provável que ela resulte em uma diminuição do desempenho, motivação e atitudes favoráveis do egresso em relação ao trabalho e à expressão das novas aprendizagens. Se ela for neutra, não haverá impactos sobre o comportamento do egresso no trabalho. Em suma, transferência positiva de treinamento é condição necessária para a ocorrência de melhoria do comportamento do egresso no trabalho. Quanto à abrangência do efeito do treinamento sobre o comportamento no trabalho, Hamblin (1978) sugeriu duas categorias: Impacto em amplitude e em profundidade. No Brasil, um dos conceitos mais utilizados para se referir à transferência positiva é, genericamente, impacto do treinamento no trabalho. O Impacto em amplitude é o efeito exercido pelo treinamento sobre o desempenho global, as atitudes e a motivação do treinando ou egresso. O Impacto em profundidade referese a efeitos mais específicos de um treinamento sobre o comportamento do treinando em seu ambiente de trabalho. O primeiro conceito possibilita o uso de um único instrumento para avaliar impacto de diferentes treinamentos, pois inclui itens aplicáveis a todos aqueles que forem estudados. $\mathrm{O}$ conceito de impacto em profundidade, por outro lado, por ser mais específico, tem sido operacionalizado por meio de instrumentos construídos a partir de objetivos instrucionais de cada treinamento. Esse tipo de medida tem sido aplicado em estudos que visam analisar a validade convergente das medidas de impacto em amplitude e profundidade, bem como para avaliar treinamentos específicos, isolando a influência direta do treinamento sobre os demais efeitos de médio e longo prazo sobre o comportamento do indivíduo e resultados organizacionais.

Para mensurar Impacto em Profundidade, é necessário construir um instrumento específico para a ação instrucional, uma vez que será direcionado para características particulares dela. Por outro lado, a mensuração de Impacto em Amplitude pode-se dar tanto por meio de um questionário de heteroavaliação (Meneses, 2002) quanto de autoavaliação (Abbad, 1999). Esse último instrumento é composto por 12 itens, associados a uma escala de concordância tipo Likert de cinco pontos.

Pesquisas vêm estudando Impacto do Treinamento no Trabalho e suas medidas correlatas relacionando com diversas variáveis, tais como em Al-Eisa et al. (2009) que analisaram o efeito de autoeficácia, suporte do supervisor e motivação para aprender com intenção para transferir. Van den Bossche et al. (2010) estudaram a relação entre Transferência de Treinamento (variável predita), feedback (variável preditora) e motivação para transferir (variável moderadora); Meneses e Abbad (2003), que investigaram as contribuições das variáveis individuais, do próprio treinamento e de suporte à transferência 
na explicação da variabilidade de Impacto do Treinamento no Trabalho. Mourão, Abbad e Zerbini (2014) analisaram em seu estudo a relação entre suporte na aplicação do treinamento, educação a distância, necessidade de treinamento e impacto do treinamento no trabalho; e encontraram que os participantes que perceberam maior suporte na aplicação do treinamento, que tinham atitudes mais favoráveis à educação a distância e que percebiam maior necessidade do treinamento, relataram maior ocorrência de impacto do treinamento no trabalho. Bell, Tannenbaum, Ford, Noe e Kraiger (2017), realizaram uma revisão da literatura dos últimos 100 anos na área de T\&D e constataram que suporte dos pares e do supervisor pode determinar até que ponto os egressos irão transferir as competências recém-adquiridas para o contexto de trabalho. A Tabela 4 mostra definições e descrições de medidas de Impacto do Treinamento no Trabalho adotadas em pesquisas anteriores.

\section{Tabela 4}

Definições e medidas de Impacto do Treinamento no Trabalho e construtos correlatos

Autores

Definições de Impacto do Treinamento no Trabalho
Instrumento para mensuração de Impacto

Gonçalves e Impacto do Treinamento no Instrumento validado por Abbad

Mourão (2011); Trabalho/Comportamento no Cargo

Lacerda e

Abbad (2003);

Menseses e

Abbad (2003) elou Transferência: Aplicação correta, no ambiente de trabalho, de Conhecimentos, Habilidades ou Atitudes adquiridas em situações de treinamento.
Chiaburu et al. Transferência de Treinamento: (2010)

Determina em que medida os egressos transferiram as competências adquiridas no treinamento para suas atividades diárias.
(1999), composto de 12 afirmativas associadas a uma escala Likert de cinco pontos, onde 1 = "Concordo totalmente" e $5=$ "Discordo totalmente".

Em Lacerda e Abbad (2003) e Gonçalvez e Mourão (2011), foi utilizada a escala de autoavaliação (Exemplo de item: "Utilizo, com frequência, em meu trabalho atual, o que foi ensinado no treinamento."). Em Meneses e Abbad, foi utilizada, também, a escala de heteroavaliação de Impacto (Exemplo de item: "O empregado utiliza, com frequência, em seu trabalho atual, o que lhe foi ensinado no treinamento.").

Escala de transferência de treinamento com seis itens (Xiao, 1996).

Exemplo de item: "Usar os novos conhecimentos do treinamento ajudou no meu trabalho." 
Tabela 4

Continuação

Autores

Definições de Impacto do

Instrumento para mensuração de

Treinamento no Trabalho

Impacto

\begin{tabular}{ll}
\hline Van den & Transferência de Treinamento: Grau \\
Bossche et al. & de compreensão percebido pelos \\
(2010) & treinandos e sua aplicação no local de \\
& trabalho.
\end{tabular}

Adaptação do inquérito de

percepção da aprendizagem (PSL),

composto por uma lista com sete

objetivos de aprendizagem a serem

avaliados em uma escala Likert de cinco pontos. Primeiro para indicar o quanto conheciam o tópico indicado $e$ depois o quanto aplicavam o mesmo tópico.

Hutchins, Nimon, Bates e Holton (2013)
Intenção de Transferir: Disposição e objetivo de um indivíduo para realizar um comportamento desejado.
LTSI (68 itens, sendo oito de características do treinando, 13 da escala de motivação, 30 da escala de ambiente de trabalho e 17 da escala de habilidade), com mais quatro itens para mensurar intenção para transferir (Exemplo de item: "Pretendo fazer todos os esforços nas próximas semanas para colocar em prática o que aprendi neste treinamento.").

Após análise da Tabela 4, desprende-se que existem diversas formas de mensurar impacto do treinamento no trabalho e seus conceitos correlatos, variando de instrumentos mais objetivos e com poucos itens a inventários mais complexos. Estudos nacionais estão mais propensos a utilizar o instrumento de Abbad (1999), possibilitando maiores comparações de resultados, porém pesquisas internacionais utilizam outros instrumentos, o que, apesar de possibilitar comparações, dificulta generalizações.

Importante ressaltar algumas formas das quais ambos os conceitos vêm sendo utilizados. O conceito de Transferência de Treinamento (aplicação eficaz no trabalho de novos conhecimentos, habilidades e atitudes aprendidos em treinamento) é mais utilizado na literatura internacional de $T \& D$, que também tem utilizado como variável critério Intenção de Transferir e Comportamento no Cargo para se referir a esse tipo de resultado pós treinamento. No Brasil, a expressão mais utilizada para se referir ao terceiro nível de avaliação, conforme Hamblin (1978) e Kirkpatrick (1976) é Impacto do Treinamento no Trabalho em amplitude, que se refere aos efeitos do treinamento sobre desempenho, motivação e atitudes do egresso em seu retorno ao trabalho; e Impacto do Treinamento no Trabalho em profundidade, que se refere a efeitos específicos de um treinamento, 
caracterizados pela transferência positiva das novas aprendizagens para o trabalho, as quais podem ser mensuradas como impactos específicos, ensinados diretamente pelo treinamento. Esses conceitos são correlatos e expressam efeitos de treinamentos, observáveis no comportamento do egresso. Diferem, frequentemente, quanto a medida utilizada para avaliar esse tipo de resultado. Impacto em amplitude adota medidas genéricas, aplicáveis a diversos programas de treinamento, enquanto que impacto em profundidade e transferência positiva de treinamento têm sido definidos operacionalmente a partir de objetivos de aprendizagem, específicos para cada treinamento.

Na presente pesquisa, será utilizado somente o conceito de Impacto do Treinamento no Trabalho em Amplitude, pois serão comparados três treinamentos distintos. Dessa forma, a aplicação de questionário de Impacto em Profundidade não é pertinente, uma vez que este é mais apropriado para contextos mais específicos.

No próximo capítulo é apresentada uma análise da produção de conhecimentos sobre motivação para o treinamento e seus relacionamentos com variáveis do contexto, perfil dos participantes de treinamento, transferência de treinamento para o trabalho. 


\section{CAPÍTULO 2: REVISÃO DE LITERATURA}

Com o intuito de analisar o conceito e medidas de motivação e sua relação com transferência de treinamento e impacto do treinamento no trabalho, foi realizada uma revisão de literatura que abrangeu uma busca de artigos científicos publicados entre 2000 e 2016 nas plataformas de busca de periódicos CAPES e Scielo. As expressões-chaves usadas nas buscas foram: Valor instrumental e treinamento; Motivation to learn e Transfer of training ou Motivação para aprender e Transferência de treinamento (com e sem aspas); "Motivation to learn" ou "Motivação para aprender"; Motivation to transfer ou Motivação para transferir (com e sem aspas); Motivation to transfer of training ou Motivação para transferência de treinamento (com e sem aspas); Expectancy theory e Transfer of training ou Teoria da expectância e Transferência de treinamento; e Força motivacional.

Para análise, foram considerados apenas os artigos revisados por pares desde o ano 2000, os demais não foram contabilizados, porém foram incluídos neste trabalho devido à sua importância para a área. Entre eles, estão textos científicos publicados nas décadas de oitenta e noventa, que foram muito citados por outros autores.

Foram encontrados 575 artigos que utilizavam uma ou mais expressões e palavraschave em seus títulos, resumos ou no texto. A pré-seleção desses artigos se deu por meio da leitura dos resumos de toda a lista de artigos identificados encontrados. Descartaram-se os artigos que abordavam superficialmente ou não possuíam relação com o tema motivação e/ou transferência de treinamento.

Após a pré-seleção dos artigos, verificou-se que 140 continham em seus resumos ou título o tema de motivação e/ou treinamento, mas somente 68 de fato abordavam o tema aqui estudado. Foram excluídos da amostra inicial artigos repetidos (coletados a partir de duas ou mais palavras-chave), artigos cujo público-alvo era de criança ou adolescente (foram considerados somente indivíduos no ambiente organizacional ou universitário) e publicados em idiomas diferentes daqueles (inglês, espanhol ou português) definidos para a busca.

Os 68 artigos selecionados (Anexo A) foram analisados por meio de uma planilha Excel que continha as seguintes categorias de conteúdo: ano de publicação do artigo, autores, palavras-chave, expressões-chaves utilizadas para encontrar o artigo, delineamento da pesquisa, desenho da pesquisa, objetivo do estudo, modelo teórico de motivação utilizado, variáveis, método (tipo de estudo, participantes e contexto, tipo de treinamento avaliado, instrumentos, procedimentos de coleta e análise de dados), principais resultados e discussões 
(limitações e contribuições). Os principais resultados dessas análises são apresentados a seguir.

\subsection{Resultados da Análise da Produção de Conhecimentos}

Foram considerados válidos para análise 68 artigos. Os textos foram analisados em três dimensões: características gerais, metodológicas e teórico-conceituais. Antes de apresentar as análises dos achados, é interessante verificar a divisão das expressões-chave utilizadas. A maior parte dos artigos foi encontrada na base CAPES (50) e os 18 restantes na base Scielo. As expressões-chaves e estratégias de busca que obtiveram um maior retorno foram: ""Motivation to transfer" OR "Motivação para transferir"” pela CAPES (frequência = 21) e "Motivation to learn" OR "Motivação para aprender" (freqüência = 14) pelo Scielo. (Anexo B). Cabe ressaltar que artigos encontrados na base CAPES e que, posteriormente, também foram encontrados no Scielo não foram contabilizados como sendo deste.

As duas expressões mais utilizadas pelos pesquisadores são motivação para transferir e para aprender. A partir disso, pode-se dizer que a literatura internacional utiliza mais referências em relação à motivação para transferir, enquanto a nacional a faz com a motivação para aprender. A seguir, os resultados da análise da produção de conhecimentos sobre motivação em estudos sobre transferência de treinamento são apresentados de acordo com as seguintes categorias de análise: (1) Características gerais dos artigos; e (2) Características metodológicas das pesquisas - natureza dos estudos, delineamento, tipo de dados analisados, variáveis e relacionamentos estudados, contextos, participantes, treinamentos estudados, estratégias de coleta e análise de dados.

Quanto aos artigos, no que se refere aos periódicos nos quais foram publicados, observa-se que $20(29,41 \%)$ são publicações brasileiras e as 48 (70,59\%) restantes de outros países, como Reino Unido (30,88\%), Estados Unidos (20,59\%), Alemanha (5,88\%), Holanda (4,42\%), Austrália e Colômbia (2,94\% cada), Polônia e Romênia (1,47\% cada) (Anexo C). Destes, o periódico que mais registrou publicações sobre o tema foi International Journal of Training and Development, com 11,78\% dos artigos.

Pode-se perceber que há uma grande diversidade nos periódicos nos quais os artigos foram publicados, sendo a maior parte deles pertencentes a quatro áreas de conhecimento: Comportamento organizacional e Gestão de recursos humanos (22,06\%), Psicologia (22,06\%), Educação (19,12\%) e Administração (13,24\%). Por outro lado, mesmo que em 
pequena quantidade, verificou-se pesquisas sobre motivação em áreas como Antropologia e Engenharia. (Anexo D).

No que diz respeito à natureza dos estudos analisados, notou-se um predomínio de artigos empíricos (57, ou seja, 83,82\%) e os restantes, teóricos. Esses resultados mostraram uma quantidade relativamente baixa de estudos teóricos na área de motivação. Gegenfurtner, Veermans, Festner e Gruber (2009), em sua revisão integrativa da literatura a respeito da motivação para transferir em treinamentos, apontam para o fato de que, embora os pesquisadores tenham concluído que a motivação para transferir é essencial para a transferência de treinamento, não havia sido feita até então uma revisão abrangente sobre o conceito sobre motivação para transferência.

Excetuando-se os artigos teóricos, a partir dos próximos tópicos, os resultados fazem referência aos 57 artigos empíricos encontrados. No tocante ao delineamento das pesquisas, foram encontrados 23 estudos correlacionais, 19 preditivos, sete descritivos, cinco exploratórios, dois de avaliação de programas e um decritivo-exploratório.

Quanto à natureza dos dados analisados, foram encontrados 38 estudos quantitativos, sete qualitativos e 12 mistos. Nota-se um predomínio de estudos quantitativos na amostra de artigos analisados. Diversos estudos adotaram métodos mistos, os quais têm sido recomendados para estudos com múltiplas variáveis (Creswell, Goodchild \& Turner, 1996; Onwuegbuzie \& Teddlie, 2003).

Com relação ao método, os assuntos serão separados de acordo com os participantes e contexto de pesquisa, procedimento de coleta de dados, instrumentos e, por fim, procedimentos de análises de dados.

Quanto ao contexto das pesquisas, se público ou privado, 28 artigos $(49,1 \%)$ não informam o tipo de organização estudada. Do restante, 14 (24,6\%) são públicas, dez (17,5\%) são privadas e duas $(3,5 \%)$ pertencem ao terceiro setor. Cabe ressaltar que em três estudos $(5,3 \%)$ foram realizados em mais de uma organização, contendo participantes de organizações públicas e privadas.

Mais da metade das organizações $(52,6 \%)$ eram organizações de trabalho e as 27 demais $(47,4 \%)$ eram educacionais. Os estudos que focaram no ambiente educacional, tiveram como público-alvo, docentes e discentes universitários, enquanto que os do ambiente organizacional, os participantes estavam vinculados a atividades e setores, como tribunais (Lacerda \& Abbad, 2003), organizações sem fins lucrativos (Smith, Jayasuruya, Caputi \& Hammer, 2008), indústria (Gegenfurtner, 2013), serviço militar (Patrick, Smy, Tombs \& 
Shelton, 2012), atividades agrícolas (Zamani, Ataei \& Bates, 2016), call-centers (Carvalho \& Mourão, 2014), dentre outros.

Quanto aos participantes, dez (17,2\%) artigos não apresentaram o gênero dos sujeitos. Dos que apresentaram, metade possuía a maioria de mulheres $(41,4 \%)$ e a outra metade maioria de homens. Em relação à variação das idades, 41 (71,9\%) estudos apresentaram faixa etária ou idade média dos participantes, podendo ser observado uma grande abrangência de público-alvo, variando de 18 a 77 anos. Além disso, duas pesquisas $(3,5 \%)$ não apresentaram precisão quanto à idade, apontando somente o intervalo de variação sem precisar o valor máximo. E ainda, 14 estudos $(24,6 \%)$ não informaram a idade ou faixa etária dos participantes.

Em relação aos treinamentos, $11(19,3 \%)$ eram treinamentos voltados ao desenvolvimento de competências técnicas (por exemplo, tratamento de dados pessoais, saúde e segurança ocupacional, papel do tutor, formação de professores, dentre outros), seis $(10,5 \%)$ ao desenvolvimento de competências transversais (coaching e motivação, assertividade e estratégias de negociação, dentre outros) e estudos que utilizaram mais de um treinamento com diversas finalidades de desenvolvimento de competências $(8,8 \%)$ (Grohmann, Beller \& Kauffeld, 2014; Meneses \& Abbad, 2003; Smith et al., 2008). Os treinamentos voltados para desenvolvimento de competências gerenciais (programa de desenvolvimento de líderes, habilidades essenciais para gerentes, dentre outros) somaram $7 \%$, enquanto que para desenvolvimento comportamental (treinamento como parte de alterações relacionadas com a função ocupada e otimização do trabalho em equipe) somou $3,5 \%$. Os $29(50,9 \%)$ restantes se referem aos estudos que não informaram o treinamento realizado pelos participantes ao qual se referiam suas avaliações, boa parte por serem em contexto de educação continuada em universidades. Esses resultados mostram que ainda há um predomínio de estudos voltados para áreas mais técnicas e gerais, e mostra a necessidade de mais estudos sobre gestão, liderança e competências gerenciais.

Quanto aos procedimentos de coleta de dados, observou-se que $80,7 \%$ utilizaram somente uma técnica (68,4\% surveys; $12,3 \%$ entrevistas), sendo que os demais, 11 estudos, utilizaram duas (survey com grupo focal, survey com entrevista, survey com intervenção e survey com revisão sistemática de literatura). Percebe-se que ainda há uma necessidade de estudos que utilizem mais de uma técnica de coleta de dados e que questionários continuam a ser a forma de coleta predominante entre os pesquisadores. 
Em relação às análises de dados utilizadas nas pesquisas, observaram-se: análises de correlação, que foram feitas em $38,60 \%$ das pesquisas; regressões múltiplas $(36,84 \%)$ e análises fatoriais (31,58\%). Essas análises inferenciais são bastante comuns nas pesquisas, pois são indicadas para estudos sobre relações entre variáveis, teste de modelos de predição e busca de evidências de validade de escalas.

Quanto às variáveis estudadas e os resultados encontrados, pode-se destacar que, nas pesquisas, motivação (motivação para transferir, para aprender, outros) foi definida como variável critério em 45,3\% dos casos, 39,6\% como variáveis antecedentes e assumiram o papel de variáveis mediadoras ou moderadoras em 11,3\%. Vale-se destacar que, em alguns estudos $(3,8 \%)$, variáveis motivacionais diferentes conceitualmente assumiram tanto um papel de variável antecedente como critério, como, por exemplo, no trabalho de Templeton (2016), em que variável critério era a motivação para educação (doutoramento) e a variável antecedente eram motivação intrínseca e extrínseca.

Diversas variáveis antecedentes mostraram relações positivas com motivação para aprender e para transferir, entre as quais as seguintes: (1) experiências emocionais sobre motivação para aprender (López \& Aguilar, 2013); (2) desenho instrucional sobre motivação para aprender (Wingo et al., 2015); (3) relação positiva da idade sobre motivação intrínseca e extrínseca (Santos, Mognon, Alcará \& Lemos, 2011); (4) papel do supervisor com motivação para aprender (Abdullah et al. 2011; Ismail, Mohamed, Sulaiman \& Sabhi, 2010); (5) tipo de inscrição do treinando no programa de treinamento (voluntária ou obrigatória) sobre a motivação para transferir (Curado et al. 2015); (6) relacionamento e satisfação instrucional com motivação para transferir (Gegenfurtner, Festner et al., 2009); e (7) estilo de aprendizagem e satisfação com as atividades (Olivos et al. 2016). Idade e autoeficácia para aprender e valor da aprendizagem mostraram relações negativas com motivação para a aprendizagem (Kochoian, Raemdonck, Frenay \& Zacher, 2016).

Resultados mostraram que variáveis de motivação para aprender são preditoras de transferência de treinamento (Al-Eisa et al., 2009; Chiaburu et al., 2010) e aprendizagem (Bräten \& Ferguson, 2015; McEown, Noels \& Saumure, 2014); e que variáveis de motivação para transferir são, também, preditoras de transferência de treinamento (Krishnamani \& Haider, 2016) e de intenção para transferir (Hutchins et al., 2013; Zaniboni et al., 2007). Assim como motivação para transferir aparece como mediadora entre características do treinamento e transferência de treinamento (Grohmann et al., 2014). 
Por fim, limitações e lacunas puderam ser notadas nos estudos, como o fato de grande parte deles adotarem medidas baseadas em percepções e autoavaliações, não utilizarem testes de desempenho para mensuração de efeitos sobre aprendizagem, retenção, generalização e transferência. Não foram localizados, na amostra pesquisada, estudos que tenham utilizado medidas objetivas de resultados de treinamento do desempenho de egressos, o que torna menos robustos os achados das pesquisas sobre motivação em contextos de treinamento. Permanece sem evidências empíricas objetivas se maior motivação para aprender e a para transferir aprendizagem melhora níveis de desempenho no trabalho.

No Brasil, há relativamente poucas pesquisas investigando motivação em contextos de educação corporativa. Os resultados da análise da literatura indicam que há fortes evidências de que quanto maior a motivação para aprender e para transferir, quanto melhor o suporte à transferência de novas aprendizagens para o trabalho, maior o impacto positivo do treinamento no desempenho, motivação e atitudes. Os modelos de investigação e de avaliação em TD\&E tem se tornado cada vez mais sofisticados com análises de relacionamentos indiretos entre variáveis, sendo a análise da mediação, uma estratégia cada vez mais utilizada em estudos que adotam modelagem por equações estruturais, que possibilitam análises fatoriais confirmatórias, análises multivariadas de relacionamentos diretos, indiretos e recíprocos. Neste estudo, será adotado um modelo de investigação que testará as relações de predição direta e mediação por meio de regressões múltiplas padrão. Após a revisão de literatura feita, a Figura 2 mostra o modelo para testar relações de predição de impacto e a Figura 3 mostra o modelo para investigar se suporte é variável mediadora da relação entre Força motivacional e Impacto do treinamento no trabalho. Esses modelos de investigação foram construídos a partir da análise da literatura e, principalmente com base nas propostas derivadas do IMPACT (Abbad, 1999; Lacerda \& Abbad, 2003; Pilati, 2004; Silva, 2007). 


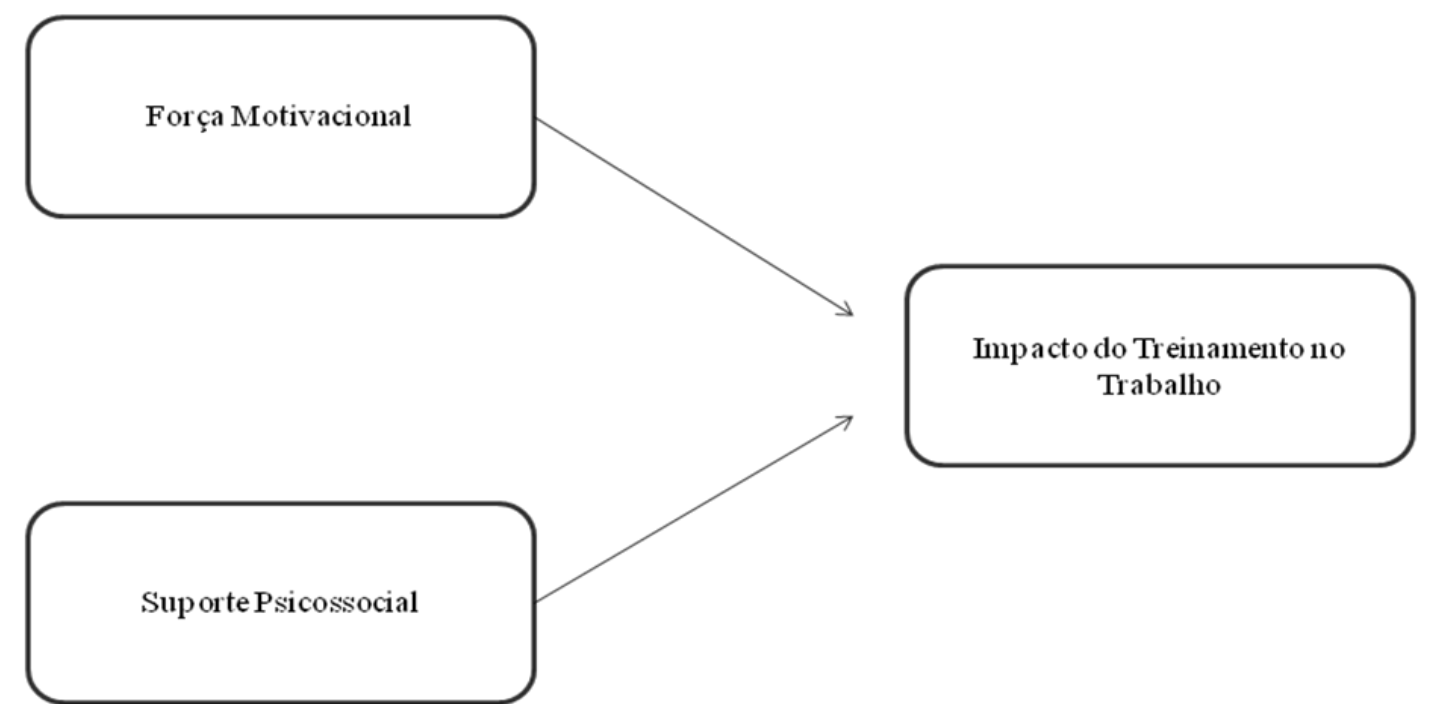

Figura 2. Modelo preditivo proposto

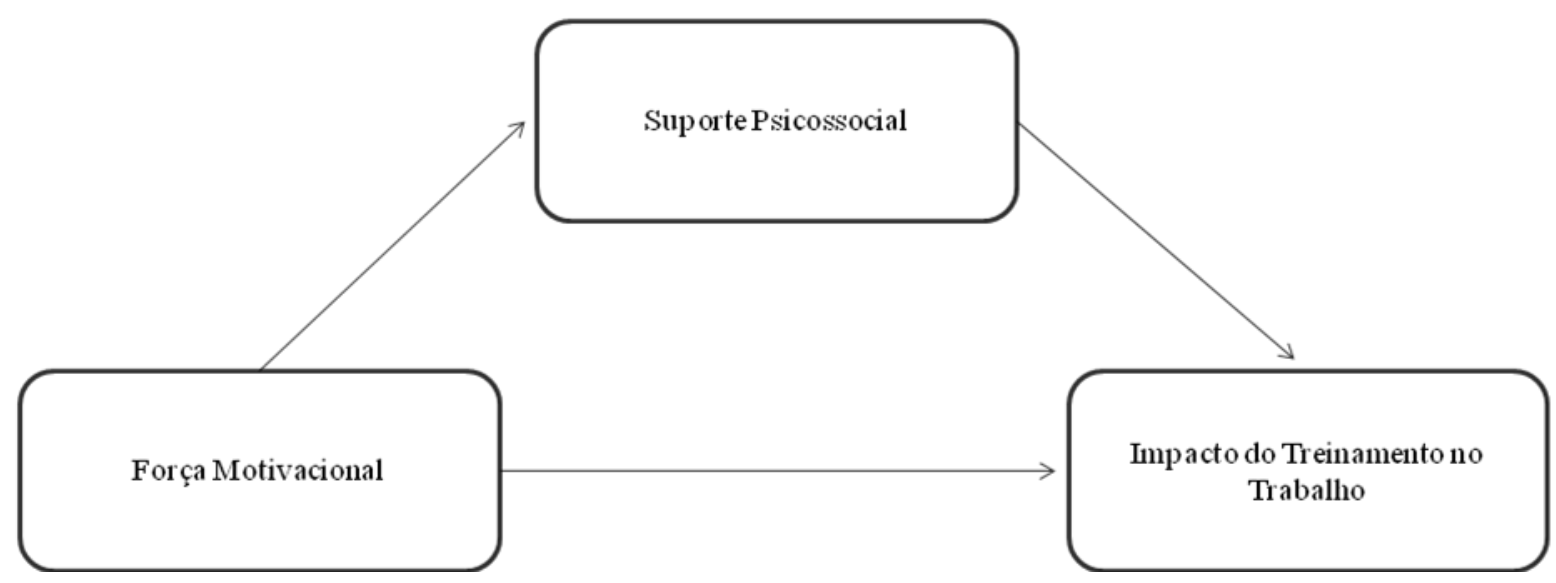

Figura 3. Modelo de Mediação proposto 


\section{CAPÍTULO 3: MÉTODO}

A seguir, são apresentadas as características metodológicas deste trabalho, em termos da organização na qual foi realizada a pesquisa, dos treinamentos analisados, dos participantes, procedimentos de coleta, instrumentos e estratégias de análise de dados.

\subsection{Contexto da pesquisa}

Este estudo foi realizado na Universidade Corporativa de uma empresa pública federal prestadora de serviço público, com mais de cem mil empregados (113.598), com sede em Brasília e estruturas regionais alocadas em quase todos os municípios brasileiros.

A escolha da organização foi não probabilística, por conveniência, levando em consideração o critério de disponibilidade e consentimento para a realização da pesquisa com acesso a pessoas para fornecimento de informações e a documentos organizacionais considerados relevantes ao estudo, entre os quais: desenho instrucional dos treinamentos, características dos participantes, contextualização dos treinamentos e materiais relacionados ao treinamento em si. A decisão de participar da pesquisa foi tomada em reunião realizada no mês de agosto de 2016 com o chefe da universidade corporativa da organização e com profissionais responsáveis por alguns dos treinamentos oferecidos.

Inicialmente, os critérios de escolha dos cursos previam a coleta de dados em amostras de três tipos de treinamentos, que pudessem diferir quanto aos resultados esperados, a saber: (1) treinamentos estratégicos, focados em resultados organizacionais, e com públicoalvo predominantemente oriundo da área fim; (2) treinamentos estratégicos, focados em resultados organizacionais, mas com público-alvo principal de participantes da área meio e (3) treinamentos ou programas com foco no indivíduo que visassem ao desenvolvimento profissional e de carreira. Entretanto, foi possível avaliar treinamentos corporativos que visavam melhorar resultados organizacionais, porém ofertados para profissionais lotados tanto em áreas meio como em áreas finalísticas da empresa. A universidade corporativa não dispunha de programas de desenvolvimento no momento da escolha dos treinamentos a serem avaliados nesta pesquisa.

Desta forma, obteve-se autorização para realizar a pesquisa com três cursos/treinamentos: (1) Agente de melhorias; (2) Gestão do Absenteísmo e o Incentivo à Presença Produtiva (Gestão do Absenteísmo); e (3) SEI - Sistema Eletrônico de Informações. 
Esses treinamentos serão apresentados a seguir. Os três treinamentos foram desenhados e ofertados pela organização aos empregados com o intuito de melhorar desempenhos dos egressos, bem como para produzir efeitos positivos sobre processos e resultados organizacionais.

\subsection{Caracterização dos treinamentos avaliados}

\section{Agente de Melhorias}

Trata-se de um treinamento presencial de 16 horas, realizado em dois dias por 863 participantes. O programa, ofertado pelas áreas de treinamento das diversas regionais da organização, tinha como objetivo geral desenvolver competências para implantar práticas de melhoria contínua em processo de trabalho. A Tabela 5 apresenta os objetivos específicos dos quatro módulos que compõem o treinamento.

\section{Tabela 5}

Objetivos específicos do treinamento de Agente de Melhorias

\begin{tabular}{|c|c|}
\hline Módulo & Objetivo Específico \\
\hline Introdução ao Agente da Melhoria & $\begin{array}{l}\text { Compreender a necessidade da mudança de } \\
\text { comportamento para a implantação da prática da melhoria } \\
\text { continua no dia a dia do gestor e de sua equipe. }\end{array}$ \\
\hline Os 7 desperdícios & $\begin{array}{l}\text { Identificar os desperdícios no processo diário de sua } \\
\text { unidade e propor contramedidas para eliminação para a } \\
\text { melhoria contínua dos processos. }\end{array}$ \\
\hline Gestão Visual & $\begin{array}{l}\text { Entender a importância da implementação da Gestão à } \\
\text { Vista nas Unidades Operacionais visando à melhoria da } \\
\text { eficiência, da comunicação e do desenvolvimento das } \\
\text { equipes na solução de problemas. }\end{array}$ \\
\hline $\begin{array}{l}\text { Os } 5 \text { Sensos - Melhorando o } \\
\text { Ambiente de Trabalho }\end{array}$ & $\begin{array}{l}\text { Implantação e gestão da metodologia 5"S" como forma } \\
\text { de controle da qualidade e redução de desperdício. }\end{array}$ \\
\hline Gerenciamento Diário & $\begin{array}{l}\text { Compreender o sistema de Gerenciamento Diário, sua } \\
\text { importância e aplicação na rotina da unidade em busca da } \\
\text { cultura da melhoria continuam a partir do } \\
\text { desenvolvimento das equipes na solução de problemas. }\end{array}$ \\
\hline
\end{tabular}


Em relação às estratégias instrucionais, observou-se na documentação do curso que predominaram aulas expositivas apoiadas por slides e por um guia contendo instruções e orientações sobre o que tutor deve realizar em sala de aula. Os materiais instrucionais indicam a utilização de exemplos extraídos das situações de trabalho, como recursos didáticos de apoio às discussões sobre os temas abordados no treinamento.

\section{Gestão do Absenteísmo e o Incentivo à Presença Produtiva}

Trata-se de um treinamento autoinstrucional, a distância (EaD), de 16 horas, ofertado por diversas regionais da organização a um quantitativo de 2.055 funcionários por meio da plataforma Moodle. O objetivo geral do treinamento é desenvolver as competências gerenciais dos líderes da Organização para uma melhor gestão das ausências e presenças no trabalho. Além disso, o desenho do curso aponta os objetivos instrucionais, conforme Tabela 6.

\section{Tabela 6}

Objetivos instrucionais do curso de Gestão do Absenteísmo

\section{Objetivos Instrucionais do treinamento Gestão do Absenteísmo e o Incentivo à} Presença Produtiva

1) Conceituar e diferenciar absenteísmo, presenteísmo e presença produtiva

2) Contextualizar o Programa de Gestão do Absenteísmo nos Correios

3) Identificar possíveis crenças limitadoras em relação à gestão do absenteísmo

4) Compreender a importância do gerenciamento do absenteísmo para a organização

5) Conhecer os tipos de absenteísmo existentes

6) Conhecer os fatores que podem causar o absenteísmo e o presenteísmo

7) Conhecer quais as consequências do absenteísmo e presenteísmo

8) Compreender a cesta de motivos que compõe o índice de absenteísmo e como ele é calculado

9) Identificar quais motivos de ausências são gerenciáveis ou não

10) Conhecer as ferramentas de apoio à gestão do absenteísmo e normas vigentes

11) Conhecer as ações desenvolvidas pelos Correios para gestão do absenteísmo

12) Conhecer os princípios da comunicação clara e assertiva com seus liderados

13) Compreender a importância da valorização dos empregados e como valorizá-los

Fonte: Documento da organização estudada

Por meio da avaliação de materiais e recursos instrucionais em $\mathrm{EaD}$, verificou-se que no manual do treinando constam instruções sobre: (1) como acessar os materiais e recursos de ensino e aprendizagem contidos no Moodle; (2) orientações sobre os direitos do participante 
de realizar o curso fora do horário de trabalho (porém sem receber a mais por isso, uma vez que é permitido que o curso seja feito durante o horário de trabalho); (3) normas de acesso aos módulos; (4) critérios para obter o certificado de conclusão do treinamento (rendimento satisfatório na avaliação de aprendizagem e realizar a avaliação de reação ao curso); (5) descrição das etapas e atividades que os participantes devem cumprir para concluir com sucesso o curso. Os conteúdos e materiais do curso são disponibilizados ao aluno pelo Moodle de acordo com a sequência pré-estabelecida dos módulos do treinamento, de modo que o trinando só poderá acessar um módulo de cada vez.

Em relação aos materiais instrucionais, observou-se que os textos apresentam conteúdos compatíveis com a complexidade e a natureza dos objetivos de aprendizagem e são enriquecidos com animações e figuras que estimulam a leitura e a retenção dos conteúdos. As estratégias utilizadas são os materiais escritos, exercícios de retenção de conteúdos com questões objetivas e palavras-cruzadas. Sobre as interações presentes no treinamento, a única adotada pelo curso é a interação aluno-material (aluno-máquina), uma vez que não há tutores e os fóruns não são utilizados.

Por fim, quanto aos exercícios e avaliações realizados, observou-se que ambos mensuram somente aspectos cognitivos, de conhecimentos básicos, conceituais e de procedimentos. Os exercícios são realizados após o término de cada módulo e a avaliação de aprendizagem é única e realizada ao final do treinamento. Os feedbacks são informativos e oferecidos automaticamente ao final de cada atividade. Vale ressaltar que a avaliação final permite três tentativas de respostas. Os critérios de aprovação no treinamento são: a leitura de todo o conteúdo e a realização das atividades avaliativas (exercícios e avaliação de aprendizagem). Além disso, antes de receber o certificado, faz-se necessário o preenchimento da avaliação de reação referente ao treinamento.

\section{Sistema Eletrônico de Informação (SEI)}

Trata-se de um treinamento autoinstrucional, a distância (EaD), de oito horas, ofertado por diversas regionais da organização a um quantitativo de 16.218 funcionários por meio da plataforma Moodle. O objetivo geral do treinamento era capacitar todos os empregados da organização para a operação do Sistema Eletrônico de Informação - SEI - na Organização, que será de uso obrigatório para a tramitação de todas as comunicações e decisões administrativas da organização. 
O Sistema Eletrônico de Informação (SEI) é uma plataforma que engloba um conjunto de módulos e funcionalidades que promovem a eficiência administrativa. É um sistema de gestão de processos documentos eletrônicos, que tem como principal característica a libertação do papel como suporte físico para documentos institucionais e o compartilhamento do conhecimento com atualização e comunicação de novos eventos em tempo real.

O treinamento é composto por seis módulos: (1) Introdução; (2) Operações com processos; (3) Operações com documentos; (4) Blocos; (5) Recuperando informações; e (6) Usuários externos. Suas estratégias instrucionais são bastante interativas, adequadas à natureza, e complexidade dos objetivos, com um treinamento bastante interativo, incluindo as atividades e exemplos. A interação é somente entre aluno-material, com linguagem programada. Os feedbacks tanto dos exercícios como das avaliações são informativos e oferecidos automática e imediatamente após cada resposta do participante. Por fim, para aprovação no curso é necessário atingir a pontuação de 70\% nas avaliações.

\subsection{Caracterização geral dos participantes}

Participaram desta pesquisa 2.975 (dois mil novecentos e setenta e cinco) funcionários da Organização que realizaram pelo menos um dos três treinamentos aqui estudados. 83,2\% (frequência $=2.475)$ corresponderam ao SEI, 14,3\% (frequência $=425$ ) à Gestão de Absenteísmo e o Incentivo à Presença Produtiva, e 2,5\% (frequência $=75$ ) ao Agente de Melhorias.

Mais da metade dos respondentes (59,2\%) era do sexo masculino e 74,3\% declararam ser casados ou estar em união estável. Em relação ao último nível de escolaridade concluído, predominaram participantes com ensino superior $(45,1 \%)$ ou especialização (41\%). Quanto ao tempo na função atual, 70,3\% relatou estar nessa função até seis anos; $43 \%$ dos

participantes ocupam cargos funções de gestão/supervisão. Por fim, em relação à obrigatoriedade do treinamento, sendo $50,8 \%$ consideraram os treinamentos como de participação optativa e os restantes como altamente recomendados (Tabela 7). 
Tabela 7

Estatísticas descritivas dos respondentes

\begin{tabular}{|c|c|c|}
\hline & Frequência (n) & Porcentagem (\%) \\
\hline \multicolumn{3}{|l|}{ Treinamento avaliado } \\
\hline Agente de melhoria & 75 & $2,5 \%$ \\
\hline \multicolumn{3}{|l|}{ Gestão do absenteísmo e o Incentivo à Presença } \\
\hline Produtiva & 425 & $14,3 \%$ \\
\hline Sistema Eletrônico de Informação (SEI) & 2475 & $83,2 \%$ \\
\hline \multicolumn{3}{|l|}{ Sexo } \\
\hline Feminino & 1213 & $40,8 \%$ \\
\hline Masculino & 1762 & $59,2 \%$ \\
\hline \multicolumn{3}{|l|}{ Estado Civil } \\
\hline Solteiro & 464 & $15,6 \%$ \\
\hline Casado/União estável & 2210 & $74,3 \%$ \\
\hline Divorciado/Separado & 281 & $9,4 \%$ \\
\hline Viúvo & 20 & $0,7 \%$ \\
\hline \multicolumn{3}{|l|}{ Escolaridade } \\
\hline Ensino fundamental & 1 & $0,0 \%$ \\
\hline Ensino Médio & 328 & $11,0 \%$ \\
\hline Ensino Superior & 1343 & $45,1 \%$ \\
\hline Especialização & 1219 & $41,0 \%$ \\
\hline Mestrado & 81 & $2,7 \%$ \\
\hline Doutorado & 3 & $0,1 \%$ \\
\hline \multicolumn{3}{|l|}{ Tempo na função atual } \\
\hline Menos de 1 ano & 371 & $12,5 \%$ \\
\hline De 1 a 3 anos & 1035 & $34,8 \%$ \\
\hline De 4 a 6 anos & 686 & $23,1 \%$ \\
\hline De 7 a 9 anos & 314 & $10,6 \%$ \\
\hline 10 anos ou mais & 569 & $19,1 \%$ \\
\hline \multicolumn{3}{|l|}{ Ocupa funcão de gestão/Supervisão? } \\
\hline Sim & 1279 & $43,0 \%$ \\
\hline Não & 1696 & $57,04 \%$ \\
\hline \multicolumn{3}{|l|}{ Obrigatoriedade do treinamento } \\
\hline Optativo & 1510 & $50,8 \%$ \\
\hline Altamente recomendado & 1465 & $49,2 \%$ \\
\hline
\end{tabular}

\subsection{Instrumentos de Coleta de Dados}

O instrumento (Anexo E) foi constituído por quatro blocos. Antes de responder as questões, os participantes deveriam escolher um dos três treinamentos para avaliar, dizendo o mês e ano em que haviam participado do treinamento e a modalidade de ensino.

O primeiro bloco, denominado "Valor do Treinamento", foi baseado na Escala de Valor Instrumental do Treinamento (EVIT) de Lacerda e Abbad (2003). O instrumento 
original é composto de 14 itens associados a duas escalas, uma que avalia Valência (Importância) e outra Instrumentalidade (Utilidade), assim os respondentes julgariam cada item por meio de duas escalas, sendo que uma delas avalia a importância de determinadas recompensas para a vida pessoal e profissional do respondente e a outra, a utilidade que ele atribui ao treinamento como meio para obter esses resultados (Abbad, Lacerda \& Pilati, 2012). A escala de Importância é composta por cinco pontos que variam de 1 (nada importante) a 5 (totalmente importante), enquanto que a escala de Utilidade varia de 1 (nada útil) a 5 (completamente útil). Na escala adotada nesta pesquisa, não foi possível formatar o questionário com os 14 itens no centro e as duas escalas nas laterais, pois a ferramenta de composição do questionário não possibilitava esse formato. O questionário aplicado nesta pesquisa contém os mesmos 14 itens, porém apresentados duas vezes, uma para cada escala. Por fim, foi acrescido ao final do bloco um item de Expectância proposto por Pilati (2004), cujo objetivo era avaliar a expectativa dos treinandos de atingir, por meio do treinamento, os resultados almejados; e dessa forma, como os três componentes da teoria de Vroom - VIE foi possível calcular a Força motivacional dos participantes. O item único é composto por uma escala tipo Likert de 0 (sem expectativa) a 10 (muita expectativa) ao qual o respondente avalia a sentença "O quanto você espera que as habilidades que você adquiriu no treinamento o ajudarão a alcançar os resultados descritos nos itens acima listados?”.

O segundo bloco, denominado "Autoavaliação do Impacto do Treinamento no Trabalho", foi baseado na escala desenvolvida por Abbad (1999), composta de 12 itens avaliados em uma escala tipo Likert de cinco pontos, em que 1 (um) corresponde ao "Discordo totalmente da afirmativa"; 2 (dois) ao "Discordo um pouco da afirmativa"; 3 (três) ao "Nem concordo nem discordo da afirmativa"; 4 (quatro) ao "Concordo com a afirmativa" e 5 (cinco) ao "Concordo totalmente com a afirmativa".

O terceiro bloco, denominado "Suporte ao Treinamento", foi baseado na Escala de Suporte à Transferência de Treinamento (EST) (Abbad, 1999). A escala original é composta por 22 afirmativas com duas dimensões: (1) Suporte Psicossocial - 16 itens ligados a fatores situacionais de apoio (nove itens) e consequências associadas ao uso de novas habilidades de trabalho (sete itens); (2) Suporte Material - seis itens que mensuram qualidade, suficiência, e disponibilidade de recursos materiais e financeiros, bem como a adequação do ambiente físico à transferência de treinamento. Todos os itens são avaliados em uma escala tipo Likert de cinco ponto, em que 1 (um) corresponde a "Nunca"; 2 (dois) a "Raramente"; 3 (três) a 
"Algumas vezes"; 4 (quatro) a "Frequentemente" e 5 (cinco) a "Sempre". A subescala adotada neste estudo não contém os itens de suporte material à transferência de treinamento.

Por fim, o quarto bloco corresponde aos dados pessoais e profissionais dos participantes: sexo, estado civil, último nível de escolaridade, área da última formação acadêmica, ano que concluiu a formação, tempo em que trabalhava na Organização e na função atual, se ocupa cargo de gestão ou supervisão e se o treinamento foi optativo (voluntário) ou obrigatório (altamente recomendado pelo gestor). Após compor o questionário com os quatro blocos, este foi levado à organização a fim de realizar uma validação semântica com seis funcionários. A partir das sugestões dadas pelos avaliadores, os questionários foram adequados à realidade da organização.

\subsection{Procedimentos de Coleta de Dados}

Para realizar a coleta de dados no formato online, o questionário, autoaplicável, foi digitalizado para o Google Forms e repassado para uma lista de egressos dos três treinamentos em um e-mail com uma carta de sensibilização. Após 15 dias, outro e-mail foi enviado à lista, com mensagem de agradecimento aos que responderam e reiterando o pedido aos demais para que participassem da pesquisa preenchendo o referido questionário. Os cuidados éticos necessários foram tomados, garantindo aos participantes o caráter sigiloso das respostas individuais, bem como a participação voluntária na pesquisa e a devolução dos resultados agrupados.

O questionário foi enviado para 10.592 egressos dos treinamentos por meio de e-mail institucional e a taxa final de retorno foi de $28,09 \%$ (frequência $=2.975$ ). Os egressos preencheram o questionário após realização do treinamento, porém o tempo entre 0 treinamento e a participação na pesquisa foi variável. As perguntas da pesquisa foram respondidas pelos participantes com base no seu consentimento e base voluntária. Os dados coletados foram salvos automaticamente pelo Google Forms, em planilha compatível com Excel, e posteriormente exportados para o SPSS versão 21.

\subsection{Procedimentos de Análise de Dados}

Para atender aos objetivos deste trabalho, foram realizadas análises descritivas (médias, desvios padrão, mínimo e máximo, frequência, skewness e curtose) e exploratórias (para identificação e exclusão de outliers). Além disso, foram realizadas correlações 
bivariadas intra e entre variáveis para verificar ocorrências de colinearidade, multicolinearidade ou singularidade.

Em outra etapa, visando atingir o objetivo específico 1, foram realizadas análises de componentes principais (PC), análise de fatoração dos eixos principais (PAF) e de consistência interna (Alpha de Cronbach), para buscar evidências de validade das escalas utilizadas no estudo. Nas análises fatoriais, foram realizados os testes dos pressupostos (tamanho da amostra, linearidade, Outliers nos casos e nas variáveis, multicolinearidade e singulariadade, fatorabilidade da matriz, confiabilidade e validade).

Foram calculadas as médias fatoriais e desvios padrões de IMTT, SUPSI e FM. Devido à desproporção de participantes dos três cursos (75 de Agente de Melhorias, 245 de Gestão do Absenteísmo, e 2.475 do SEI), foram agrupados em uma só categoria os casos Agente de Melhorias e Gestão do Absenteísmo, totalizando 500 casos e escolhidos, aleatoriamente, 500 casos do treinamento SEI. Com esses 1.000 casos válidos, após equalização do número de respondentes, foram realizados testes $t$ de Student a fim de comparar os dois grupos de treinamentos em termos de IMTT, SUPSI e FM.

As respostas de 2975 participantes aos itens das escalas foram submetidas ao teste de resíduos padronizados, com nota de corte de \pm 2 e identificados, visando a identificação de casos extremos multivariados que poderiam afetar as análises de regressão múltipla. Foram encontrados 59 casos com valores iguais ou superiores a +2 e 91 iguais ou superiores a -2 , resultando na eliminação de 150 casos e restando para as demais análises 2.825 casos válidos.

Após realização de teste de pressupostos (Durbin-Watson, teste de resíduos), foram realizadas análises de regressão múltipla padrão para analisar a influência das variáveis preditoras (Força Motivacional e Suporte Psicossocial à Transferência de Treinamento) sobre Impacto do Treinamento no Trabalho. Foram adotadas como variáveis as médias fatoriais das variáveis preditoras e critério, calculadas, em uma primeira etapa, para a amostra completa de participantes dos três treinamentos (casos válidos $=2.825)$. Em seguida, visando à análise da consistência dos resultados, foram escolhidas aleatoriamente, a partir dos 2.825 casos, três amostras de 400 participantes, cujas médias fatoriais foram submetidas a três análises de regressão múltipla padrão.

Foram realizadas análises de regressão múltipla para os treinamentos agrupados de acordo com as seguintes categorias: 1 = Agente de Melhorias e Gestão do Absenteísmo ( $\mathrm{N}=$ $487)$, e 2 = SEI $(\mathrm{N}=2.338)$. Como este último treinamento tinha uma amostra muito superior à obtida para os demais treinamentos, as análises de regressão múltipla, além de terem sido 
aplicadas em toda a amostra do treinamento SEI, foram calculadas também em três subamostras de 400 casos cada, escolhidas aleatoriamente a partir da amostra completa de participantes desse curso. As análises de RM para os dois tipos de curso foram realizadas após terem sido encontradas diferenças estatisticamente significativas entre as médias fatoriais das três variáveis do modelo de regressão múltipla, as quais indicaram que o treinamento SEI foi o que apresentou menor força motivacional, menor suporte psicossocial e menor impacto no trabalho. Visando analisar o valor preditivo das variáveis antecedentes sobre impacto para os dois tipos de curso (MelhoraAbsent X SEI), foram feitas comparações entre as equações de regressão múltipla obtidas.

A quarta etapa de análise de RM foi realizada com objetivo de testar a hipótese de que a variável Suporte Psicossocial à Transferência é mediadora do relacionamento entre Força Motivacional e Impacto do Treinamento no Trabalho. Essa análise foi realizada de acordo com o procedimento de Baron e Kenny (1986). Os resultados das análises supracitadas serão apresentados a seguir. Foi utilizado o pacote estatístico SPSS (Statistical Package for Social Sciences), versão 21.0 . 


\section{CAPÍTULO 4: RESULTADOS}

A seguir são descritos os resultados da busca de evidências de validade dos instrumentos e da análise dos relacionamentos entre variáveis preditoras e a variável critério Impacto do Treinamento no Trabalho - IMTT.

\subsection{Evidências de Validade das Escalas}

As 2.975 respostas numéricas dos participantes aos itens do questionário, aplicado em formato online em uma amostra de empregados egressos de três treinamentos corporativos, ofertados pela universidade corporativa da empresa estatal, foram submetidos a análises estatísticas descritivas e exploratórias, análises fatoriais exploratórias, fidedignidade e regressão múltipla padrão. Nesta seção descrevem-se as estruturas empíricas das escalas componentes de Força Motivacional (Valência, Instrumentalidade e Expectância) - FM, Suporte Psicossocial à Transferência de Treinamento - SUPSI e Impacto do Treinamento no Trabalho - IMTT.

Força motivacional (FM) é definida neste estudo como um construto composto por três dimensões: (1) Valência (ou importância do treinamento); (2) Instrumentalidade (ou utilidade do treinamento) e (3) Expectância (expectativa quanto ao treinamento) (Lacerda \& Abbad, 2002; Pilati, 2004; Vroom, 1964). As duas primeiras dimensões foram avaliadas por meio de duas escalas, sendo uma delas, de percepção de importância (ou valência) e a outra, de utilidade do treinamento (instrumentalidade). A última foi mensurada por meio de um item único.

Também foram investigadas evidências de validade do instrumento de 16 itens referentes a Suporte psicossocial à Transferência de Treinamento (SUPSI), definido como as percepções sobre o apoio gerencial, dos colegas e da organização à aplicação de novas aprendizagens no ambiente de trabalho (Abbad et al., 2012) e da escala de 12 itens de avaliação do Impacto do Treinamento no Trabalho - IMTT, definido como o efeito da transferência de treinamento sobre o desempenho do egresso no trabalho (Abbad, Pilati, Borges-Andrade \& Sallorenzo, 2012).

A seguir são apresentadas as estruturas empíricas das escalas, conforme resultados de análises fatoriais exploratórias e de fidedignidade. 


\subsubsection{Escala de Instrumentalidade (Utilidade do Treinamento)}

Em relação à subescala de Instrumentalidade, as correlações entre as respostas dos participantes aos itens variaram de 0,43 a 0,80 , indicando a presença de correlações bivariadas estatisticamente significativas, de magnitudes moderadas e altas entre todas as variáveis. A análise dos componentes principais sugeriu uma estrutura empírica com um único componente que explica $65,22 \%$ da variância total das respostas dos participantes aos itens da escala. Utilizou-se o critério dos eigenvalues (valores próprios) maiores ou iguais a um.

Os resultados da análise fatorial pelo método da Fatoração dos Eixos Principais (Principal Axis Factoring - PAF) e análise de consistência interna (Alpha de Cronbach) do instrumento também indicaram a presença de um único fator, denominado Instrumentalidade do Treinamento, composto por 14 itens com valor próprio de 8,77, variância total explicada de $62,65 \%$, cargas fatoriais variando de 0,68 a 0,88 e Alfa de Cronbach igual a 0,96 . Na Tabela 8, são apresentadas as médias, os desvios padrões, as cargas fatoriais, as comunalidades $\left(\mathrm{h}^{2}\right)$, as correlações item-total e informações adicionais sobre a estrutura empírica da escala.

Tabela 8

Estrutura Empírica da Escala de Instrumentalidade (Utilidade) do Treinamento

\begin{tabular}{lccccc}
\hline \multicolumn{1}{c}{ Descrição dos itens } & Média & $\begin{array}{c}\text { Desvio } \\
\text { Padrão }\end{array}$ & $\mathbf{h}^{2}$ & $\begin{array}{c}\text { Cargas } \\
\text { Fatoriais }\end{array}$ & $\begin{array}{c}\text { Correlação } \\
\text { item-total }\end{array}$ \\
\hline $\begin{array}{l}\text { O quanto o treinamento que realizei é } \\
\text { ÚTIL para resolver problemas de trabalho. }\end{array}$ & 3,76 & 1,21 & 0,46 & 0,68 & 0,66 \\
$\begin{array}{l}\text { O quanto o treinamento que realizei é } \\
\text { ÚTIL para melhorar minha atuação em } \\
\text { tarefas não relacionadas ao meu cargo. }\end{array}$ & 3,19 & 1,34 & 0,49 & 0,70 & 0,68 \\
$\begin{array}{l}\text { O quanto o treinamento que realizei é } \\
\text { ÚTIL para melhorar meu desempenho } \\
\text { relacionado às tarefas do meu cargo. }\end{array}$ & 3,51 & 1,30 & 0,55 & 0,74 & 0,73 \\
$\begin{array}{l}\text { O quanto o treinamento que realizei é } \\
\text { ÚTIL para resolver problemas que não se } \\
\text { relacionam diretamente com a } \\
\text { organização. }\end{array}$ & 2,54 & 1,39 & 0,55 & 0,74 & 0,73 \\
$\begin{array}{l}\text { O quanto o treinamento que realizei é } \\
\text { ÚTIL para melhorar meu relacionamento } \\
\text { com familiares e amigos. }\end{array}$ & 2,20 & 1,35 & 0,59 & 0,77 & 0,75 \\
$\begin{array}{l}\text { O quanto o treinamento que realizei é } \\
\text { ÚTIL para aumentar meu salário. }\end{array}$ & 2,11 & 1,31 & 0,59 & 0,77 & 0,75 \\
\hline
\end{tabular}


Tabela 8

Continuação

\begin{tabular}{|c|c|c|c|c|c|}
\hline Descrição dos itens & Média & $\begin{array}{l}\text { Desvio } \\
\text { Padrão }\end{array}$ & $\mathbf{h}^{2}$ & $\begin{array}{c}\text { Cargas } \\
\text { Fatoriais }\end{array}$ & $\begin{array}{l}\text { Correlação } \\
\text { item-total }\end{array}$ \\
\hline $\begin{array}{l}\text { O quanto o treinamento que realizei é } \\
\text { ÚTIL para manter-me em meu cargo atual. }\end{array}$ & 2,89 & 1,46 & 0,63 & 0,79 & 0,78 \\
\hline $\begin{array}{l}\text { O quanto o treinamento que realizei é } \\
\text { ÚTIL para aumentar as oportunidades } \\
\text { profissionais, nessa organização. }\end{array}$ & 3,21 & 1,39 & 0,64 & 0,80 & 0,78 \\
\hline $\begin{array}{l}\text { O quanto o treinamento que realizei é } \\
\text { ÚTIL para melhorar meu currículo. }\end{array}$ & 3,29 & 1,38 & 0,64 & 0,80 & 0,78 \\
\hline $\begin{array}{l}\text { O quanto o treinamento que realizei é } \\
\text { ÚTIL para melhorar o relacionamento com } \\
\text { meu gestor. }\end{array}$ & 3,18 & 1,39 & 0,66 & 0,81 & 0,79 \\
\hline $\begin{array}{l}\text { O quanto o treinamento que realizei é } \\
\text { ÚTIL para aumentar minhas chances de } \\
\text { conseguir melhores empregos. }\end{array}$ & 2,61 & 1,39 & 0,71 & 0,85 & 0,83 \\
\hline $\begin{array}{l}\text { O quanto o treinamento que realizei é } \\
\text { ÚTIL para melhorar meu relacionamento } \\
\text { com meus colegas de trabalho. }\end{array}$ & 2,71 & 1,41 & 0,75 & 0,87 & 0,85 \\
\hline $\begin{array}{l}\text { O quanto o treinamento que realizei é } \\
\text { ÚTIL para atingir minhas mais altas } \\
\text { aspirações profissionais. }\end{array}$ & 2,75 & 1,43 & 0,76 & 0,87 & 0,85 \\
\hline $\begin{array}{l}\text { O quanto o treinamento que realizei é } \\
\text { ÚTIL para sentir-me mais valorizado pelo } \\
\text { meu grupo de trabalho. }\end{array}$ & 2,89 & 1,41 & 0,77 & 0,88 & 0,86 \\
\hline $\begin{array}{l}\mathrm{N}=2.975 \\
\text { Média do fator }=2,92 \\
\text { Desvio Padrão }=1,11 \\
\text { Valor próprio }(\text { Eigenvalue })=8,77 \\
\% \text { da variância explicada }=62,65 \% \\
\text { Número de itens }=14 \\
\text { Alfa de Cronbach: } \alpha=0,96\end{array}$ & & & & & \\
\hline
\end{tabular}

As médias obtidas dos itens variaram entre 2,11 ( $\mathrm{DP}=1,31)$ e 3,76 $(\mathrm{DP}=1,21)$ correspondentes aos itens "O quanto o treinamento que realizei é ÚTIL para aumentar meu salário" e "O quanto o treinamento que realizei é ÚTIL para resolver problemas de trabalho", respectivamente. Deve-se ressaltar que o item que possui a maior média é também o que possui menor desvio padrão da amostra indicando uma maior homogeneidade de respostas dos participantes a este item. Além disso, observa-se que a média fatorial foi de 2,92 (DP = 1,11), o que indica uma média baixa (em uma escala de cinco pontos). Dessa forma, pode-se dizer que a percepção dos respondentes quanto à utilidade (instrumentalidade) do treinamento 
é desfavorável. Os resultados das análises fatoriais mostraram índices psicométricos favoráveis que evidenciam a validade e a fidedignidade da escala.

\subsubsection{Escala de Valência (Importância do Treinamento)}

Em relação à escala de percepção dos participantes sobre a valência (ou importância do treinamento), observaram-se correlações estatisticamente significativas entre todas as variáveis, com coeficientes variando entre 0,42 e 0,78 , indicando que a matriz de dados é fatorável. A análise dos componentes principais sugeriu uma estrutura empírica com um componente que explica $65,30 \%$ da variância total das respostas dos participantes aos itens da escala. Utilizou-se o critério dos eigenvalues (valores próprios) maiores ou iguais a um. Esses resultados indicaram a presença de um único fator. A estrutura unifatorial também foi obtida por meio do método de fatoração dos eixos principais (Principal Axis Factoring - PAF) e da análise de consistência interna do instrumento. Esse fator, denominado Instrumentalidade do treinamento, contém 14 itens, com valor próprio (eigenvalue) de 8,78, variância total explicada de 62,73\%, cargas fatoriais variando de 0,67 a 0,88 e Alfa de Cronbach igual a 0,96. Todos esses índices são favoráveis e indicam a qualidade dessa escala para uso na pesquisa.

A Tabela 9 mostra a composição e a estrutura empírica da escala de Valência do treinamento em termos de médias fatoriais, desvio padrão, cargas fatoriais, comunalidades $\left(\mathrm{h}^{2}\right)$, correlação item-total e informações adicionais.

\section{Tabela 9}

Estrutura Empírica da Escala de Valência (Importância) do Treinamento

\begin{tabular}{|c|c|c|c|c|c|}
\hline Descrição dos itens & Média & $\begin{array}{l}\text { Desvio } \\
\text { Padrão }\end{array}$ & $h^{2}$ & $\begin{array}{c}\text { Cargas } \\
\text { Fatoriais }\end{array}$ & $\begin{array}{c}\text { Correlação } \\
\text { item-total }\end{array}$ \\
\hline $\begin{array}{l}\text { O quanto o treinamento que realizei é } \\
\text { IMPORTANTE para resolver problemas } \\
\text { de trabalho. }\end{array}$ & 3,79 & 1,20 & 0,45 & 0,67 & 0,66 \\
\hline $\begin{array}{l}\text { O quanto o treinamento que realizei é } \\
\text { IMPORTANTE para melhorar minha } \\
\text { atuação em tarefas não relacionadas ao } \\
\text { meu cargo. }\end{array}$ & 3,17 & 1,33 & 0,48 & 0,69 & 0,68 \\
\hline $\begin{array}{l}\text { O quanto o treinamento que realizei é } \\
\text { IMPORTANTE para melhorar meu } \\
\text { desempenho relacionado às tarefas do } \\
\text { meu cargo. }\end{array}$ & 3,50 & 1,29 & 0,55 & 0,74 & 0,73 \\
\hline
\end{tabular}


Tabela 9

Continuação

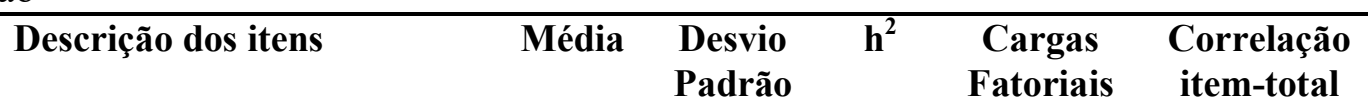

O quanto o treinamento que realizei é

$2,51 \quad 1,38$

atoriais

0,73

IMPORTANTE para resolver problemas

que não se relacionam diretamente com

a organização.

O quanto o treinamento que realizei é

$2,16 \quad 1,32 \quad 0,59 \quad 0,77 \quad 0,75$

IMPORTANTE para aumentar meu salário.

O quanto o treinamento que realizei é

IMPORTANTE para melhorar meu

$2,18 \quad 1,34 \quad 0,61 \quad 0,78 \quad 0,76$

relacionamento com familiares e

amigos.

O quanto o treinamento que realizei é

IMPORTANTE para manter-me em

meu cargo atual.

O quanto o treinamento que realizei é

IMPORTANTE para melhorar meu

currículo.

O quanto o treinamento que realizei é

IMPORTANTE para melhorar o

3,18

relacionamento com meu gestor.

O quanto o treinamento que realizei é

IMPORTANTE para aumentar as

oportunidades profissionais, nessa

organização.

O quanto o treinamento que realizei é

IMPORTANTE para aumentar minhas

chances de conseguir melhores

empregos.

O quanto o treinamento que realizei é

IMPORTANTE para melhorar meu

1,40

0,75

0,87

0,85

relacionamento com meus colegas de

trabalho.

O quanto o treinamento que realizei é

IMPORTANTE para atingir minhas

$$
2,7
$$

1,45

0,76

0,87

0,85

mais altas aspirações profissionais.

O quanto o treinamento que realizei é valorizado pelo meu grupo de trabalho. 


\section{Tabela 9}

Continuação

$\mathrm{N}=2.975$

Média do fator $=2,91$

Desvio padrão $=1,10$

Valor próprio (Eigenvalue) $=8,78$

$\%$ da variância explicada $=62,73 \%$

Número de itens $=14$

Alfa de Cronbach: $\alpha=0,96$

As médias obtidas dos itens variaram entre 2,16 ( $\mathrm{DP}=1,32)$ e 3,79 $(\mathrm{DP}=1,20)$ correspondendo aos itens "O quanto o treinamento que realizei é IMPORTANTE para aumentar meu salário" e "O quanto o treinamento que realizei é IMPORTANTE para resolver problemas de trabalho", respectivamente. Além disso, observa-se que a média fatorial foi de 2,91 ( $\mathrm{DP}=1,10)$, o que indica uma média baixa (em uma escala de cinco pontos). Dessa forma, pode-se dizer que a percepção dos respondentes quanto à importância (valência) dos treinamentos é baixa. Além disso, é importante observar que os itens que obtiveram menor e maior média para utilidade (instrumentalidade) e importância (valência) foram os mesmos, o que evidencia uma melhor percepção dos respondentes com relação ao treinamento para resolução de problemas relacionados ao trabalho e uma pior percepção em relação ao aumento de salário.

Os resultados mostraram índices psicométricos favoráveis que evidenciam a validade e a fidedignidade da escala de instrumentalidade adotada neste estudo.

\subsubsection{Medida de Expectância (Expectativa)}

A Expectativa dos egressos em relação ao quanto o treinamento contribuirá para o alcance de resultados por eles almejados (Expectância) foi mensurada por meio de um único item ("O quanto você espera que as habilidades que você adquiriu no treinamento o ajudarão a alcançar os resultados descritos nos itens acima listados.") em uma escala de 11 pontos (Pilati, 2004). A média de Expectância encontrada foi igual a 5,90 (DP =2,82), o que indica um valor mediano para as expectativas em relação ao treinamento. Importante ressaltar que a moda das respostas foi igual a 8 , o que indica uma expectativa mais alta em relação ao treinamento. Observa-se que apesar dos valores para as demais dimensões de Força Motivacional terem sido baixos, os participantes ainda possuem expectativas positivas em relação ao que o treinamento lhes trará de benefício. 
Após a análise dessas três primeiras escalas (Instrumentalidade, Valência e Expectância), calculou-se a Força Motivacional dos egressos para o treinamento. A Força Motivacional, definida por Vroom (1964) como a quantidade de esforço realizado por um indivíduo para motivar-se, foi calculada por meio do produto entre as médias dos fatores de Valência, Instrumentalidade e a média dos escores atribuídos pelos participantes ao item de Expectância (Pilati, 2004; Vroom, 1964). Dessa forma, a média de Força Motivacional foi de 72,37 (DP = 67,54), valor relativamente baixo, uma vez que o escore máximo a ser alcançado seria de 250, assim, pode-se dizer que a motivação dos egressos está baixa.

\subsubsection{Escala de Suporte Psicossocial à Transferência de Treinamento}

A matriz de dados relativos aos 16 itens do questionário de SUPSI mostraram sete itens com correlações baixas e estatisticamente não significativas com as demais variáveis. Por esses motivos, esses itens foram retirados das demais análises de componentes principais, fatoriais exploratórias e de fidedignidade.

As correlações entre as respostas dos participantes aos restantes 9 (nove) itens de SUPSI foram todas estatisticamente significativas com coeficientes variando de 0,48 a 0,80 , indicando a fatorabilidade da matriz de dados. A análise dos componentes principais sugeriu uma estrutura empírica com um único componente que explica $67,74 \%$ da variância total das respostas dos participantes aos itens da escala. Utilizou-se o critério dos eigenvalues (valores próprios) maiores ou iguais a um. Esses resultados indicaram a presença de um fator, ao contrário do que se apontou quando avaliado com todos os itens. A estrutura unifatorial também foi obtida por meio do método de fatoração dos eixos principais (Principal Axis Factoring $-P A F)$ e da análise de consistência interna do instrumento. Esse fator contém nove itens, com valor próprio (eigenvalue) de 5,75, variância total explicada de 63,86\%, cargas fatoriais variando de 0,68 a 0,89 e Alfa de Cronbach igual a 0,94.

A Tabela 10 mostra as características da escala de Suporte Psicossocial à Transferência de Treinamento em termos de médias fatoriais, desvio padrão, cargas fatoriais, comunalidades $\left(\mathrm{h}^{2}\right)$, correlação item-total e informações adicionais. 
Tabela 10

Estrutura Empírica da Escala de Suporte Psicossocial à Transferência de Treinamento

\begin{tabular}{|c|c|c|c|c|c|}
\hline Descrição dos itens & Média & $\begin{array}{l}\text { Desvio } \\
\text { Padrão }\end{array}$ & $\mathbf{h}^{2}$ & $\begin{array}{c}\text { Cargas } \\
\text { Fatoriais }\end{array}$ & $\begin{array}{c}\text { Correlação } \\
\text { item-total }\end{array}$ \\
\hline $\begin{array}{l}\text { Quando tenho dificuldades em aplicar } \\
\text { eficazmente as novas habilidades, recebo } \\
\text { orientações sobre como fazê-lo. }\end{array}$ & 2,61 & 1,28 & 0,60 & 0,68 & 0,75 \\
\hline $\begin{array}{l}\text { Tenho recebido elogios quando aplico } \\
\text { corretamente no trabalho as novas } \\
\text { habilidades que aprendi. }\end{array}$ & 2,35 & 1,23 & 0,61 & 0,75 & 0,75 \\
\hline $\begin{array}{l}\text { Eu recebo as informações necessárias à } \\
\text { correta aplicação das novas habilidades } \\
\text { no meu trabalho. }\end{array}$ & 2,61 & 1,29 & 0,72 & 0,78 & 0,82 \\
\hline $\begin{array}{l}\text { Meus colegas mais experientes apóiam as } \\
\text { tentativas que faço de usar no trabalho o } \\
\text { que aprendi no treinamento. }\end{array}$ & 2,64 & 1,30 & 0,64 & 0,78 & 0,76 \\
\hline $\begin{array}{l}\text { Tenho sido encorajado pelo meu gestor } \\
\text { imediato a aplicar, no meu trabalho, o que } \\
\text { aprendi no treinamento. }\end{array}$ & 2,50 & 1,35 & 0,79 & 0,80 & 0,86 \\
\hline $\begin{array}{l}\text { Meu gestor imediato tem criado } \\
\text { oportunidades para planejar comigo o uso } \\
\text { das novas habilidades. }\end{array}$ & 2,38 & 1,29 & 0,75 & 0,80 & 0,82 \\
\hline $\begin{array}{l}\text { Os objetivos de trabalho estabelecidos } \\
\text { pelo meu gestor me encorajam a aplicar o } \\
\text { que aprendi no treinamento. }\end{array}$ & 2,60 & 1,30 & 0,64 & 0,85 & 0,78 \\
\hline $\begin{array}{l}\text { Os obstáculos e dificuldades associados à } \\
\text { aplicação de novas habilidades que } \\
\text { adquiri no treinamento são identificados e } \\
\text { removidos pelo meu gestor. }\end{array}$ & 2,33 & 1,22 & 0,57 & 0,85 & 0,73 \\
\hline $\begin{array}{l}\text { Tenho tido oportunidades de usar no meu } \\
\text { trabalho as habilidades que aprendi no } \\
\text { treinamento. }\end{array}$ & 2,28 & 1,25 & 0,46 & 0,89 & 0,66 \\
\hline $\begin{array}{l}\mathrm{N}=2.975 \\
\text { Média do fator }=2,48 \\
\text { Desvio Padrão }=1,05 \\
\text { Valor próprio }(\text { Eigenvalue })=6,10 \\
\% \text { da variância explicada }=67,74 \% \\
\text { Número de itens }=9 \\
\text { Alfa de Cronbach: } \alpha=0,94\end{array}$ & & & & & \\
\hline
\end{tabular}

As médias obtidas dos itens variaram entre 2,28 (DP = 1,25) e 2,64 $(\mathrm{DP}=1,30)$ correspondendo aos itens "Tenho tido oportunidades de usar no meu trabalho as habilidades que aprendi no treinamento" e "Meus colegas mais experientes apóiam as tentativas que faço de usar no trabalho o que aprendi no treinamento", respectivamente, indicando médias baixas. Além disso, observa-se que a média fatorial foi de 2,48 (DP $=1,05)$, o que mostra 
avaliações de valor intermediário tendendo a desfavorável dos respondentes quanto ao Suporte Psicossocial à Transferência de Treinamento.

Todos os resultados evidenciam a qualidade psicométrica dessa versão reduzida da escala de suporte para uso nesta pesquisa. Os itens retirados da escala possuíam além de correlações baixas, cargas fatoriais ambíguas. Outro problema da escala se deve ao fato de ter sido utilizado somente a parte referente ao suporte psicossocial, deixando de fora os itens referentes ao suporte material, existentes na escala original.

\subsubsection{Escala de Impacto do Treinamento no Trabalho}

Quanto à escala de Impacto do treinamento no trabalho - IMTT, foram encontradas correlações estatisticamente significativas entre as respostas dos participantes aos itens da escala, cujos coeficientes variaram de 0,43 a 0,81 , indicando a fatorabilidade da matriz de dados. A análise dos componentes principais sugeriu uma estrutura empírica com um componente que explica $68,01 \%$ da variância total das respostas dos participantes aos itens da escala. Utilizou-se o critério dos eigenvalues (valores próprios) maiores ou iguais a um. Esses resultados indicaram a presença de um único fator. A estrutura unifatorial também foi obtida por meio do método de fatoração dos eixos principais (Principal Axis Factoring - PAF) e da análise de consistência interna do instrumento. Esse fator contém 12 itens, com valor próprio (eigenvalue) de 7,83, variância total explicada de 65,26\%, cargas fatoriais variando de 0,57 a 0,88 e Alfa de Cronbach igual a 0,96. Todos esses índices são favoráveis e indicam a qualidade dessa escala para uso na pesquisa. A Tabela 11 mostra a estrutura empírica da escala de Impacto do Treinamento no Trabalho em termos de médias fatoriais, desvio padrão, cargas fatoriais, comunalidades $\left(\mathrm{h}^{2}\right)$, correlação item-total e informações adicionais.

\section{Tabela 11}

Estrutura Empírica da Escala de Impacto do Treinamento no Trabalho

\begin{tabular}{lccccc}
\hline \multicolumn{1}{c}{ Descrição dos itens } & Média & $\begin{array}{c}\text { Desvio } \\
\text { Padrão }\end{array}$ & $\mathbf{h}^{2}$ & $\begin{array}{c}\text { Cargas } \\
\text { Fatoriais }\end{array}$ & $\begin{array}{c}\text { Correlação } \\
\text { item-total }\end{array}$ \\
\hline $\begin{array}{l}\text { Recordo-me bem dos conteúdos ensinados } \\
\text { no treinamento. }\end{array}$ & 3,22 & 1,07 & 0,33 & 0,57 & 0,56 \\
$\begin{array}{l}\text { Esse treinamento que fiz me tornou mais } \\
\text { receptivo a mudanças no trabalho. }\end{array}$ & 2,96 & 1,21 & 0,59 & 0,77 & 0,75 \\
$\begin{array}{l}\text { Aproveito as oportunidades que tenho para } \\
\text { colocar em prática o que me foi ensinado } \\
\text { no treinamento. }\end{array}$ & 3,03 & 1,34 & 0,65 & 0,80 & 0,79 \\
\hline
\end{tabular}


Tabela 11

Contiuação

\begin{tabular}{|c|c|c|c|c|c|}
\hline Descrição dos itens & Média & $\begin{array}{l}\text { Desvio } \\
\text { Padrão }\end{array}$ & $\mathbf{h}^{2}$ & $\begin{array}{c}\text { Cargas } \\
\text { Fatoriais }\end{array}$ & $\begin{array}{c}\text { Correlação } \\
\text { item-total }\end{array}$ \\
\hline $\begin{array}{l}\text { Minha participação no treinamento serviu } \\
\text { para aumentar minha motivação para o } \\
\text { trabalho. }\end{array}$ & 2,90 & 1,23 & 0,64 & 0,80 & 0,78 \\
\hline $\begin{array}{l}\text { Utilizo, com frequência, em meu trabalho } \\
\text { atual, o que foi ensinado no treinamento. }\end{array}$ & 2,61 & 1,36 & 0,65 & 0,81 & 0,79 \\
\hline $\begin{array}{l}\text { Quando aplico o que aprendi no } \\
\text { treinamento, executo meu trabalho com } \\
\text { maior rapidez. }\end{array}$ & 2,93 & 1,27 & 0,68 & 0,82 & 0,80 \\
\hline $\begin{array}{l}\text { O treinamento que fiz beneficiou meus } \\
\text { colegas de trabalho, que aprenderam } \\
\text { comigo algumas novas habilidades. }\end{array}$ & 2,78 & 1,25 & 0,68 & 0,82 & 0,80 \\
\hline $\begin{array}{l}\text { A qualidade do meu trabalho melhorou } \\
\text { mesmo naquelas atividades que não } \\
\text { pareciam estar relacionadas ao conteúdo } \\
\text { do treinamento. }\end{array}$ & 2,66 & 1,21 & 0,71 & 0,84 & 0,82 \\
\hline $\begin{array}{l}\text { Minha participação nesse treinamento } \\
\text { aumentou minha autoconfiança (agora } \\
\text { tenho mais confiança na minha } \\
\text { capacidade de executar meu trabalho com } \\
\text { sucesso). }\end{array}$ & 2,84 & 1,27 & 0,72 & 0,84 & 0,82 \\
\hline $\begin{array}{l}\text { As habilidades que aprendi no } \\
\text { treinamento fizeram com que eu } \\
\text { cometesse menos erros em meu trabalho e } \\
\text { em atividades relacionadas ao conteúdo } \\
\text { do treinamento. }\end{array}$ & 2,84 & 1,33 & 0,73 & 0,85 & 0,84 \\
\hline $\begin{array}{l}\text { Após minha participação no treinamento, } \\
\text { tenho sugerido, com maior frequência, } \\
\text { mudanças nas rotinas de trabalho. }\end{array}$ & 2,62 & 1,23 & 0,72 & 0,85 & 0,83 \\
\hline $\begin{array}{l}\text { A qualidade do meu trabalho melhorou } \\
\text { nas atividades diretamente relacionadas } \\
\text { ao conteúdo do treinamento. }\end{array}$ & 2,83 & 1,26 & 0,77 & 0,88 & 0,86 \\
\hline $\begin{array}{l}\mathrm{N}=2.975 \\
\text { Média do fator }=2,85 \\
\text { Desvio Padrão }=1,03 \\
\text { Valor próprio (Eigenvalue) }=7,83 \\
\% \text { da variância explicada }=65,26 \% \\
\text { Número de itens }=12 \\
\text { Alfa de Cronbach: } \alpha=0,96\end{array}$ & & & & & \\
\hline
\end{tabular}

As médias obtidas dos itens variaram entre 2,61 ( $\mathrm{DP}=1,36)$ e 3,22 $(\mathrm{DP}=1,07)$ correspondendo aos itens "Utilizo, com frequência, em meu trabalho atual, o que foi ensinado 
no treinamento" e "Recordo-me bem dos conteúdos ensinados no treinamento", respectivamente. $\mathrm{O}$ item de menor média não se deu ao acaso, uma vez a maior amostra corresponde aos egressos do curso SEI e há participantes da pesquisa que não possuem no local de trabalho o acesso ao sistema para aplicar o aprendido o treinamento. Além disso, observa-se que a média fatorial foi de 2,85 ( $\mathrm{DP}=1,03)$, indicando percepções medianas, tendentes à desfavoráveis dos respondentes quanto ao Impacto do Treinamento no Trabalho.

Os resultados mostraram índices psicométricos favoráveis que evidenciam a validade e a fidedignidade da escala IMTT. Essa escala já foi anteriormente submetida à análise confirmatória por Pilati e Abbad (2005) na qual também foram encontradas evidências de validade dessa escala.

\subsection{Comparação entre os treinamentos}

Visando atingir o objetivo 2 desta pesquisa, comparar os treinamentos no que se refere às percepções de Suporte Psicossocial à transferência de Treinamento, Força Motivacional e Impacto do Treinamento no Trabalho, foi realizado Teste $\mathrm{T}$ para amostras independentes de participantes dos dois tipos de treinamentos avaliados: (1) Agentes de Melhoria e Gestão de Absenteísmo (todos os 500 respondentes); e (2) SEI (subamostra aleatória de 500 respondentes).

\subsubsection{Escala de Instrumentalidade (Utilidade do Treinamento)}

Os egressos dos treinamentos de Agente de Melhorias e de Gestão do Absenteísmo obtiveram uma melhor percepção da utilidade do treinamento $(t(973,81)=3,78, \mathrm{DP}=0,90)$ do que os egressos do $\operatorname{SEI}(t(973,81)=2,72$, DP $=1,05)$. A diferença de médias entre as condições foi de 1,06; e o intervalo de confiança de $95 \%$ para a diferença estimada das médias populacionais é de 0,94 a 1,18 . O teste $t$ para amostras independentes revelou que, se a hipótese nula fosse verdadeira, tal resultado seria improvável $(t(973,81)=17,20 ; p<$ 0,001). Conclui-se que os egressos dos Treinamentos de gestão (Agente de Melhorias e Gestão do Absenteísmo) atribuem maior utilidade aos treinamentos do que os egressos do SEI. 


\subsubsection{Escala de Valência (Importância do Treinamento)}

Os participantes dos treinamentos de Agente de Melhorias e de Gestão do Absenteísmo obtiveram uma melhor percepção da importância do treinamento $(t(971,69)=$ $3,78, \mathrm{DP}=0,89)$ do que os egressos do $\operatorname{SEI}(t(971,69)=2,71, \mathrm{DP}=1,05)$. A diferença de médias entre as condições foi de 1,07; e o intervalo de confiança de 95\% para a diferença estimada das médias populacionais é de 0,95 a 1,20. O teste $t$ para amostras independentes revelou que, se a hipótese nula fosse verdadeira, tal resultado seria improvável $(t(971,69)=$ 17,45; $p<0,001)$. Pode-se concluir que os egressos dos treinamentos de gestão atribuem maior importância aos treinamentos do que os egressos do SEI.

\subsubsection{Medida de Expectância (Expectativa)}

Os egressos dos treinamentos de Agente de Melhorias e de Gestão do Absenteísmo obtiveram uma melhor percepção de expectativa em relação ao treinamento $(t(937,54)=$ $7,53, \mathrm{DP}=2,18)$ do que os egressos do $\operatorname{SEI}(t(937,54)=5,60, \mathrm{DP}=2,82)$. A diferença de médias entre as condições foi de 1,93; e o intervalo de confiança de 95\% para a diferença estimada das médias populacionais é de 1,62 a 2,25. O teste $t$ para amostras independentes revelou que, se a hipótese nula fosse verdadeira, tal resultado seria improvável $(t(937,54)=$ 12,13; $p<0,001)$. Assim, pode-se concluir que os egressos dos treinamentos de gestão possuem expectativas mais favoráveis em relação aos treinamentos do que os egressos do SEI.

\subsubsection{Medida de Força Motivacional}

Os participantes dos treinamentos de Agente de Melhorias e de Gestão do Absenteísmo obtiveram uma melhor expectativa em relação ao treinamento $(t(975,77)=$ $123,75, \mathrm{DP}=70,66)$ do que os egressos do $\operatorname{SEI}(t(975,77)=61,03, \mathrm{DP}=60,69)$. A diferença de médias entre as condições foi de 62,72; e o intervalo de confiança de $95 \%$ para a diferença estimada das médias populacionais é de 54,55 a 70,90. O teste $t$ para amostras independentes revelou que, se a hipótese nula fosse verdadeira, tal resultado seria improvável $(t(975,77)=$ 15,06; $p<0,001)$. Pode-se concluir que os egressos dos treinamentos de gestão possuem maior força motivacional para o treinamento do que os egressos do SEI. 


\subsubsection{Escala de Suporte Psicossocial ao Treinamento}

Os egressos dos treinamentos de Agente de Melhorias e de Gestão do Absenteísmo obtiveram uma melhor percepção de Suporte Psicossocial à Transferência de treinamento $(t(957,38)=3,15, \mathrm{DP}=0,84)$ do que os egressos do SEI $(t(957,38)=2,31$, DP $=1,04) . \mathrm{A}$ diferença de médias entre as condições foi de 0,84; e o intervalo de confiança de $95 \%$ para a diferença estimada das médias populacionais é de 0,73 a 0,96 . O teste $t$ para amostras independentes revelou que, se a hipótese nula fosse verdadeira, tal resultado seria improvável $(t(957,38)=14,07 ; p<0,001)$. Dessa forma, pode-se concluir que os egressos dos treinamentos de gestão possuem percepções de Suporte Psicossocial à Transferência de Treinamento mais favoráveis do que os egressos do SEI.

\subsubsection{Escala de Impacto do Treinamento no Trabalho}

Os participantes dos treinamentos de Agente de Melhorias e de Gestão do Absenteísmo obtiveram uma melhor percepção do Impacto do Treinamento no Trabalho $(t(919,02)=3,70, \mathrm{DP}=0,74)$ do que os egressos do SEI $(t(919,02)=2,60, \mathrm{DP}=1,00) . \mathrm{A}$ diferença de médias entre as condições foi de 1,10; e o intervalo de confiança de $95 \%$ para a diferença estimada das médias populacionais é de 0,99 a 1,21. O teste $t$ para amostras independentes revelou que, se a hipótese nula fosse verdadeira, tal resultado seria improvável $(t(919,02)=19,81 ; p<0,001)$. Assim, conclui-se que os egressos dos treinamentos de gestão perceberam maior Impacto do Treinamento no Trabalho do que os egressos do SEI.

\subsection{Teste do Modelo Geral de Investigação}

Os resultados das análises de regressão múltipla para testar o modelo de predição de Impacto do Treinamento no Trabalho (variável critério) com Força Motivacional e Suporte Psicossocial como variáveis preditoras são apresentados a seguir. Estas análises estão associadas ao objetivo 3 desta pesquisa de investigar o relacionamento de predição existente entre essas variáveis.

As variáveis do modelo foram submetidas a análises exploratórias. Não foram encontrados casos omissos entre as respostas. Contudo, foram identificados e eliminados os casos extremos multivariados que poderiam afetar as análises de regressão que estivessem com resíduos padronizados iguais ou inferiores a -2 ou iguais e superiores +2 . Após esses 
procedimentos, foram encontrados 59 casos com valores iguais ou superiores a +2 e 91 iguais ou superiores a -2 . Em função disto, foram eliminados 150 casos, restando para as demais análises 2.825 casos válidos.

Os testes de pressupostos (linearidade, correlações, VIF, TOL), normalidade, independência de resíduos (Durbin-Watson) mostraram que a técnica RM era aplicável aos dados desta pesquisa. A seguir são apresentados os resultados das nove análises de regressão múltipla padrão, sendo que, na primeira parte, são descritos os resultados para a amostra completa de participantes dos três treinamentos avaliados e, na segunda parte, os resultados das análises de RM feitas separadamente para as amostras de duas categorias de treinamento: (1) participantes do SEI e (2) participantes dos treinamentos denominados Agente de Melhorias e Gestão do Absenteísmo (MelhoraAbsent).

\subsubsection{Resultados da Regressões Múltiplas para os três treinamentos}

Os resultados das análises de Regressão Múltipla (RM) padrão para toda a amostra (N $=2.825)$, bem como para três subamostras de 400 casos, escolhidos aleatoriamente, são apresentados nas Tabelas 12, 13, 14 e 15.

Tabela 12

RM para Impacto dos três treinamentos sobre o trabalho dos egressos

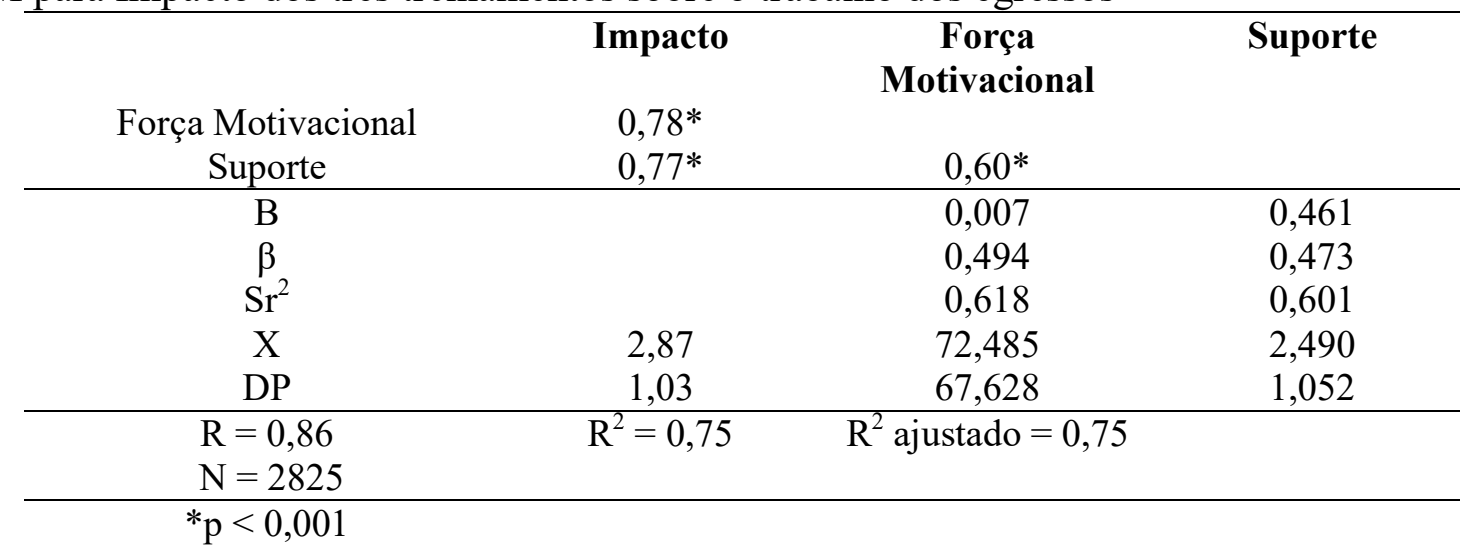

Os resultados mostram que as variáveis FM e SUPSI são preditoras de impacto do treinamento no trabalho, indicando que quanto maior a força motivacional e o suporte, maior é a percepção de impacto do treinamento no trabalho pelo egresso dos três treinamentos. 
Tabela 13

RM para impacto dos três treinamentos sobre o trabalho dos egressos - Subamostra 1

\begin{tabular}{cccc}
\hline & Impacto & $\begin{array}{c}\text { Força } \\
\text { Motivacional }\end{array}$ & Suporte \\
\hline $\begin{array}{c}\text { Força Motivacional } \\
\text { Suporte }\end{array}$ & $0,77^{*}$ & $0,62^{*}$ & \\
\hline $\mathrm{B}$ & $0,75^{*}$ & 0,008 & 0,444 \\
$\beta$ & & 0,489 & 0,449 \\
$\mathrm{Sr}^{2}$ & 0,582 & 0,550 \\
$\mathrm{X}$ & & 72,442 & 2,495 \\
$\mathrm{DP}$ & 2,88 & 66,233 & 1,039 \\
\hline $\mathrm{R}=0,84$ & 1,03 & $\mathrm{R}^{2}$ ajustado $=0,71$ & \\
$\mathrm{~N}=400$ & $\mathrm{R}^{2}=0,71$ & &
\end{tabular}

Tabela 14

RM para impacto dos três treinamentos sobre o trabalho dos egressos - Subamostra 2

\begin{tabular}{cccc}
\hline & Impacto & $\begin{array}{c}\text { Força } \\
\text { Motivacional }\end{array}$ & Suporte \\
\hline $\begin{array}{c}\text { Força Motivacional } \\
\text { Suporte }\end{array}$ & $0,76^{*}$ & & \\
$\mathrm{~B}$ & $0,80^{*}$ & $0,62^{*}$ & \\
$\beta$ & & 0,006 & 0,517 \\
$\mathrm{Sr}^{2}$ & 0,428 & 0,532 \\
$\mathrm{X}$ & & 0,556 & 0,639 \\
$\mathrm{DP}$ & 2,89 & 71,408 & 2,525 \\
$\mathrm{R}=0,87$ & 1,01 & 66,699 & 1,041 \\
$\mathrm{~N}=400$ & $\mathrm{R}^{2}=0,75$ & $\mathrm{R}^{2}$ ajustado $=0,75$ & \\
\hline $\mathrm{p}<0,001$ & &
\end{tabular}

\section{Tabela 15}

RM para impacto dos três treinamentos sobre o trabalho dos egressos - Subamostra 3

\begin{tabular}{cccc}
\hline & Impacto & $\begin{array}{c}\text { Força } \\
\text { Motivacional }\end{array}$ & Suporte \\
\hline $\begin{array}{c}\text { Força Motivacional } \\
\text { Suporte }\end{array}$ & $0,80^{*}$ & & \\
\hline $\mathrm{B}$ & $0,80^{*}$ & $0,68^{*}$ & \\
$\beta$ & & 0,007 & 0,477 \\
$\mathrm{Sr}^{2}$ & 0,482 & 0,476 \\
$\mathrm{X}$ & & 0,593 & 0,588 \\
$\mathrm{DP}$ & 2,83 & 72,452 & 2,493 \\
$\mathrm{R}=0,88$ & 1,05 & 69,157 & 1,051 \\
$\mathrm{~N}=400$ & $\mathrm{R}^{2}=0,77$ & $\mathrm{R}^{2}$ ajustado $=0,77$ & \\
\hline $\mathrm{p}<0,001$ & &
\end{tabular}

Por meio da análise dos resultados, percebe-se que os resultados das três subamostras convergem, são similares quanto à magnitude e a direção dos relacionamentos entre as variáveis preditoras e critério, tal como refletem os coeficientes Beta e correlações semiparciais. Os modelos explicam uma porção estatisticamente significativa da variabilidade das 
respostas dos participantes à escala de impacto do treinamento no trabalho com altos coeficientes de regressão múltipla, variando entre 0,84 a 0,88 e coeficientes de determinação, variando entre 0,71 a 0,77 .

\subsubsection{Resultados das Regressões Múltiplas separadas por tipo de treinamento}

Os resultados das análises exploratórias mostraram que as médias fatoriais de impacto do treinamento no trabalho eram estatisticamente distintas, quando comparados os dois tipos de treinamento avaliados nesta pesquisa: treinamento em gestão (Agentes de Melhorias e Gestão do Absenteísmo) e técnico-administrativo (SEI). A seguir são apresentados separadamente os resultados das regressões múltiplas padrão, os referentes à amostra de participantes do treinamento em SEI e os referentes aos dois outros treinamentos focados em gestão. Cada modelo foi testado quatro vezes, de modo a verificar a consistência dos resultados em amostras menores, extraídas aleatoriamente da amostra completa de respondentes da pesquisa.

Os resultados das 4 (quatro) Regressões Múltiplas (RM) referentes às quatro amostras de participantes do treinamento SEI são descritos nas Tabelas 16, 17, 18 e 19. Os resultados da RM referentes à amostra completa de 487 participantes dos dois treinamentos restantes, Agente de Melhorias e Gestão do absenteísmo, são descritos na Tabela 20.

\section{Tabela 16}

RM para impacto do treinamento SEI sobre o trabalho dos egressos

\begin{tabular}{cccc}
\hline & Impacto & $\begin{array}{c}\text { Força } \\
\text { Motivacional }\end{array}$ & Suporte \\
\hline $\begin{array}{c}\text { Força Motivacional } \\
\text { Suporte }\end{array}$ & $0,75^{*}$ & & \\
\hline $\mathrm{B}$ & $0,75^{*}$ & $0,56^{*}$ & \\
$\beta$ & & 0,008 & 0,467 \\
$\mathrm{Sr}^{2}$ & 0,480 & 0,488 \\
$\mathrm{X}$ & & 0,608 & 0,614 \\
$\mathrm{DP}$ & 2,70 & 61,597 & 2,345 \\
$\mathrm{R}=0,85$ & 0,99 & 61,725 & 1,038 \\
$\mathrm{~N}=2338$ & $\mathrm{R}^{2}=0,73$ & $\mathrm{R}^{2}$ ajustado $=0,73$ & \\
\hline $\mathrm{*}<0,001$ & & &
\end{tabular}

Assim como nos resultados com os três cursos, pode-se notar que FM e SUPSI também são preditoras de Impacto do Treinamento no Trabalho, indicando que quanto maior for a avaliação de Força Motivacional e de Suporte, maior é a percepção de Impacto do Treinamento no Trabalho pelo egresso dos três treinamentos. 
Tabela 17

RM para impacto do treinamento SEI sobre o trabalho dos egressos - Subamostra 1

\begin{tabular}{cccc}
\hline & Impacto & $\begin{array}{c}\text { Força } \\
\text { Motivacional }\end{array}$ & Suporte \\
\hline $\begin{array}{c}\text { Força Motivacional } \\
\text { Suporte }\end{array}$ & $0,75^{*}$ & & \\
\hline $\mathrm{B}$ & $0,78^{*}$ & $0,59^{*}$ & \\
$\beta$ & & 0,007 & 0,491 \\
$\mathrm{Sr}^{2}$ & 0,448 & 0,515 \\
$\mathrm{X}$ & & 0,578 & 0,632 \\
$\mathrm{DP}$ & 2,69 & 62,857 & 2,350 \\
$\mathrm{R}=0,86$ & 1,01 & 64,366 & 1,062 \\
$\mathrm{~N}=400$ & $\mathrm{R}^{2}=0,74$ & $\mathrm{R}^{2}$ ajustado $=0,74$ & \\
\hline $\mathrm{p}<0,001$ & & &
\end{tabular}

Tabela 18

RM para impacto do treinamento SEI sobre o trabalho dos egressos - Subamostra 2

\begin{tabular}{cccc}
\hline & Impacto & $\begin{array}{c}\text { Força } \\
\text { Motivacional }\end{array}$ & Suporte \\
\hline $\begin{array}{c}\text { Força Motivacional } \\
\text { Suporte }\end{array}$ & $0,76^{*}$ & & \\
$\mathrm{~B}$ & $0,77^{*}$ & $0,59^{*}$ & \\
$\beta$ & & 0,008 & 0,483 \\
$\mathrm{Sr}^{2}$ & & 0,474 & 0,493 \\
$\mathrm{X}$ & 2,68 & 0,604 & 0,619 \\
$\mathrm{DP}$ & 1,01 & 60,150 & 2,337 \\
$\mathrm{R}=0,86$ & $\mathrm{R}^{2}=0,74$ & $\mathrm{R}^{2}$ ajustado $=0,74$ & \\
$\mathrm{~N}=400$ & & & \\
$* \mathrm{p}<0,001$ & &
\end{tabular}

Tabela 19

RM para impacto do treinamento SEI sobre o trabalho dos egressos - Subamostra 3

\begin{tabular}{cccc}
\hline & Impacto & $\begin{array}{c}\text { Força } \\
\text { Motivacional }\end{array}$ & Suporte \\
\hline $\begin{array}{c}\text { Força Motivacional } \\
\text { Suporte }\end{array}$ & $0,73^{*}$ & $0,56^{*}$ & \\
$\mathrm{~B}$ & $0,75^{*}$ & 0,007 & 0,464 \\
$\beta$ & & 0,457 & 0,497 \\
$\mathrm{Sr}^{2}$ & & 0,575 & 0,607 \\
$\mathrm{X}$ & 2,68 & 58,971 & 2,328 \\
$\mathrm{DP}$ & 1,00 & 61,729 & 1,070 \\
\hline $\mathrm{R}=0,84$ & $\mathrm{R}^{2}=0,71$ & $\mathrm{R}^{2}$ ajustado $=0,71$ & \\
$\mathrm{~N}=400$ & & &
\end{tabular}

Os resultados das regressões múltiplas nas três subamostras confirmaram, de modo geral, os obtidos na amostra completa, indicando que a equação de RM se ajusta bem aos dados e os modelos explicam uma porção estatisticamente significativa da variabilidade do Impacto do treinamento no trabalho nas amostras. Os resultados são similares quanto à 
magnitude e a direção dos relacionamentos entre as variáveis preditoras e critério, tal como refletem os coeficientes Beta e correlações semi-parciais. Os modelos explicam uma porção estatisticamente significativa da variabilidade das respostas dos participantes à escala de Impacto do Treinamento no Trabalho com altos coeficientes de regressão múltipla, variando entre 0,84 a 0,86 e coeficientes de determinação, variando entre 0,71 a 0,74 .

\section{Tabela 20}

RM para impacto dos treinamentos Agente de Melhoria e Gestão do Absenteísmo sobre o trabalho dos egressos

\begin{tabular}{cccc}
\hline & Impacto & $\begin{array}{c}\text { Força } \\
\text { Motivacional }\end{array}$ & Suporte \\
\hline $\begin{array}{c}\text { Força Motivacional } \\
\text { Suporte }\end{array}$ & $0,76^{*}$ & $0,56^{*}$ & \\
\hline $\mathrm{B}$ & $0,64^{*}$ & 0,006 & 0,270 \\
$\beta$ & & 0,584 & 0,314 \\
$\mathrm{Sr}^{2}$ & & 0,631 & 0,401 \\
$\mathrm{X}$ & 3,72 & 124,761 & 3,173 \\
$\mathrm{DP}$ & 0,72 & 70,330 & 0,832 \\
\hline $\mathrm{R}=0,80$ & $\mathrm{R}^{2}=0,64$ & $\mathrm{R}^{2}$ ajustado $=0,64$ & \\
$\mathrm{~N}=487$ & & &
\end{tabular}

Assim como nos resultados relatados anteriormente, notou-se que FM e SUPSI também são preditoras de impacto do treinamento no trabalho, indicando que quanto maior for a avaliação de Força Motivacional e maior o Suporte, maior é a percepção de Impacto do Treinamento no Trabalho pelo egresso dos três treinamentos.

Independentemente da amostra selecionada, nota-se a que variância explicada pelo modelo foi significativa, sendo a menor de $64 \%$ e a maior de $77 \%$. Dessa forma, o modelo final pode ser visto na Figura 4. 


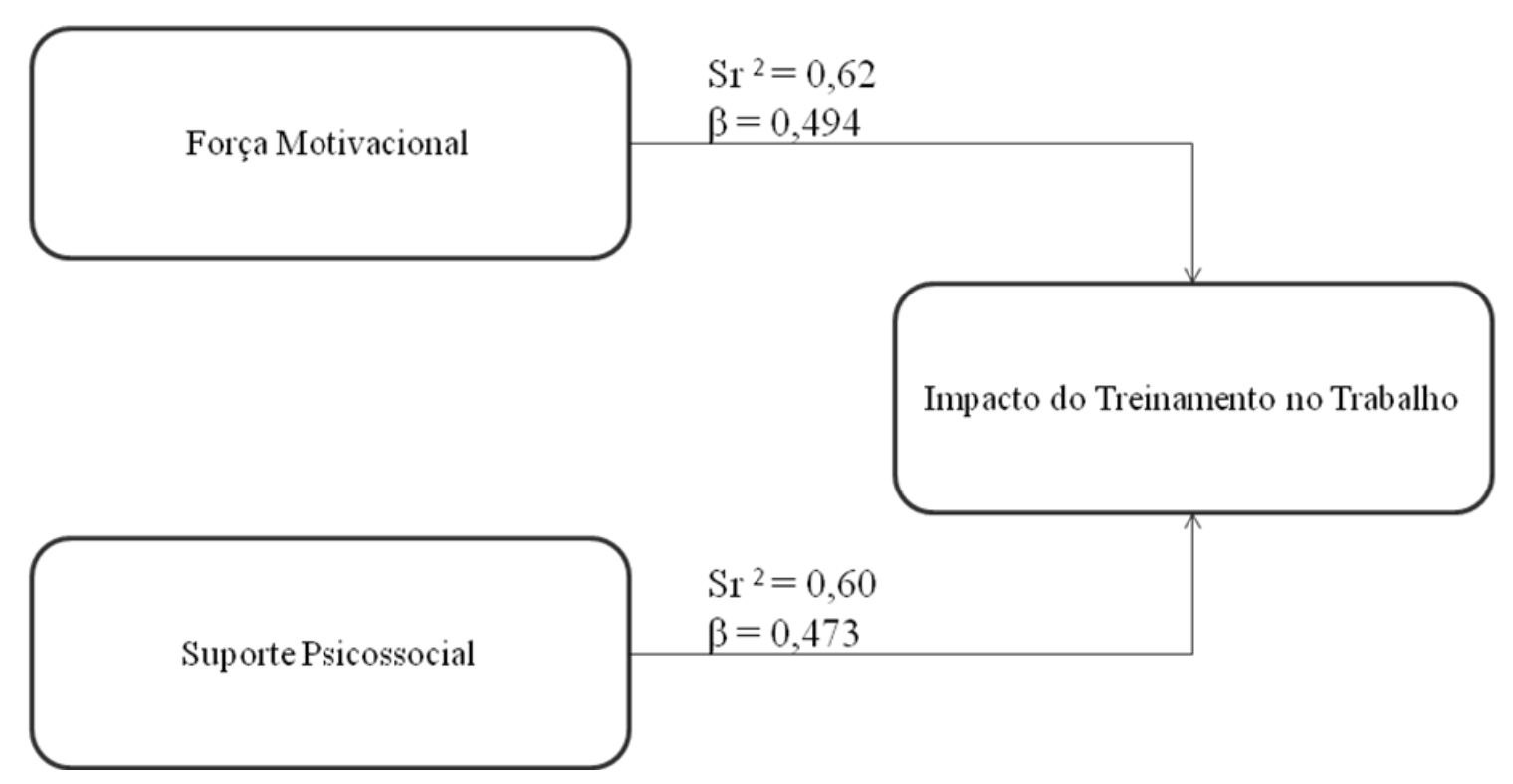

Figura 4. Modelo final Preditivo de Impacto do Treinamento no Trabalho

\subsection{Teste do Modelo de Mediação}

Antes de realizar o teste de mediação foram verificadas e confirmadas as três condições para que uma variável, no caso Suporte Psicossocial ao Treinamento (SUPSI), seja mediadora. (1) A mediadora (SUPSI) é uma preditora estatisticamente significativa da variável dependente (IMTT); (2) A variável independente (FM) é preditora estatisticamente significativa da variável mediadora (SUPSI); e (3) Quando a variável independente (FM) e a mediadora (SUPSI) estiverem presentes na equação, uma relação significativa, anteriormente detectada, entre a variável independente (FM) e a variável dependente (IMTT) decresce em magnitude.

\subsubsection{Resultados da Regressão para Mediação dos três treinamentos}

Quando avaliadas duas a duas as relações entre as variáveis, observou-se que Suporte Psicossocial é uma preditora estatisticamente significativa de Impacto do Treinamento no Trabalho $\left(\beta=0,78 ; p<0,001 ; \mathrm{R}^{2}=0,59\right)$, indicando que a primeira condição para análise de mediação foi satisfeita. A segunda condição também foi satisfeita, uma vez que Força Motivacional predisse uma porção significativa da variabilidade de Suporte Psicossocial $(\beta=$ 0,$\left.60 ; p<0,001 ; \mathrm{R}^{2}=0,36\right)$.

Testando a terceira condição, quando as duas variáveis antecedentes foram colocadas juntas na análise de regressão múltipla, observou-se que ambas predizem uma porção 
significativa da variabilidade das respostas aos itens com Impacto do Treinamento no Trabalho sendo predito por Força Motivacional $\left(\beta=0,49 ; p<0,001 ; \mathrm{R}^{2}=0,75\right)$ e Suporte Psicossocial $\left(\beta=0,47 ; p<0,001 ; \mathrm{R}^{2}=0,75\right)$. Antes da variável SUPSI ser inserida na equação, verificou-se que Força Motivacional explicava uma porção significativa da variação de Impacto do Treinamento no Trabalho $\left(\beta=0,78 ; p<0,001 ; \mathrm{R}^{2}=0,60\right)$. Após comparação dos resultados, observou-se que uma diminuição do valor Beta de FM de 0,78 para 0,49 na presença de SUPSI no modelo de RM. Esse decréscimo na magnitude da contribuição de Força Motivacional na explicação de Impacto sugere que Suporte Psicossocial é mediadora parcial das relações entre FM e IMTT.

\subsubsection{Resultados da análise de Mediação para Agente de Melhorias e Gestão do Absenteísmo}

Quando avaliadas duas a duas as relações entre as variáveis, observou-se que Suporte Psicossocial é uma preditora estatisticamente significativa de Impacto do Treinamento no Trabalho $\left(\beta=0,64 ; p<0,001 ; \mathrm{R}^{2}=0,41\right)$, indicando que a primeira condição para análise de mediação foi satisfeita. A segunda condição também foi satisfeita, uma vez que Força Motivacional predisse uma porção significativa da variabilidade de Suporte Psicossocial $(\beta=$ 0,$\left.56 ; p<0,001 ; \mathrm{R}^{2}=0,31\right)$.

A fim de testar a terceira condição, quando as duas variáveis antecedentes foram colocadas juntas na análise de regressão múltipla, observou-se que ambas predizem uma porção significativa da variabilidade das respostas aos itens com Impacto do Treinamento no Trabalho sendo predito por Força Motivacional $\left(\beta=0,58 ; p<0,001 ; \mathrm{R}^{2}=0,65\right)$ e Suporte Psicossocial $\left(\beta=0,31 ; p<0,001 ; \mathrm{R}^{2}=0,65\right)$. Antes da variável SUPSI ser inserida na equação, verificou-se que Força Motivacional explicava uma porção significativa da variação de Impacto do Treinamento no Trabalho $\left(\beta=0,76 ; p<0,001 ; \mathrm{R}^{2}=0,58\right)$. Após comparação dos resultados, observou-se que uma diminuição do valor Beta de FM de 0,76 para 0,58 na presença de SUPSI no modelo de RM. Esse decréscimo na magnitude da contribuição de Força Motivacional na explicação de Impacto sugere que Suporte Psicossocial é mediadora parcial das relações entre FM e IMTT.

\subsubsection{Resultados da análise de Mediação para o Treinamento SEI}

Quando avaliadas duas a duas as relações entre as variáveis, observou-se que Suporte Psicossocial é uma preditora estatisticamente significativa de Impacto do Treinamento no 
Trabalho $\left(\beta=0,75 ; p<0,001 ; \mathrm{R}^{2}=0,57\right)$, indicando que a primeira condição para análise de mediação foi satisfeita. A segunda condição também foi satisfeita, uma vez que Força Motivacional predisse uma porção significativa da variabilidade de Suporte Psicossocial $(\beta=$ 0,$\left.56 ; p<0,001 ; \mathrm{R}^{2}=0,31\right)$.

Por fim, testando a terceira condição, quando as duas variáveis antecedentes foram colocadas juntas na análise de regressão múltipla, observou-se que ambas predizem uma porção significativa da variabilidade das respostas aos itens com Impacto do Treinamento no Trabalho sendo predito por Força Motivacional $\left(\beta=0,48 ; p<0,001 ; \mathrm{R}^{2}=0,73\right)$ e Suporte Psicossocial $\left(\beta=0,49 ; p<0,001 ; \mathrm{R}^{2}=0,73\right)$. Antes da variável SUPSI ser inserida na equação, verificou-se que Força Motivacional explicava uma porção significativa da variação de Impacto do Treinamento no Trabalho $\left(\beta=0,75 ; p<0,001 ; \mathrm{R}^{2}=0,56\right)$. Após comparação dos resultados, observou-se que uma diminuição do valor Beta de FM de 0,75 para 0,48 na presença de SUPSI no modelo de RM. Esse decréscimo na magnitude da contribuição de Força Motivacional na explicação de Impacto sugere que Suporte Psicossocial é mediadora parcial das relações entre FM e IMTT.

Em síntese, independentemente da amostra, há evidências de que Suporte Psicossocial à Transferência é mediadora parcial do relacionamento entre a variável preditora Força Motivacional e a variável critério Impacto do Treinamento no Trabalho, o que significa dizer que SUPSI influencia a relação entre FM e IMTT, o que na prática significa dizer que é necessário que as organizações invistam mais em Suporte Psicossocial à Transferência de Treinamento para que haja uma facilitação do Impacto do Treinamento no Trabalho.

$\mathrm{Na}$ próxima seção serão discutidos os principais resultados desta pesquisa, bem como as implicações teóricas, metodológicas e práticas desses resultados, comparando-as com os principais achados da revisão de literatura. 


\section{CAPÍTULO 5: DISCUSSÃO}

Neste capítulo serão discutidos o alcance dos objetivos e o confronto dos resultados obtidos nesta pesquisa com os de outros estudos que abordaram os temas de Motivação, Suporte à Transferência e Impacto do Treinamento no Trabalho. Além disso, ao final, são apresentadas as principais contribuições, limitações deste estudo e uma proposta de agenda de pesquisa.

O objetivo geral deste estudo foi avaliar a influência de percepções de Suporte Psicossocial à Transferência (SUPSI) e Força Motivacional (FM) sobre Impacto do Treinamento no Trabalho (IMTT), a partir da avaliação de três treinamentos corporativos (Agente de Melhorias, Gestão do Absenteísmo e da Presença Produtiva e Sistema Eletrônico de Informação). Esse objetivo foi atingido, uma vez que se verificou a predição de FM e SUPSI sobre IMTT, bem como a mediação parcial de SUPSI na relação entre FM e IMTT. Esses achados são discutidos nos objetivos específicos a seguir.

Atendendo ao objetivo específico 1 desta pesquisa, as escalas utilizadas neste estudo apresentaram altos índices de confiabilidade e de validade. As subescalas de Valência (importância) e de Instrumentalidade (utilidade) obtiveram, ambas, um índice de consistência interna de $\alpha=0,96$, um pouco maior que o encontrado por Lacerda e Abbad (2003), $\alpha=0,94$, e maior do que o encontrado por Pilati (2004), $\alpha=0,88$ (Valência) e $\alpha=0,89$ (Instrumentalidade). Essas medidas mostraram-se válidas e confiáveis também quando combinadas para compor a medida de valor instrumental do treinamento, utilizada por Lacerda \& Abbad (2003) e Silva (2007). A medida de Expectância foi realizada por meio de um único item, o que a torna menos confiável.

Neste estudo, o cálculo de FM foi feito conforme estudos anteriores (Alves-Filho \& Borges, 2014; Pilati, 2004; Vroom, 1964), multiplicando-se as médias fatoriais de Valência, Instrumentalidade e a média de Expectância (VIE). Os resultados encontrados convergem com aqueles obtidos em outros estudos realizados em contextos diferentes, como na área de saúde (Alves-Filho \& Borges, 2014) e em pastorais da criança (Carvalho \& Souza, 2007) e no setor público, pesquisa na qual um dos objetivos era construir um instrumento de mensuração de VIE (Zaniboni, Fraccaroli, Truxillo, Bertolino \& Bauer, 2007). Além desses, é digno de nota um estudo que adaptou o instrumento de valor instrumental de Lacerda e Abbad (2003) para o contexto de avaliação de um programa corporativo de orientação profissional (Silva, 2007). 
A escala de Suporte Psicossocial à Transferência de Treinamento obteve $\alpha=0,94$, pouco maior que a encontrada por Abbad (1999): $\alpha=0,91$, e por Lacerda e Abbad (2003): $\alpha$ $=0,92$, porém um pouco menor do que encontrada por Pilati (2004): $\alpha=0,96$. Escalas de Suporte tem sido utilizadas em diversas pesquisas nacionais e estrangeiras para mensurar construtos como o suporte social (Chiaburu et al., 2010) e suporte do supervisor (Abdullah et al., 2011; Ismail et al., 2010), as quais são medidas correlatas às adotadas em pesquisas nacionais de suporte psicossocial e material à transferência (Abbad, 1999; Abbad \& Sallorenzo, 2001; Lacerda \& Abbad, 2003; Pantoja, Porto, Mourão \& Borges-Andrade, 2005; Pereira, 2009; Silva, 2008; Tamayo \& Abbad, 2006). A subescala de suporte psicossocial adota nesta pesquisa mostrou índices psicométricos satisfatórios e consistentes, porém, há itens problemáticos que foram eliminados das análises fatoriais, como nos estudos de Meneses e Abbad (2003) e Pilati (2004).

Por fim, a escala de Impacto do Treinamento no Trabalho, medida em amplitude, obteve $\alpha=0,96$, maior do que foi encontrado em Abbad (1999): $\alpha=0,93$, Lacerda e Abbad (2003): $\alpha=0,94$, e Pilati (2004): $\alpha=0,89$. Essa escala foi utilizada anteriormente em diversos estudos em diferentes contextos de autarquias (Gonçalves \& Mourão, 2011) e tipos de organizações diversas (Meneses \& Abbad, 2003; Mourão et al., 2014; Silva, 2006; e Tamayo \& Abbad, 2006).

O objetivo específico 2 também foi atingido, uma vez que os treinamentos de gestão analisados possuem percepções mais positivas em relação às três variáveis, quando comparados com o treinamento SEI. Uma das possíveis explicações para essas diferenças talvez esteja relacionada à falta de acesso dos egressos ao sistema SEI, que, no momento da coleta de dados, não havia sido implantado em todas as unidades da organização. A aplicação dos conhecimentos e habilidades de uso do SEI no trabalho ficou inviabilizada ou dificultada pela falta de acesso de usuários ao sistema. O caráter obrigatório do uso do SEI por todos os funcionários e a falta de acesso de algumas unidades ao sistema informatizado (ausência de suporte material à transferência) pode ter influenciado negativamente a motivação dos egressos do treinamento para transferir essas habilidades para o trabalho e a percepção de suporte organizacional e material à expressão dessas novas aprendizagens no encaminhamento e acompanhamento de processos em comunicações administrativas da organização.

Curado et al. (2015) encontraram, em seu estudo, que participantes de treinamentos voluntários mostraram maior impacto e motivação para transferir do que os de treinamentos 
obrigatórios. Enquanto que Gegenfurtner, Könings, Kosmajac e Gebhardt (2016) encontraram, contra suas expectativas, a correlação entre a orientação a meta de desempenho e transferência de treinamento foi mais positiva quando a entrada nos treinamentos era realizada de forma obrigatória. Apesar do treinamento SEI não ter tido caráter obrigatório, o uso das aprendizagens no trabalho será obrigatório, uma vez que já está em processo de implementação. Essa situação pode ter levado à diminuição da motivação das pessoas para aprender e para transferir a aprendizagem para o contexto de trabalho. Além disso, as restrições situacionais de acesso ao sistema podem ter contribuído para o menor impacto do SEI no trabalho dos egressos.

Cumprindo o objetivo específico 3, observou-se que Suporte Psicossocial é preditor de Impacto do treinamento no trabalho, resultado similar ao encontrado em estudos que adotaram as mesmas medidas, como em Abbad (1999), e Meneses e Abbad (2003) ou medidas correlatas como em Al-Eisa et al. (2009); Bhatti, Ali, Isa e Battour (2014); Chauhan, Ghosh, Rai e Shukla (2016); Pereira (2009); Saks e Belcourt (2006); Schindler e Burkholder (2016); e Silva (2008). Depieri (2006) também encontrou que SUPSI é um preditor de Impacto, porém, ao contrário dos resultados aqui encontrados, as características individuais, tais como motivação, não se mostraram preditoras de IMTT. Em sua revisão, Bell et al. (2017) apontam que condições de trabalho, dentre elas suporte do supervisor e de pares, influenciam positivamente a efetividade do treinamento, bem como a relação positiva entre suporte e motivação.

Os achados de Silva (2007) vão ao encontro dos resultados da presente pesquisa, uma vez as duas dimensões de FM (valência e instrumentalidade) foram também preditoras de impacto. Motivação também é tida como preditora de IMTT, assim como nos estudos de Lacerda e Abbad (2003), Sallorenzo (2000), e Silva (2007), bem como Chiaburu e Lindsay (2008); Lieberman e Hoofman (2008); Van den Bossche et al. (2010); Hutchins et al. (2013); Schindler e Burkholder (2014); e Bhatti et al. (2014) que utilizaram medidas correlatas de IMTT (Transferência, intenção de transferir). Importante ressaltar que os instrumentos brasileiros utilizaram a mesma medida de impacto, enquanto que os estrangeiros utilizaram diferentes instrumentos e que variaram entre si, bem como na mensuração das demais variáveis (FM e SUPSI).

Por fim, o objetivo específico 4 também foi alcançado, uma vez que foram encontrados indícios de que SUPSI é mediadora parcial da relação entre FM e IMTT, o que significa dizer que quando a variável suporte psicossocial é inserida na equação de RM, 
diminui a magnitude da relação de predição de FM e IMTT, tal como foi observado no valor dos Betas obtidos nas etapas de análise de mediação, realizadas de acordo com as recomendações técnicas de Baron e Kenny (1986).

Esses resultados têm implicações práticas. Uma delas é que, nos casos em que o treinamento não possui apelo motivacional, é preciso promover e desenvolver, na organização, o suporte psicossocial (social e gerencial), de modo a criar um ambiente propício à transferência de conhecimentos, atitudes e habilidades para o contexto de trabalho. Outra implicação desses resultados é informar os gerentes sobre a importância de oferecer suporte ao uso de novas aprendizagens no trabalho e incluir em programas gerenciais objetivos instrucionais que ligados às habilidades de gestão do suporte à transferência e à aprendizagem no trabalho.

A mediação parcial testada neste estudo, não tem sido pouco analisada por outros estudos relativos à motivação. Observa-se na literatura revisada neste estudo que outras variáveis têm sido encontradas como mediadoras de relacionamentos entre variáveis em TD\&E. Grohmann et al. (2014), por exemplo, encontraram motivação para transferir como variável mediadora total da relação entre características do treinamento e transferência de treinamento. Apenas, Al-Eisa et al. (2009) encontraram uma mediação completa de suporte do supervisor sobre a relação entre autoeficácia e intenção de transferir. Esse resultado foi o mais próximo do encontrado neste estudo com suporte mediando relacionamento entre uma variável do treinando e um resultado do treinamento. Esses autores encontraram também que encontraram que, quando a motivação para aprender foi inserida no modelo de regressão múltipla com suporte, a motivação mediou parcialmente à relação entre suporte do supervisor e intenção de transferir. Mais estudos precisam ser realizados para investigar a função mediadora de suporte gerencial e social à transferência em modelos de avaliação de efeitos de treinamento nos níveis de aprendizagem e impacto no trabalho.

\subsection{Considerações Finais}

Os resultados do presente estudo indicaram relação positiva entre FM e SUPSI, bem como dessas duas variáveis na predição de IMTT. Evidenciando, também, a importância da relação entre Suporte e as medidas correlatas de Impacto do Treinamento no trabalho. Corroborando com Bell et al. (2017), que concluíram após revisão que suporte dos pares e do supervisor podem determinar até que ponto as competências recém-adquiridas serão aplicadas no trabalho, assim como o fato do contexto de trabalho (suporte organizacional, por 
exemplo) influenciar nas atividades de desenvolvimento e em sua efetividade, uma vez que pode aumentar ou diminuir a motivação dos participantes para aprender e aplicar o que aprenderam no treinamento. Esses autores também apontaram para a influência que fatores do contexto, como suporte e experiências pré-treinamento exercem sobre a condição do funcionário participar ou não de um treinamento não-obrigatório. Neste estudo, apesar de nenhum treinamento ter caráter obrigatório, um deles, SEI, capacitou os funcionários para o uso obrigatório, em um futuro próximo, das habilidades de manuseio do sistema de comunicação e tramitação de processos e documentos. Essa obrigatoriedade pode, neste estudo, ter afetado a motivação para transferir, uma vez que nem todos os egressos dispunham do sistema para exercitar as novas aprendizagens no seu retorno ao trabalho.

As principais contribuições teóricas desta pesquisa consistem na análise da literatura, mostrando as principais abordagens utilizadas que dá subsídio às comparações com diversas teorias de motivação; no ponto de partida para que as teorias sejam comparadas e, no mesmo contexto, verificar a que melhor explica as situações de treinamento; e no reforço do efeito preditor das variáveis de Suporte Psicossocial à Transferência e de Força Motivacional sobre o Impacto do Treinamento no Trabalho, bem como o papel de mediadora parcial que a variável Suporte Psicossocial exerce sobre o relacionamento entre Força Motivacional e Impacto do Treinamento no Trabalho.

As contribuições metodológicas englobam as evidências de validade das três escalas utilizadas nesse estudo, confirmando resultados anteriores; a análise de mediação tendo como variável mediadora Suporte Psicossocial à Transferência, utilizando RM para investigação de evidências de mediação; e a avaliação de três treinamentos de dois tipos diferentes, o que contribuiu aumentando as chances de obter maior variabilidade nas respostas dos participantes às escalas, a partir de análise dos objetivos e resultados esperados pela organização para cada curso. Na literatura da área, os relatos de pesquisa, de modo geral, não descrevem os treinamentos estudados, o que dificulta a compreensão de eventuais diferenças nos resultados devidas ao tipo de treinamento (técnico, administrativo, gerencial, etc) e à sua importância para a organização (estratégica, tática ou operacional). Neste estudo observou-se que os cursos ligados à gestão organizacional de processos, que visam provocar mudanças que aumentem a eficiência e eficácia de processos de trabalho, obtiveram maiores níveis de impacto no trabalho dos egressos do que o treinamento em habilidades administrativas de manuseio de sistema de comunicação e tramitação de processos, que visam aumentar a eficiência e conferir maior transparência às decisões administrativas. Os resultados sugerem 
que os treinamentos voltados à mudança organizacional e aumento de eficiência e eficácia de processos de trabalho, provavelmente produziram um ambiente organizacional de maior suporte e motivação extrínseca e, consequentemente, o que resultou em maior impacto desses dois treinamentos (Agente de melhorias e Gestão do Absenteísmo) no trabalho do que o treinamento SEI.

Por fim, as contribuições práticas: é necessário que a organização conheça as metas e objetivos profissionais e pessoais dos seus funcionários e tente fazer com que os treinamentos os ajudem a alcançá-los. Outra implicação prática dos resultados deste estudo é que a organização precisa desenvolver intencionalmente o suporte psicossocial, de gerentes, pares e colegas, à aprendizagem e à transferência de treinamento para o trabalho. O desenvolvimento de uma cultura de aprendizagem contínua e de educação continuada e ao longo de toda a vida funcional é de grande importância para a educação corporativa, pois aumentará as chances de produzir melhorias no desempenho de egressos de treinamento e impactos positivos sobre processos e resultados organizacionais valorizados pela organização. Essa cultura de aprendizagem contínua na organização, ao ser consolidada, promoveria a disseminação de práticas de compartilhamento de ideias e soluções de problemas, de busca ativa de novos conhecimentos, habilidades e atitudes e de abertura às ideias inovadoras, criando um clima de abertura à troca, transmissão e expressão de novas competências no trabalho. Além disso, na análise de necessidades de treinamento, é preciso identificar as condições materiais necessárias à transferência de treinamentos para o trabalho, de modo a diminuir as chances de que as novas aprendizagens sejam esquecidas pela falta de oportunidade de praticá-las no local de trabalho. O treinamento SEI, por exemplo, foi oferecido a pessoas que ainda não tinham acesso ao sistema informatizado que possibilitaria a transferência das habilidades de manuseio dessa ferramenta, logo após o treinamento. Essa situação pode levar à diminuição do impacto do treinamento no trabalho, como observado nos resultados desta pesquisa.

Dentre as limitações do estudo, cabe mencionar inicialmente que a pesquisa foi realizada em uma única organização e os fenômenos foram restritos à realidade estudada, reduzindo a possibilidade de generalização dos resultados para outros contextos. Além disso, houve a impossibilidade de aplicação do questionário heteroavaliativo de Impacto do Treinamento no Trabalho, que poderia gerar resultados comparativos com os de autoavaliação. Tem-se ainda, entre as limitações do presente estudo, o fato do treinamento SEI não ser aplicado ainda a todos os funcionários, tendo somente uma pequena parcela de egressos podendo aplicar a aprendizagem do treinamento no trabalho. Não foi perguntada no 
questionário a faixa etária dos participantes, o que poderia ser uma variável controle neste estudo. Ademais, as avaliações foram feitas após o treinamento, não podendo comparar a Motivação dos participantes antes deste iniciar, além do fato das escalas de Suporte Material e Impacto em Profundidade não terem sido aplicadas, e da medida de expectância possuir somente um item, impossibilitando a generalização dos casos. Por fim, os conceitos, referenciais teóricos, definições operacionais e medidas, na literatura revisada, não são os mesmos, gerando fragmentação de achados, devido à dificuldade de extrair conclusões robustas sobre as relações entre as variáveis. Os construtos de IMTT, FM e SUPSI possuem diversas medidas correlatas, porém não se sabe se possuem validade convergente ou divergente. A proliferação de definições, medidas e referenciais teóricos, neste sentido, dificultou a discussão e a avaliação da consistência dos achados sobre motivação, suporte e impacto de treinamentos no trabalho.

De acordo com os resultados apresentados e discutidos, propõe-se como agenda de pesquisa para estudos futuros: (1) Aplicar os instrumentos utilizados neste estudo em outras organizações, e em diferentes tipos de treinamentos quanto à modalidade (presencial e a distância), ao nível de resultados do treinamento para a organização (estratégico, tático, operacional), aos efeitos esperados no comportamento do egresso, processos e resultados organizacionais; visando replicar o estudo e conferir maior validade externa aos achados; (2) Aplicar questionários de auto e heteroavaliação de impacto e suporte nos participantes e em seus gestores; (3) Utilizar medidas de Impacto do Treinamento no Trabalho em Profundidade, baseadas em objetivos de treinamento; (4) Analisar a relação entre as variáveis Suporte à Transferência e Força Motivacional utilizando análises mais complexas para investigar relacionamentos diretos e indiretos entre as variáveis estudadas; (5) Incluir a variável Suporte Material na escala de Suporte à Transferência de Treinamento; (6) Incluir avaliações antes, durante e depois do treinamento, a fim de avaliar as variações da Força Motivacional e as percepções em relação ao Suporte à Transferência de Treinamento; (7) Acrescentar no modelo de avaliação outras características individuais (autoeficácia, valores etc) como preditoras do Impacto do Treinamento no Trabalho; (8) Analisar a relação de mediação de suporte sobre motivação e impacto do treinamento no trabalho em contextos diferentes; (9) Realizar mais estudos para compreender de que modo Motivação e Suporte se relacionam e como ambas atuam na predição de Impacto do Treinamento no Trabalho e suas medidas correlatas; (10) Testar os efeitos de moderação entre as variáveis FM, SUPSI e IMTT; (11) Adotar modelagem por equações estruturais e path analysis para testar esses 
relacionamentos entre variáveis; (12) Realizar análises fatoriais confirmatórias com todos os instrumentos utilizados; e (13) Construir e buscar evidência de validade de medida de expectância.

Considera-se, por fim, que o presente trabalho foi capaz de avaliar o Impacto do Treinamento no Trabalho e suas variáveis preditoras Suporte Psicossocial à Transferência de Treinamento e Força Motivacional dos egressos dos três cursos, tendo alcançado os objetivos específicos do presente estudo. 


\section{REFERÊNCIAS}

Abbad, G. S. (1999). Um modelo integrado de avaliação do impacto do treinamento no trabalho - IMPACT. Tese de Doutorado, Universidade de Brasília, Brasília, DF, Brasil.

Abbad, G. S., Lacerda, E. R. M., \& Pilati, R. (2012). Medidas de motivação e valor instrumental do treinamento. In G. S. Abbad, L. Mourão, P. P. M. Meneses, T. Zerbini, J. E. Borges-Andrade, \& R. Vilas-Boas (eds) Medidas de Avaliação em Treinamento, Desenvolvimento e Educação: ferramentas para gestão de pessoas. (pp. 198-215). Porto Alegre: Artmed.

Abbad, G. S., Pilati, R., Borges-Andrade, J. E., \& Sallorenzo, L. H. (2012). Impacto do treinamento no trabalho - medida em amplitude. In G. S. Abbad, L. Mourão, P. P. M. Meneses, T. Zerbini, J. E. Borges-Andrade, \& R. Vilas-Boas (eds) Medidas de Avaliação em Treinamento, Desenvolvimento e Educação: ferramentas para gestão de pessoas. (pp. 145-162). Porto Alegre: Artmed.

Abbad, G. S., \& Sallorenzo, L. H. (2001). Desenvolvimento e validação de escalas de suporte à transferência de treinamento. Revista de Administração - USP, 36(2), 33-45.

Abbad, G. S., Sallorenzo, L. H., Coelho-Junior, F. A., Zerbini, T., Vasconcelos, L., \& Todeschini, K. (2012). Supote à transferência de treinamento e suporte à aprendizagem. In G. S. Abbad, L. Mourão, P. P. M. Meneses, T. Zerbini, J. E. Borges-Andrade, \& R. Vilas-Boas (eds) Medidas de Avaliação em Treinamento, Desenvolvimento e Educação: ferramentas para gestão de pessoas. (pp. 244-263). Porto Alegre: Artmed.

Abdullah, M. B., Baroto, M. B., Ismail, A., \& Tat, H. H. (2011). Supervisor's role in training programs as a manager of learning program. LogForum, 7(2), 17-26.

Al-Eisa, A. S., Furayyan, M. A., \& Alhemoud, A. M. (2009). An empirical examination of the effects of self-efficacy, supervisor support and motivation to learn on transfer intention. Management decision, 47(8), 1221-1244.

Alves-Filho, A., \& Borges, L. D. O. (2014). A Motivação dos Profissionais de Saúde das Unidades Básicas de Saúde. Psicologia Ciência e Profissão, 34(4), 984-1001.

Baron, R. M., \& Kenny, D. A. (1986). The Moderator-Mediator Variable Distinction in Social Psychological Research: conceptual, strategic, and statistical considerations. Journal of Personality and Social Psychology, 51(6), 1173-1182.

Bauer, K. N., Orvis, K. A., Ely, K., \& Surface, E. A. (2015). Re-examination of motivation in learning contexts: meta-analytically investigating the rol type of motivation plays in the prediction of key training outcomes. Journal of Business and Psychology, 31(1), 33-50.

Bell, B. S., Tannenbaum, S. I., Ford, J. K., Noe, R. A., \& Kraiger K. (2017). 100 Years of Training and Development Research: What We Know and Where We Should Go. Journal of Applied Psychology, 1-19. 
Bhatti, M. A., Ali, S., Isa, M., Faizal, M., \& Battour, M. M. (2014). Training transfer and transfer motivation: the influence of individual, environmental, situational, training design, and affective reaction factors. Performance Improvement Quarterly, 27(1), 5182 .

Borges-Andrade, J. E. (1982). Avaliação somativa de sistemas instrucionais: integração de três propostas. Tecnologia Educacional, 11(46), 29-39.

Bosset, I., Bourgeois, E. (2015). Motivation to transfer: linking perceived organizational suppot to training personal goals. Zeitschrift für Erziehungswissenschaft, 18(1), 169199.

Bråten, I., \& Ferguson, L. E. (2015). Beliefs about sources of knowledge predict motivation for learning in teacher education. Teaching and Teacher Education, 50, 13-23.

Bueno, J. M. H., Zenorini, R. D. P. C., Santos, A. A. A. D., Matumoto, A. Y., \& Buchatsky, J. (2007). Investigação das propriedades psicométricas de uma escala de metas de realização. Estudos de Psicologia (Campinas), 24(1), 79-87.

Burke, L. A., \& Hutchins, H. M. (2007). Training transfer: an integrative literature review. Human Resource Development Review, 6(3), 263-296.

Campbell, J. P., \& Kuncel, N. R. (2001). Individual and team training. In N. Anderson, D. S. Ones, H. K. Sinangil, \& C. Viswesvaran (eds) Handbook of Industrial, Work and Organizational Psychology: Volume 1, Personnel Psychology (pp. 278-312). Thousand Oaks, CA: Sage.

Carvalho, S., \& Mourão, L. (2014). Análise de necessidade de treinamento em call centers. Revista Eletrônica de Administração, 79(3), 740-772.

Carvalho, V. D. D., \& Souza, W. J. D. (2007). Pobres no ter, ricos no ser: trabalho voluntário e motivação na Pastoral da criança. Revista de Administração Contemporânea, 11(2), 113-134.

Chauhan, R., Ghosh, P., Rai, A., \& Shukla, D. (2016). The impact of support at the workplace on transfer of training: a study of an Indian manufacturing unit. International Journal of Training and Development, 20(3), 200-213.

Chiaburu, D. S., \& Lindsay, D. R. (2008). Can do or will do? The importance of self-efficacy and instrumentality for training transfer.Human Resource Development International, 11(2), 199-206.

Chiaburu, D. S., \& Tekleab, A. G. (2005). Individual and contextual influences on multiple dimensions of training effectiveness. Journal of European Industrial Training, 29(8), 604-626.

Chiaburu, D. D., Van Dam, K, \& Hutchins, H. M. (2010). Social support in the workplace and training transfer: a longitudinal analysis. International Journal of Selection and Assessment, 18(2), 187-200. 
Colquitt, J. A., LePine, J. A., \& Noe, R. N. (2000). Toward and integrative theory of training motivation: a meta-analytic path analysis of 20 years of research. Journal of Applied Psychology, 85(5), 678-707.

Creswell, J. W., Goodchild, L., \& Turner, P. (1996). Integrated qualitative and quantitative research: Epistemology, history, and designs. In J. Smart (Ed.), Higher education: Handbook of theory and research (pp. 90-136). New York: Agathon Press.

Curado, C., Henriques, P. L., \& Ribeiro, S. (2015). Voluntary or mandatory enrollment in training and the motivation to transfer training. International Journal of Training and Development, 19(2), 98-109.

Depieri, M. A. (2006). Impacto de educação corporativa: Educação continuada em processos educativos - FORFOR. Dissertação de Mestrado, Universidade de Brasília, Brasília, DF, Brasil.

Ferreira, A. B. H. (1999). Aurélio século XXI: o dicionário da Lingua Portuguesa. Retrieved from https://contas.tcu.gov.br/dicionario/home.asp

Freitas, I. A., Borges-Andrade, J. E., Abbad, G. S., \& Pilati, R. (2006). Medidas de impacto de TD\&E no trabalho e nas organizações. In J. E.Borges-Andrade, G. S. Abbad, \& L. Mourão (eds). Treinamento, desenvolvimento e educação em organzações e trabalho: fundamentos para gestão de pessoas (pp. 489-504). Porto Alegre: Artmed.

Gagné, R. M., \& Deci, E. L. (2005). Self-determination theory and work motivation. Journal of Organizational Behavior, 26(4), 331-362.

Gagné, R. M., \& Medsker, K. L. (1996). The conditions of learning: Training applications. New York: Harcourt Brace College Publishers.

Gegenfurtner, A. (2011). Motivation and transfer in professional training: a meta-analysis of the moderating effects of knowledge type, instruction and assessment conditions. Educational Research Review, 6(3), 153-168.

Gegenfurtner, A. (2013). Dimensions of motivation to transfer: A longitudinal analysis of their influence on retention, transfer, and attitude change. Vocations and Learning, 6(2), 187-205.

Gegenfurtner, A., Festener, D., Gallenberger, W., Lehtinen, E., \& Gruber, H. (2009). Predicting autonomous and controlled motivation to transfer training. International Journal of Training and Development, 13(2), 124-138.

Gegenfurtner, A., Könings, K. D., Kosmajac, N., \& Gebhardt, M. (2016). Voluntary or mandatory training participation as a moderator in the relationship between goal orientations and transfer of training. International Journal of Training and Development, 20(4), 290-301. 
Gegenfurtner, A., Veermans, K., Festner, D., \& Gruber, H. (2009). Motivation to transfer training: an integrative literature review. Human Resource Development Review, 8(3), 403-423.

Gonçalves, A., \& Mourão, L. (2011). A expectativa em relação ao treinamento influencia o impacto das ações de capacitação? Revista de Administração Pública, 45(2), 483-513.

Grohmann, A., Beller, J., \& Kauffeld, S. (2014). Exploring the critical role of motivation to transfer in the training transfer process. International Journal of Training and Development, 18(2), 84-103.

Hamblin, A. C. (1978). Avaliação e controle do treinamento. São Paulo: McGraw-Hill do Brasil.

Hicks, W. D., \& Klimoski, R. J. (1987). Entry into training programs and its effects on training outcomes: a field experiment. Academy of Management Journal, 30(3), 542552.

Holton, E. F. (1996). The flawed four-level evaluation model. Human resource development quarterly, 7(1), 5-21.

Hutchins, H. M, Nimon, K., Bates, R., \& Holton, E. (2013). Can the LTSI predict transfer performance? Testing intent to transfer as a proximal transfer of training outcome. International Journal of Selection and Assessment, 21(3), 251-263.

Ismail, A., Hasan, A. B. M., \& Sulaiman, A. Z. (2010). Supervisor's role as an antecedent of training transfer and motivation to learn in training programs. Economica, 7(2), 18-37.

Jodlbauer, S., Selenko, E., Batinic, B, \& Stiglbauer, B. (2012). The relationship between job dissatisfaction and training transfer. International Journal of Training and Development, 16(1), 39-53.

Kaufman, R., \& Keller, J. M. (1994). Levels of evaluation: Beyond Kirkpatrick. Human Resource Development Quarterly, 5(4), 371-380.

Kirkpatrick, D. L. (1976). Evaluation of training. In R. L. Craig, Training and Development handbook (pp. 18.1-18.27). New Yourk: McGraw-Hill.

Kochoian, N., Raemdonck, I., Frenay, M., \& Zacher, H. (2016). The role of age and occupational future time perspective in workers' motivation to learn. Vocations and Learning, 1-19.

Krishnamani, S., \& Haider, Y. (2016). Transfer of learning from executive education programs in developing economies: the key role of motivation. Development and Learning in Organizations: An International Journal, 30(1), 15-18.

Lacerda, E. R. M. (2002). Impacto do Treinamento no Trabalho: Investigando Variáveis Motivacionais e Organizacionais como suas Preditoras. Dissertação de Mestrado, Universidade de Brasília, Brasília, DF, Brasil. 
Lacerda, E. R. M., \& Abbad, G. (2003). Impacto do treinamento no trabalho: investigando variáveis motivacionais e organizacionais como preditoras. Revista de Administração Contemporânea, 7(4), 77-96.

Liebermann, S., \& Hoffmann, S. (2008). The impact of practical relevance on training transfer: evidence from a service quality training program for German bank clerks. International Journal of Training and Development, 12(2), 74-86.

Lock, E. A., \& Latham, G. P. (1990). A theory of goal setting and task performance. New Jersey: Prentice-Hall.

Lópes, M. G. M., \& Aquilar, A. P. (2013). Emotions as learning enhancers of foreign language learning motivation. Profile Issues in Teachers Professional Development, 15(1), 109-124.

Martins, D. (2014). Avaliação de Transferência e Impacto do Treinamento no Trabalho. Dissertação de Mestrado, Universidade de Brasília, Brasília, DF, Brasil.

Massenberg, A. C., Spurk, D., \& Kauffeld, S. (2015). Social support at the workplace, motivation to transfer and training transfer: a multilevel indirect effects model. International Journal of Training and Development, 19(3), 161-178.

Mathieu, J. E., Tannenbaum, S. I., \& Salas, E. (1992). Influences of individual and situacional characteristics on measures of training effectiveness. Academy of Management Journal, 35(4), 828-847.

McEown, M. S., Noels, K. A., \& Saumure, K. D. (2014). Students' self-determined and integrative orientations and teachers' motivational support in a Japanese as a foreign language context. System, 45, 227-241.

Meneses, P. P. M (2002). Auto-eficácia, Locus de Controle, Suporte à Transferência e Impacto do Treinamento no Trabalho. Dissertação de Mestrado, Universidade de Brasília, Brasília, DF, Brasil.

Meneses, P. P. M., \& Abbad, G. S. (2003). Preditores individuais e situacionais de auto e heteroavaliação de impacto de treinamento no trabalho. Revista de Administração Contemporânea, 7 (Edição Especial), 185-204.

Mourão, L., Abbad, G. S., \& Zerbini, T. (2014). Avaliação da efetividade e dos preditores de um treinamento a distância em uma instituição bancária de grande porte. Revista de Administração (São Paulo), 49(3), 534-548.

Mourão, L., \& Marins, J. (2010). Quem está motivado para aprender nos cursos oferecidos pelas empresas?. Paidéia, 20(46), 187-196.

Noe, R. A. (1986). Trainees' attributes and attitudes: neglected influences on training effectiveness. Academy of Management Review, 11(4), 736-749. 
Noe, R. A., \& Schmitt, N. (1986). The influence of trainee attitudes on training effectiveness: test of a model. Personnel Psychology, 39(3), 497-523.

Olivos, P., Santos, A., Martín, S., Cañas, M., Gómez-Lázaro, E., \& Maya, Y. (2016). The relationship between learning styles and motivation to transfer of learning in a vocational training programme. Suma Ppsicológica, 23(1), 25-32.

Onwuegbuzie, A. J., \& Teddlie, C. (2003). A framework for analyzing data in mixed methods research. In A. Tashakkori \& C. Teddlie (Eds.), Handbook of mixed methods in social and behavioral research (pp. 351-383). Thousand Oaks, CA: Sage.

Pantoja, M. J., Porto, J. B., Mourão, L., \& Borges-Andrade, J. E. (2005). Valores, suporte psicossocial e impacto do treinamento no trabalho. Estudos de Psicologia (Natal), 10(2), $255-265$.

Patrick, J., Smy, V., Tombs, M., \& Shelton, K. (2012). Being in one's chosen job determines pre-training attitudes and training outcomes. Journal of Occupational and Organizational Psychology, 85(2), 245-257.

Pereira, S. C. M. (2009). Avaliação de efeitos de uma ação de TD\&E no desempenho dos egressos e da organização. Disseertação de Mestrado, Universidade de Brasília, Brasília, DF, Brasil.

Pilati, R. (2004). Modelo de efetividade do treinamento no trabalho: aspectos dos treinandos e moderação do tipo de treinamento. Tese de Doutorado, Universidade de Brasília, Brasília, DF, Brasil.

Pilati, R., \& Abbad, G. S. (2005). Análise fatorial confirmatória da escala de impacto do treinamento no trabalho. Psicologia: Teoria e Pesquisa, 21(1), 43-51.

Saks, A. M., \& Belcourt, M. (2006). An investigation of training activities and transfer of training in organizations. Human resource management, 45(4), 629-648.

Salas, E. \& Cannon-Bowers, J. (2001). The science of training: a decade of progress. Annual Review of Psychology, 52(1), 471-499.

Sallorenzo, L. H. (2000). Avaliação de impacto do treinamento no trabalho: analisando e comparando modelos predição. Dissertação de Mestrado, Universidade de Brasília, Brasília, DF, Brasil.

Santos Jr, A. B. (2011). Avaliação de impacto de um treinamento introdutório sobre o Desempenho dos egressos. Dissertação de Mestrado. Universidade de Brasília, Brasília.

Santos, A. A. A. D., \& Mognon, J. F. (2016). Motivation Assessment Scale for Learning in Higher Education (EMAPRE-U): validity evidence. Psico-USF, 21(1), 101-110.

Santos, A. A. A. D., Mognon, J. F., Alcará, A. R., \& Lemos, T. H. (2011). Motivação para aprender: evidência de validade convergente entre duas medidas. Aletheia, (35-36), 3650 . 
Santos, L. A., \& Souza, M. A. D. (2014). O impacto da Anomia Organizacional sobre a motivação para aprernder no contexto de uma Instituição Federal do Ensino Superior de um estado do sudeste brasileiro. Boletim-Academia Paulista de Psicologia, 34(87), 387406.

Schindler, L. A., \& Burkholder, G. J. (2016). A mixed methods examination of the influence of dimensions of support on training transfer. Journal of Mixed Methods Research, 10(3), 292-310.

Shweiki, E., Martin, N. D., Beekley, A. C., Jenoff, J. S., Koenig, G. J., Kaulback, K. R., ... \& Zubair, M. H. (2015). Applying Expectancy theory to residency training: proposing opportunities to understand resident motivation and enhance residency training. Advances in medical education and practice, 6, 339-346.

Silva, M. E. (2006). Relações entre impacto do treinamento no trabalho e estratégia empresarial: o caso da Eletronorte. Revista de Administração Contemporânea, 10(3), 91-110

Silva, C. R. E. (2007). Orientação profissional: utilidade, valor e impacto na gestão da carreira e na vida pessoal. Dissertação de Mestrado. Universidade de Brasília, Brasília, DF, Brasil.

Silva, W. (2008). O impacto das ações de capacitação na atuação gerencial: um estudo de caso no setor público. Tese de Doutorado. Universidade de Brasília, Brasília.

Smith, R., Jayasuriya, R., Caputi, P., \& Hammer, D. (2008). Exploring the role of goal theory in understanding training motivation. International Journal of Training and Development, 12(1), 54-72.

Stufflebeam, D. (2003). The CIPP model for evaluation. In D. L. Stufflebeam \& T. Kellaghan (Eds.), The International Handbook of Educational Evaluation (pp. 31-62). Boston, MA: Kluwer Academic.

Tamayo, N., \& Abbad, G. S. (2006). Autoconceito profissional e suporte à transferência e impacto do treinamento no trabalho. Revista de Administração Contemporânea, 10(3), 9-28.

Templeton, R. (2016). Doctorate motivation: an (auto) ethnography. Australian Universities' Review, The, 58(1), 39.

Truxillo, D.M., \& Weathers, V.M. (2005). Evaluation of a Substance Abuse Training Program for Supervisors: Some Preliminary Findings. Portland: Oregon Nurses Association.

Van den Bossche, P., Segers, M., \& Jansen, N. (2010). Transfer of training: the role of feedback in supportive social networks. International Journal of Training and Development, 14(2), 81-94. 
van der Locht, M., van Dam, K., \& Chiaburu, D. S. (2013). Getting the most of management training: the role of identical elements for training transder. Personnel Review, 42(4), 422-439.

Vroom, V. H. (1964). Work and Motivation. New York: Wiley

Wingo, M. T., Thomas, K. G., Thompson, W. G., \& Cook, D. A. (2015). Enhancing motivation with the "virtual" supervisory role: a randomizes trial. BMC medical education, 15(1), 76-82.

Warr, P., Allan, C., \& Bird, K. (1999). Predicting three levels of training outcome. Journal of Ocupational an Organizational PsychologyI,72(3), 351-375.

Warr, P., Bird, M., \& Rackham, N. (1970). Evaluation of Management Training: A Practical Framework, with Cases, for Evaluating Training Needs and Results. London: Gower Press.

Xiao, J. (1996). The relationship between organizational factors and the transfer of training in the electronics industry in Shenzhen, China. Human Resource Development Quarterly, 7, 55-73.

Yarnall, J. (1998). Line managers as careers developers: rhetoric or reality? Personnel Review, 27(5), 378-395.

Zamani, N., Ataei, P., \& Bates, R. (2016). The use of the Persian translation of the Learning Transfer System Inventory in the context of agricultural sustainability learning in Iran. International Journal of Training and Development, 20(1), 92-104.

Zaniboni, S., Fraccaroli, F., Truxillo, D. M., Bertolino, M., \& Bauer, T. N. (2007). Training valence, instrumentality and expectancy scale (T-VIES-it): factor structure and nomological network in an Italian sample. Journal of Workplace Learning, 23(2), 133151. 


\section{Anexo A}

Referência dos artigos selecionados para Revisão de Literatura 
Abbad, G., Borges-Andrade, J. E., Sallorenzo, L. H., Gama, A. L. G., \& Morandine, D. (2001). Projeto instrucional, aprendizagem, satisfação com o treinamento e autoavaliação de impacto do treinamento no trabalho. Revista Psicologia Organizações e Trabalho, 1(2), 129-161.

Abdullah, M. M. B., Baroto, M. B., Ismail, A., \& Tat, H. H. (2011). Supervisor's role in traning programs as a manager of learning program. LogForum, 7(2), 19-26.

Al-Eisa, A. S., Furayyan, M. A., \& Alhemoud, A. M. (2009). An empirical examination of the effects of self-efficacy, supervisor support and motivation to learn on transfer intention. Management Decision, 47(8), 1221-1244.

Alves Filho, A., \& Borges, L. D. O. (2014). A Motivação dos Profissionais de Saúde das Unidades Básicas de Saúde. Psicologia Ciência e Profissão, 34(4), 984-1001.

Araújo, M. V. D., Silva, J. W. B. D., \& Franco, E. M. (2014). Motivação para o aprendizado em estudantes de graduação em Psicologia. Psicologia: teoria e prática, 16(2), 185-198.

Aziz, S. F. A., \& Ahmad, S. (2011). Stimulating training motivation using the right training characteristic. Industrial and Commercial Training, 43(1), 53-61.

Banerjee, P., Gupta, R., \& Bates, R. (2016). Influence of Organizational Learning Culture on Knowledge Worker's Motivation to Transfer Training: Testing Moderating Effects of Learning Transfer Climate. Current Psychology, 1-12.

Bauer, K. N., Orvis, K. A., Ely, K., \& Surface, E. A. (2016). Re-examination of motivation in learning contexts: Meta-analytically investigating the role type of motivation plays in the prediction of key training outcomes. Journal of Business and Psychology, 31(1), 3350 .

Beluce, A. C., \& Oliveira, K. L. D. (2015). Students' Motivation for Learning in Virtual Learning Environments. Paidéia (Ribeirão Preto), 25(60), 105-113.

Beluce, A. C., \& OLIVEIRA, K. L. D. (2016). Escala de estratégias e motivação para aprendizagem em ambientes virtuais. Revista Brasileira de Educação, 21(66), 593-610.

Borges, L. D. O., \& Alves Filho, A. (2001). A mensuração da motivação e do significado do trabalho. Estudos de Psicologia (Natal), 6(2), 177-194.

Boruchovitch, E. (2008). Escala de motivação para aprender de universitários (EMA-U): propriedades psicométricas. Avaliação psicológica, 7(2), 127-134.

Bosset, I. A., \& Bourgeois, E. (2015). Motivation to transfer: linking perceived organizational support to training to personal goals. Zeitschrift für Erziehungswissenschaft, 18(Suppl.), 169-199.

Bråten, I., \& Ferguson, L. E. (2015). Beliefs about sources of knowledge predict motivation for learning in teacher education. Teaching and Teacher Education, 50, 13-23. 
Bueno, J. M. H., Zenorini, R. D. P. C., Santos, A. A. A. D., Matumoto, A. Y., \& Buchatsky, J. (2007). Investigação das propriedades psicométricas de uma escala de metas de realização. Estudos de Psicologia (Campinas), 24(1), 79-87.

Carvalho, V. D. D., \& Souza, W. J. D. (2007). Pobres no ter, ricos no ser: trabalho voluntário e motivação na Pastoral da Criança. Revista de Administração Contemporânea, 11(2), 113-134.

Chiaburu, D. S., Van Dam, K., \& Hutchins, H. M. (2010). Social support in the workplace and training transfer: A longitudinal analysis. International Journal of Selection and Assessment, 18(2), 187-200.

Curado, C., Henriques, P. L., \& Ribeiro, S. (2015). Voluntary or mandatory enrollment in training and the motivation to transfer training. International Journal of Training and Development, 19(2), 98-109.

Gegenfurtner, A. (2011). Motivation and transfer in professional training: A meta-analysis of the moderating effects of knowledge type, instruction, and assessment conditions. Educational Research Review, 6(3), 153-168.

Gegenfurtner, A. (2013). Dimensions of motivation to transfer: A longitudinal analysis of their influence on retention, transfer, and attitude change. Vocations and Learning, 6(2), 187-205.

Gegenfurtner, A., Festner, D., Gallenberger, W., Lehtinen, E., \& Gruber, H. (2009). Predicting autonomous and controlled motivation to transfer training. International Journal of Training and Development, 13(2), 124-138.

Gegenfurtner, A., \& Vauras, M. (2012). Age-related differences in the relation between motivation to learn and transfer of training in adult continuing education. Contemporary Educational Psychology, 37(1), 33-46.

Gegenfurtner, A., Veermans, K., Festner, D., \& Gruber, H. (2009). Integrative literature review: Motivation to transfer training. Human Resource Development Review, 8(3), 403-423.

Ghosh, P., Chauhan, R., \& Rai, A. (2015). Supervisor support in transfer of training: looking back at past research. Industrial and Commercial Training, 47(4), 201-207.

Gonçalves, A., \& Mourão, L. (2011). A expectativa em relação ao treinamento influencia o impacto das ações de capacitação?. Revista de Administração Pública, 45(2), 483-513.

Grohmann, A., Beller, J., \& Kauffeld, S. (2014). Exploring the critical role of motivation to transfer in the training transfer process. International Journal of Training and Development, 18(2), 84-103.

Hamblin, A. C. (1978). Avaliação e controle do treinamento. São Paulo: McGraw-Hill do Brasil.

Henning, M. A., Hawken, S. J., Krägeloh, C., Zhao, Y., \& Doherty, I. (2011). Asian medical students: quality of life and motivation to learn. Asia Pacific Education Review, 12(3), 
437-445.

Huang, J. L., Blume, B. D., Ford, J. K., \& Baldwin, T. T. (2015). A tale of two transfers: Disentangling maximum and typical transfer and their respective predictors. Journal of Business and Psychology, 30(4), 709-732.

Hutchins, H. M., Nimon, K., Bates, R., \& Holton, E. (2013). Can the LTSI predict transfer performance? Testing intent to transfer as a proximal transfer of training outcome. International Journal of Selection and Assessment, 21(3), 251-263.

Ismail, A., Hasan, A. B. M., \& Sulaiman, A. Z. (2010). Supervisor's role as an antecedent of training transfer and motivation to learn in training programs. Acta Universitatis Danubius. Economica, 6(2).

Jacot, A., Raemdonck, I., \& Frenay, M. (2015). A review of motivational constructs in learning and training transfer. Zeitschrift für Erziehungswissenschaft, 18(Suppl.), 201219.

James, M. A. (2012). An investigation of motivation to transfer second language learning. The Modern Language Journal, 96(1), 51-69.

Jodlbauer, S., Selenko, E., Batinic, B., \& Stiglbauer, B. (2012). The relationship between job dissatisfaction and training transfer. International Journal of Training and Development, 16(1), 39-53.

Kamardeen, I. (2013). Motivation-driven learning and teaching model for construction education. Australasian Journal of Construction Economics and Building, The, 13(1), 36-49.

Kochoian, N., Raemdonck, I., Frenay, M., \& Zacher, H. (2016). The Role of Age and Occupational Future Time Perspective in Workers' Motivation to Learn. Vocations and Learning, 1-19.

Kontoghiorghes, C. (2002). Predicting motivation to learn and motivation to transfer learning back to the job in a service organization: A new systemic model for training effectiveness. Performance Improvement Quarterly, 15(3), 114-129.

Krishnamani, S., \& Haider, Y. (2016). Transfer of learning from executive education programs in developing economies: the key role of motivation. Development and Learning in Organizations: An International Journal, 30(1), 15-18.

Lacerda, É. R. M., \& Abbad, G. (2003). Impacto do treinamento no trabalho: investigando variáveis motivacionais e organizacionais como suas preditoras. Revista de Administração contemporânea, 7(4), 77-96.

Leung, M. Y., Chen, D., \& Chan, I. Y. S. (2011). Attributes of Hong Kong construction engineering student learning approaches: Investigation of Chinese and western personal values. Journal of Professional Issues in Engineering Education and Practice, 138(3), 224-233.

López, M. G. M., \& Aguilar, A. P. (2013). Emotions as learning enhancers of foreign 
language learning motivation. Profile Issues in Teachers Professional Development, 15(1), 109-124.

van der Locht, M., van Dam, K., \& Chiaburu, D. S. (2013). Getting the most of management training: the role of identical elements for training transfer. Personnel Review, 42(4), 422-439.

Marini, J. A. D. S., \& Boruchovitch, E. (2014). Self-regulated learning in students of pedagogy. Paidéia (Ribeirão Preto), 24(59), 323-330.

Massenberg, A. C., Schulte, E. M., \& Kauffeld, S. (2016). Never Too Early: Learning Transfer System Factors Affecting Motivation to Transfer Before and After Training Programs. Human Resource Development Quarterly, 1-31.

Massenberg, A. C., Spurk, D., \& Kauffeld, S. (2015). Social support at the workplace, motivation to transfer and training transfer: a multilevel indirect effects model. International Journal of Training and Development, 19(3), 161-178.

McEown, M. S., Noels, K. A., \& Saumure, K. D. (2014). Students' self-determined and integrative orientations and teachers' motivational support in a Japanese as a foreign language context. System, 45, 227-241.

Meneses, P. P. M., \& Abbad, G. (2003). Preditores individuais e situacionais de auto e heteroavaliação de impacto do treinamento no trabalho. Revista de Administração Contemporânea, 7(SPE), 185-204.

Mourão, L., \& Marins, J. (2010). Quem está motivado para aprender nos cursos oferecidos pelas empresas. Paidéia (Ribeirão Preto), 20(46), 187-196.

Olivos, P., Santos, A., Martín, S., Cañas, M., Gómez-Lázaro, E., \& Maya, Y. (2016). The relationship between learning styles and motivation to transfer of learning in a vocational training programme. Suma Psicológica, 23(1), 25-32.

Patrick, J., Smy, V., Tombs, M., \& Shelton, K. (2012). Being in one's chosen job determines pre-training attitudes and training outcomes. Journal of Occupational and Organizational Psychology, 85(2), 245-257.

Peters, S., Barbier, M., Faulx, D., \& Hansez, I. (2012). Learning and motivation to transfer after an e-learning programme: impact of trainees' motivation to train, personal interaction and satisfaction. Innovations in Education and Teaching International, 49(4), 375-387.

Quesada-Pallarès, C., \& Gegenfurtner, A. (2015). Toward a unified model of motivation for training transfer: a phase perspective. Zeitschrift für Erziehungswissenschaft, 18(Suppl.), 107-121.

Ruiz, V. M. (2003). Motivação na universidade: uma revisão da literatura. Estudos de Psicologia (Campinas), 20(2), 15-24.

Santos, L. A., \& Souza, M. A. D. (2014). O impacto da Anomia Organizacional sobre a motivação para aprender no contexto de uma Instituição Federal do Ensino Superior de 
um estado do sudeste brasileiro. Boletim-Academia Paulista de Psicologia, 34(87), 387406.

Santos, A. A. A., \& Mognon, J. F. (2016). Motivation Assessment Scale for Learning in Higher Education (EMAPRE-U): Validity Evidence. Psico-USF, 21(1), 101-110.

Santos, A. A. A., Mognon, J. F., Alcará, A. R., \& Lemos, T. H. (2011). Motivação para aprender: evidência de validade convergente entre duas medidas. Aletheia, (35-36), 3650 .

Santos, A. A. A., Mognon, J. F., Lima, T. H., \& Cunha, N. B. (2011). A relação entre vida acadêmica e a motivação para aprender em universitários. Psicologia Escolar e Educacional, 15(2), 283-290.

Schindler, L. A., \& Burkholder, G. J. (2016). A Mixed Methods Examination of the Influence of Dimensions of Support on Training Transfer. Journal of Mixed Methods Research, 10(3), 292-310.

Shweiki, E., Martin, N. D., Beekley, A. C., Jenoff, J. S., Koenig, G. J., Kaulback, K. R., ... \& Zubair, M. H. (2015). Applying Expectancy Theory to residency training: proposing opportunities to understand resident motivation and enhance residency training. Advances in medical education and practice, 6, 339-346.

Silva, S. D. C. G., \& Mourão, L. (2014). Análise de necessidades de treinamento em Call Centers. Revista Eletrônica de Administração, 20(3), 740-772.

Smith, R., Jayasuriya, R., Caputi, P., \& Hammer, D. (2008). Exploring the role of goal theory in understanding training motivation. International Journal of Training and Development, 12(1), 54-72.

Templeton, R. (2016). Doctorate motivation: an (auto) ethnography. Australian Universities' Review, 58(1), 39-44.

Van den Bossche, P., Segers, M., \& Jansen, N. (2010). Transfer of training: the role of feedback in supportive social networks. International Journal of Training and Development, 14(2), 81-94.

Vanthournout, G., Kyndt, E., Gijbels, D., \& Van den Bossche, P. (2015). Understanding the direct and indirect relations between motivation to participate, goal orientation and the use of self-regulation strategies during a formal training. Zeitschrift für Erziehungswissenschaft, 18(Supp1.), 89-106.

Weissbein, D. A., Huang, J. L., Ford, J. K., \& Schmidt, A. M. (2011). Influencing learning states to enhance trainee motivation and improve training transfer. Journal of Business and Psychology, 26(4), 423-435.

Wingo, M. T., Thomas, K. G., Thompson, W. G., \& Cook, D. A. (2015). Enhancing motivation with the "virtual" supervisory role: a randomized trial. BMC Medical Education, 15, 1-7.

Zamani, N., Ataei, P., \& Bates, R. (2016). The use of the Persian translation of the Learning 
Transfer System Inventory in the context of agricultural sustainability learning in Iran. International Journal of Training and Development, 20(1), 92-104.

Zaniboni, S., Fraccaroli, F., Truxillo, D. M., Bertolino, M., \& Bauer, T. N. (2011). Training valence, instrumentality, and expectancy scale (T-VIES-it) Factor structure and nomological network in an Italian sample. Journal of Workplace Learning, 23(2), 133 151.

Zimmermann, A., \& Ravishankar, M. N. (2016). A systems perspective on offshoring strategy and motivational drivers amongst onshore and offshore employees. Journal of World Business, 51(4), 548-567. 


\section{Anexo B}

Relação entre a quantidade de artigos por expressões-chave 
Tabela de quantidade de artigos por expressões-chaves

Expressão-chave

Artigos

"Motivation to transfer" OR "Motivação para transferir" (CAPES) 21

"Motivation to learn" OR "Motivação para aprender" (Scielo) 14

"Motivation to learn" OR "Motivação para aprender" (CAPES) 9

Expectancy theory AND Transfer of training (CAPES) 4

"Motivation to learn" AND "Transfer of training" (CAPES) 4

Motivation to transfer of training OR Motivação para transferência de 4

treinamento (Scielo)

Força motivacional (Scielo) 3

Motivation to transfer of training (CAPES) 3

Força motivacional (CAPES) 2

"Motivation to transfer of training" (CAPES) 2

Motivation to learn AND Transfer of training OR Motivação para aprender 1

AND Transferência de treinamento (Scielo)

"Motivation to transfer" OR "Motivação para transferir" (Scielo) 1

Motivation to transfer OR Motivação para transferir (Scielo) 1

Teoria da expectância AND Tranferencia de treinamento (CAPES) 1

Valor instrumental AND Treinamento (CAPES) 1

Valor instrumental AND Treinamento (Scielo) 1 


\section{Anexo C}

Relação de periódicos por países 
Tabela de relação de periódicos por países

\section{Periódicos}

País

Frequência

(\%)

Advances in Medical Education and Practice;

Reino Unido

$21(30,87 \%)$

BMC Medical Education;

Development and Learning in Organizations: An

International Journal;

Educational Research Review;

Industrial And Commercial Training;

Innovations in Education and Teaching

International;

International Journal of Selection and Assessment;

International Journal of Training and

Development;

Journal of Workplace Learning;

Management Decision;

Personnel Review;

Teaching and Teacher Education

Aletheia;

Brasil

$20(29,40 \%)$

Avaliação Psiológica;

Boletim da Academia Paulista de Psicologia;

Estudos de Psicologia (Campinas);

Estudos de Psicologia (Natal);

Paidéia;

Psico-USF;

Psicologia: Ciência e Profissão;

Psicologia Escolar e Educacional;

Psicologia: Teoria e Prática;

Revista de Administração Contemporânea;

Revista Brasileira de Educação;

Revista de Administração Pública;

Revista de Estudos de Psicologia (Campinas);

Revista Eletrônica de Administração;

Revista Psicologia: Organizações e Trabalho

Contemporary Educational Psychology;

Estados Unidos

$14(20,58 \%)$

Current Psychology;

Human Resource Development Quarterly;

Human Resource Development Review;

Journal of Business and Psychology;

Journal of Mixed Methods Research;

Journal of Occupational and Organizational

Psychology;

Journal of Professional Issues in Engineering

Education \& Practice;

Journal of World Business;

Performance Improvement Quarterly;

System;

The Modern Language Journal 
Continução

Periódicos

País

Frequência

(\%)

Zeitschrift für Ethnologie

Alemanha

$4(5,88 \%)$

Asia Pacific Education Review;

Holanda

$3(4,41 \%)$

Vocations and Learning

Australasian Journal of Construction Economics

Austrália

$2(2,94 \%)$

and Building;

Australian Universities' Review

Profile;

Colômbia

$2(2,94 \%)$

Suma Psicológica

LogForum

Polônia

$1(1,47 \%)$

Acta Universitatis Danubius : Oeconomica

Romênia

$1(1,47 \%)$ 


\section{Anexo D}

Relação de periódicos por área 
Tabela de relação de periódicos por área

\section{Periódicos}

Área

Frequência

(\%)

Development and Learning in Organizations: An

International Journal;

Human Resource Development Quarterly;

Human Resource Development Review;

Industrial And Commercial Training;

International Journal of Training and

Development; Journal of Workplace Learning;

Performance Improvement Quarterly

Aletheia;

Avaliação Psiológica;

Psicologia

$15(22,05 \%)$

Boletim da Academia Paulista de Psicologia;

Current Psychology;

Estudos de Psicologia (Campinas);

Estudos de Psicologia (Natal);

Journal of Occupational and Organizational

Psychology;

Personnel Review;

Psico-USF;

Psicologia: Ciência e Profissão;

Psicologia Escolar e Educacional;

Psicologia: Teoria e Prática;

Revista de Estudos de Psicologia (Campinas);

Revista Psicologia: Organizações e Trabalho;

Suma Psicológica

Advances in Medical Education and Practice;

Asia Pacific Education Review;

Australian Universities' Review;

Educational Research Review;

Innovations in Education and Teaching

International;

Journal of Mixed Methods Research;

Profile;

Revista Brasileira de Educação;

System;

Teaching and Teacher Education;

The Modern Language Journal;

Vocations and Learning

Acta Universitatis Danubius : Oeconomica;

Administração

$9(13,23 \%)$

Journal of World Business;

LogForum;

Management Decision;

Revista de Administração Contemporânea;

Revista de Administração Pública;

Educação

$13(19,11 \%)$

Revista Eletrônica de Administração 
Continuação

\begin{tabular}{lcc}
\hline \multicolumn{1}{c}{ Periódicos } & Área & $\begin{array}{c}\text { Frequência } \\
(\mathbf{\%})\end{array}$ \\
\hline $\begin{array}{l}\text { International Journal of Selection and Assessment; } \\
\text { Journal of Business and Psychology }\end{array}$ & Gestão e Psicologia & $5(7,35 \%)$ \\
$\begin{array}{l}\text { Contemporary Educational Psychology; } \\
\text { Paidéia }\end{array}$ & Psicologia e Educação & $4(5,88 \%)$ \\
$\begin{array}{l}\text { Zeitschrift für Ethnologie } \\
\begin{array}{l}\text { Australasian Journal of Construction Economics } \\
\text { and Building; }\end{array}\end{array}$ & Antropologia & $4(5,88 \%)$ \\
$\begin{array}{l}\text { Journal of Professional Issues in Engineering } \\
\text { Education \& Practice }\end{array}$ & Engenharia & $2(2,94 \%)$ \\
BMC Medical Education & & \\
& Medicina e Educação & $1(1,47 \%)$ \\
\hline
\end{tabular}




\section{Anexo E}

Instrumento de coleta de dados 


\section{Questionário - Motivação em Treinamentos}

*Obrigatório

\section{Bloco 1: Valor do Treinamento}

Com base no treinamento escolhido por você, avalie as afırmativas que se seguem de acordo com:

- A UTILIDADE das habilidades aprendidas nesse treinamento para o alcance dos resultados descritos em cada item, ou seja, o quão ÚTIL para ALCANÇAR RESULTADOS a afirmativa é.

- A IMPORTÂNCIA de cada item para sua vida profissional, independentemente das habilidades que você aprendeu nesse treinamento, ou seja, o quão IMPORTANTE para sua VIDA PROFISSIONAL a afırmativa é.

Escala:

UTILIDADE: de 1 (nada útil) a 5 (completamente útil);

IMPORTÂNCIA: dє 1 (nada importante) a 5 (totalmentє importante).

1a. O quanto o treinamento quє realizei é ÚTIL para resolver problemas de trabalho. *

$$
\begin{array}{lllll}
1 & 2 & 3 & 4 & 5
\end{array}
$$

Nada útil $\bigcirc \bigcirc \bigcirc \bigcirc$ Completamente útil

1b. O quanto o treinamento que realizei é IMPORTANTE para resolver problemas d€ trabalho. *

$$
\begin{array}{lllll}
1 & 2 & 3 & 4 & 5
\end{array}
$$

Nada importante $\bigcirc \bigcirc \bigcirc \bigcirc$ Totalmente importante

2a. 0 quanto o treinamento qu€ realizei é ÚTIL para melhorar meu desempenhc relacionado às tarefas do meu cargo. *

$\begin{array}{lllll}1 & 2 & 3 & 4 & 5\end{array}$

Nada útil $\bigcirc \bigcirc \bigcirc \bigcirc$ Completamente útil

2b. O quanto o treinamento que realizei é IMPORTANTE para melhorar meu desempenho relacionado às tarefas do meu cargo. *

$\begin{array}{lllll}1 & 2 & 3 & 4 & 5\end{array}$

Nada importante $\bigcirc \bigcirc \bigcirc \bigcirc$ Totalmente important $€$

3a. 0 quanto o treinamento quє realizei é ÚTIL para aumentar as oportunidades profissionais, nessa organização. * 
3b. O quanto o treinamento que realizei é IMPORTANTE pare aumentar as oportunidades profissionais, nessa organização. *

$$
\begin{array}{lllll}
1 & 2 & 3 & 4 & 5
\end{array}
$$

Nada importante $\bigcirc \bigcirc \bigcirc \bigcirc$ Totalmente importante

4a. O quanto o treinamentc que realizei é ÚTIL para melhorar meu relacionamento com familiares e amigos. *

$$
\begin{array}{lllll}
1 & 2 & 3 & 4 & 5
\end{array}
$$

Nada útil $\bigcirc \bigcirc \bigcirc \bigcirc$ Completamente útil

4b. O quanto o treinamento que realizei é IMPORTANTE parc melhorar meu relacionamento com familiares e amigos. *

$$
\begin{array}{lllll}
1 & 2 & 3 & 4 & 5
\end{array}
$$

Nada importante $\bigcirc \bigcirc \bigcirc \bigcirc$ Totalmente importante

5a. O quanto o treinamento que realizei é ÚTIL para aumentar meu salário. *

$$
\begin{array}{lllll}
1 & 2 & 3 & 4 & 5
\end{array}
$$

Nada útil $\bigcirc \bigcirc \bigcirc$ completamente útil

5b. O quanto o treinamento que realizei é IMPORTANTE parć aumentar meu salário. *

$$
\begin{array}{lllll}
1 & 2 & 3 & 4 & 5
\end{array}
$$

Nada importante $\bigcirc \bigcirc \bigcirc \bigcirc$ Totalmente importante

6a. O quanto o treinamentc que realizei é ÚTIL para manter-me em meu cargo atual. *

$$
\begin{array}{lllll}
1 & 2 & 3 & 4 & 5
\end{array}
$$

Nada útil $\bigcirc \bigcirc \bigcirc$ completamente útil

6b. 0 quanto o treinamento qu€ realizei é IMPORTANTE para manter-me em meu cargo atual. *

$$
\begin{array}{lllll}
1 & 2 & 3 & 4 & 5
\end{array}
$$

Nada importante $\bigcirc \bigcirc \bigcirc \bigcirc$ Totalmente important $€$

7a. O quanto o treinamento quє realizei é ÚTIL para sentir-m€ mais valorizado pelc meu grupo de trabalho. * 
7b. 0 quanto o treinamento qu€ realizei é IMPORTANTE para sentir-me mais valorizado pelo meu grupo de trabalho. *

$$
\begin{array}{lllll}
1 & 2 & 3 & 4 & 5
\end{array}
$$

Nada importante $\bigcirc \bigcirc \bigcirc \bigcirc$ Totalmente important $€$

8a. $O$ quanto o treinamento qu€ realizei é ÚTIL para aumentar minhas chances de conseguir melhores empregos. *

$$
\begin{array}{lllll}
1 & 2 & 3 & 4 & 5
\end{array}
$$

Nada útil $\bigcirc \bigcirc \bigcirc$ Completamente útil

8b. 0 quanto o treinamento qu€ realizei é IMPORTANTE para aumentar minhas chances de conseguir melhores empregos. *

$\begin{array}{lllll}1 & 2 & 3 & 4 & 5\end{array}$

Nada importante $\bigcirc \bigcirc \bigcirc \bigcirc$ Totalmente importante

9a. 0 quanto o treinamento quє realizei é ÚTIL para melhorar meu relacionamento com meus colegas de trabalho. *

$$
\begin{array}{lllll}
1 & 2 & 3 & 4 & 5
\end{array}
$$

Nada útil $\bigcirc \bigcirc \bigcirc \bigcirc$ Completamente útil

9b. $O$ quanto o treinamento qu€ realizei é IMPORTANTE para melhorar meu relacionamento com meus colegas de trabalho. *

$$
\begin{array}{lllll}
1 & 2 & 3 & 4 & 5
\end{array}
$$

Nada importante $\bigcirc \bigcirc \bigcirc \bigcirc$ Totalmente important $\epsilon$

10a. O quanto o treinamento qu€ realizei é ÚTIL para resolver problemas qu€ não se relacionam diretamente com a organização. *

$$
\begin{array}{lllll}
1 & 2 & 3 & 4 & 5
\end{array}
$$

Nada útil $\bigcirc \bigcirc \bigcirc \bigcirc$ Completamente útil

10b. O quanto o treinamento que realizei é IMPORTANTE para resolver problemas que não se relacionam diretamente com a organização. * 
11a. 0 quanto o treinamento qu€ realizei é ÚTIL para melhorar o meu currículo. *

$\begin{array}{lllll}1 & 2 & 3 & 4 & 5\end{array}$

Nada útil $\bigcirc \bigcirc \bigcirc \bigcirc$ Completamente útil

11b. 0 quanto o treinamento que realizei é IMPORTANTE para melhorar o meu currículo. *

$$
\begin{array}{lllll}
1 & 2 & 3 & 4 & 5
\end{array}
$$

Nada importante $\bigcirc \bigcirc \bigcirc \bigcirc$ Totalmente importante

12a. O quanto o treinamento qu€ realizei é ÚTIL para melhorar o relacionamento com meu gestor. *

$$
\begin{array}{lllll}
1 & 2 & 3 & 4 & 5
\end{array}
$$

Nada útil $\bigcirc \bigcirc \bigcirc \bigcirc \bigcirc$ Completamente útil

12b. 0 quanto o treinamento que realizei é IMPORTANTE para melhorar o relacionamento com meu gestor. *

$$
\begin{array}{lllll}
1 & 2 & 3 & 4 & 5
\end{array}
$$

Nada importante $\bigcirc \bigcirc \bigcirc \bigcirc$ Totalmente importante

13a. $O$ quanto o treinamento qu€ realizei é ÚTIL para melhorar minha atuação em tarefas não relacionadas ao meu cargo. *

$$
\begin{array}{lllll}
1 & 2 & 3 & 4 & 5
\end{array}
$$

Nada útil $\bigcirc \bigcirc \bigcirc \bigcirc$ completamente útil

13b. O quanto o treinamento que realizei é IMPORTANTE para melhorar minha atuação em tarefas não relacionadas ao meu cargo. *

$$
\begin{array}{lllll}
1 & 2 & 3 & 4 & 5
\end{array}
$$

Nada importante $\bigcirc \bigcirc \bigcirc \bigcirc \bigcirc$ Totalmente important $€$

14a. 0 quanto o treinamento qu€ realizei é ÚTIL para atingir minhas mais altas aspirações profissionais. *

$$
\begin{array}{lllll}
1 & 2 & 3 & 4 & 5
\end{array}
$$


14b. O quanto o treinamento que realizei é IMPORTANTE para atingir minhas mais altas aspirações profissionais. *

$\begin{array}{lllll}1 & 2 & 3 & 4 & 5\end{array}$

Nada importante $\bigcirc \bigcirc \bigcirc \bigcirc$ Totalmente important $€$

\section{Expectativa}

Pensando no treinamento escolhido por você, respondc a seguinte questão, escolhendo o número que melhor representa a sua percepção.

Marque de 1 (Se você não tem expectativas de que esse treinamento o ajudará a alcançar os resultados listados nos itens acima descritos) a 10 (Se você tem expectativas muito fortes de qut as habilidades que você desenvolveu nesse treinamento o ajudarão a alcançar esses resultados).

0 quanto você espera que as habilidades que você adquiriu no treinamentc o ajudarão a alcançar os resultados descritos nos itens acima listados. *

$\begin{array}{llllllllll}1 & 2 & 3 & 4 & 5 & 6 & 7 & 8 & 9 & 10\end{array}$

Sem expectativa $\bigcirc \bigcirc \bigcirc \bigcirc \bigcirc \bigcirc \bigcirc \bigcirc \bigcirc$ Muita expectativé

« Voltar ContInuar "

$40 \%$ concluído

Powered by

Este conteúdc não fol crlado nem aprovado pelo Google.

Denunclar abusc - Termos de Servlçc - Termos Adlclonals 


\section{Questionário - Motivação em Treinamentos}

*Obrigatório

\section{Bloco 2: Autoavaliação do impacto do treinamento no trabalho}

Orientação Geral:

A seguir são apresentadas algumas afirmativas a respeito do impacto do treinamento no seu trabalho e do apoio dado pela organização ao uso das novas habilidades.

Leia atentamente o conteúdo das afirmativas a seguir e avalie o quanto cada uma delas descreve o que você pensa a respeito do impacto exercido pelo treinamento indicado por você no trabalho que realiza, considerando, para tal, o período transcorrido desde o término do mesmo até a data de hoje. Pense também no apoio que vem recebendo para usar no seu trabalho o que aprendeu no treinamento.

Para responder a cad $c$ questão, escolha o ponto da escala que melhor descreve a suć situação.

1. Utilizo, com frequência, em meu trabalho atual, o que foi ensinadc no treinamento. *

Discordo totalment $\epsilon$ da afirmativa

Discordo um pouco de afirmativa

Nem concordo nem discordo dé afirmativa

Concordo com a afirmative

Concordo totalmente com $\boldsymbol{c}$ afirmativa

\section{Aproveito as oportunidades que tenho para colocar em prátič o que me foi ensinado no treinamento. *}

Discordo totalment $€$ da afirmativa

Discordo um pouco dé afırmativa

Nem concordo nem discordo dé afirmativa

Concordo com a afirmative

Concordo totalmente com ć afirmativa

\section{As habilidades que aprendi no treinamento fizeram com que eu cometesse menos erros em meu trabalho e em atividades relacionadas ao conteúdo do treinamento. *}

Discordo totalment $€$ da afirmativa

Discordo um pouco dé afirmativa

Nem concordo nem discordo dé afirmativa

Concordo com a afirmative

Concordo totalmente com $\varepsilon$ afirmativa

\section{Recordo-me bem dos conteúdos ensinados nc treinamento. *}

Discordo totalmente da afirmativa

Discordo um pouco dé afirmativa

Nem concordo nem discordo dé afirmativa

Concordo com a afirmative 
Concordo totalmente com á afirmativa

5. Quando aplico o que aprendi nc treinamento, executo meu trabalho com maior rapidez. *

Discordo totalment $\epsilon$ da afirmativa

Discordo um pouco de afirmativa

Nem concordo nem discordo dé afirmativa

Concordo com a afirmative

Concordo totalmente com ć afirmativa

6. A qualidade do meu trabalho melhorou nas atividades diretamente relacionadas ao conteúdo do treinamento.

Discordo totalment $\epsilon$ da afirmativa

Discordo um pouco dé afırmativa

Nem concordo nem discordo dé afirmativa

Concordo com a afirmativa

Concordo totalmente com á afirmativa

7. A qualidade do meu trabalho melhorou mesmo naquelas atividades que não pareciam estar relacionadas ac conteúdo do treinamento. *

Discordo totalment $€$ da afirmativa

Discordo um pouco dé afirmativa

Nem concordo nem discordo dé afirmativa

Concordo com a afirmative

Concordo totalmente com c afirmativa

8. Minha participação no treinamento serviu para aumentar minha motivação para c trabalho.

Discordo totalmentє da afirmativa

Discordo um pouco dé afirmativa

Nem concordo nem discordo dé afirmativa

Concordo com a afirmativa

Concordo totalmente com c afirmativa

9. Minha participação nesse treinamento aumentou minha autoconfiança (agora tenho mais confianç: na minha capacidade de executar meu trabalho com sucesso).

Discordo totalmente da afirmativa

Discordo um pouco de afirmativa

Nem concordo nem discordo dé afirmativa

Concordo com a afirmative

Concordo totalmente com a afirmativa

10. Após minha participação no treinamento, tenho sugerido, com maior frequência, mudanças nas rotinas de trabalho. *

Discordo totalmente da afirmativé

Discordo um pouco dé afirmativa

Nem concordo nem discordo dé afirmativa

Concordo com a afirmativé

Concordo totalmente com ć afirmativa 
11. Esse treinamento que fiz me tornou mais receptivo a mudanças no trabalho. *

Discordo totalment $\epsilon$ da afirmativa

Discordo um pouco dé afirmativa

Nem concordo nem discordo de afirmativa

Concordo com a afirmativa

Concordo totalmente com c afirmativa

12. 0 treinamento qu€ fiz beneficiou meus colegas $d \epsilon$ trabalho, que aprenderam comigo algumas novas habilidades.

Discordo totalment $\epsilon$ da afirmativa

Discordo um pouco dé afirmativa

Nem concordo nem discordo dé afirmativa

Concordo com a afirmativé

Concordo totalmente com $\bar{c}$ afirmativa

« Voltar

Contlnuar »

$60 \%$ concluído 


\section{Questionário - Motivação em Treinamentos}

*Obrigatório

\section{Bloco 3: Suporte ao Treinamento}

Orientação Geral:

A seguir, são apresentadas afirmativas $\bar{c}$ respeito do apoio oferecido pelé organização ao uso das novas habilidades no trabalho.

Para responder a cada questão, marquє o ponto na escala que melhor descrevє a sua situação.

1. Tenho tido oportunidades de usar no meu trabalho as habilidades que aprendi no treinamento.

Nunca

Raramente

Algumas vezes

Frequentemente

Sempre

2. Falta-me tempo para aplicar no trabalho o que aprendi no treinamento. *

Nunca

Raramente

Algumas vezes

Frequentemente

Sempre

3. Os objetivos de trabalho estabelecidos pelo meu gestor me encorajam a aplicar o que aprendi no treinamento. *

Nunca

Raramente

Algumas vezes

Frequentemente

Sempre

4. Os prazos de entrega de trabalhos inviabilizam o uso das habilidades que eu aprendi no treinamento. *

Nunca

Raramente

Algumas vezes

Frequentemente

Sempre

5. Tenho tido oportunidades de praticar habilidades importantes (recém-adquiridas no treinamento), mas, comumente, pouco usadas no trabalho. * 
Nunca

Raramente

Algumas vezes

Frequentemente

Sempre

6. Os obstáculos e dificuldades associados à aplicação das novas habilidades que adquiri no treinamento são identificados e removidos pelo meu gestor. *

Nunca

Raramente

Algumas vezes

Frequentemente

Sempre

7. Tenho sido encorajado pelo meu gestor imediato a aplicar, no meu trabalho, o que aprendi no treinamento. *
Nunca
Raramente
Algumas vezes
Frequentemente
Sempre

8. Meu gestor imediatc tem criado oportunidades para planejar comigo o uso das novas habilidades. *
Nunca
Raramente
Algumas vezes
Frequentemente
Sempre

9. Eu recebo as informações necessárias à correta aplicação das novas habilidades nc meu trabalho. *
Nunca
Raramente
Algumas vezes
Frequentemente
Sempre

10. Em meu ambiente de trabalho, minhas sugestões, em relação ao que foi ensinado no treinamento, são levadas em consideração. *
Nunca
Raramente
Algumas vezes
Frequentemente
Sempre 
11. Meus colegas mais experientes apóiam as tentativas que faço d€ usar no trabalho o que aprendi no treinamento. *
Nunca
Raramente
Algumas vezes
Frequentemente
Sempre

12. Aqui, passam despercebidas minhas tentativas de aplicar no trabalho as novas habilidades que aprendi no treinamento. *
Nunca
Raramente
Algumas vezes
Frequentemente
Sempre

13. Minha organização ressalta mais os aspectos negativos (ex.: lentidão, dúvidas) do que os positivos em relação ao uso das novas habilidades. *
Nunca
Raramente
Algumas vezes
Frequentemente
Sempre

14. Tenho recebido elogios quando aplico corretamente nc trabalho as novas habilidades que aprendi. *
Nunca
Raramente
Algumas vezes
Frequentemente
Sempre

15. Quando tenho dificuldades em aplicar eficazmente as novas habilidades, recebo orientações sobre como fazê-lo. *
Nunca
Raramente
Algumas vezes
Frequentemente
Sempre

16. Chamam minha atenção quando cometo erros ao utilizar as habilidades que adquiri no treinamento. *
Nunca
Raramente
Algumas vezes
Frequentemente
Sempre 


\section{Questionário - Motivação em Treinamentos}

*Obrigatório

\section{Bloco 4: Dados Pessoais e Profissionć is}

\section{Sexo: *}

Feminino

Masculino

Estado civil: *
Solteiro
Casado/União estável
Divorciado/Separado
Viúvo

Qual seu último nível de escolaridade concluído? *
Ensino Fundamental
Ensino Médio
Ensino Superior
Especialização
Mestrado
Doutorado

Qual a área da sua última formação acadêmica concluída? *

Em que ano você concluiu sua últime formação? *

Há quanto tempo (em anos completos) você trabalha nos Correios? *

Há quanto tempo você está em sua funçãc atual? *
Menos de 1 ano
de 1 a 3 anos
de 4 a 6 anos
de 7 a 9 anos
de 10 anos ou mais

Você ocupa função de gestão/supervisãc (possui subordinados)? *

Sim 
Não

0 treinamento, aqui avaliado, foi para você: *

Optativo/voluntáric

Altamente recomendado pelo gestor

\section{Comentários gerais:}

« Voltar

Envlar

Nunca envie senhas pelo Formulários Google.

100\% concluído.

Powered by 